\title{
THE VALIDITY OF THE ACHIEVEMENT-ORIENTATION MODEL FOR GIFTED MIDDLE SCHOOL STUDENTS
}

by

Jennifer Ann Ritchotte

A dissertation submitted to the faculty of The University of North Carolina at Charlotte In partial fulfillment of the requirements for the degree of Doctor of Philosophy in Special Education

Charlotte

2013

Approved by:

Dr. Claudia Flowers

Dr. Kelly Anderson

Dr. Jeanneine Jones

Dr. Brenda Romanoff

Dr. Paola Pilonieta 
(C)2013

Jennifer Ann Ritchotte ALL RIGHTS RESERVED 


\begin{abstract}
JENNIFER ANN RITCHOTTE. The validity of the Achievement-Orientation Model for gifted middle school students (Under the direction of DR. CLAUDIA FLOWERS)

Gifted underachievement represents a frustrating loss of potential for society. Although attempts have been made to develop interventions to reverse gifted underachievement, the theoretical underpinnings of these interventions have yet to be empirically validated. The purpose of this study was to investigate the validity of the Achievement-Orientation Model for gifted middle school students. Based on a sample of 156 gifted sixth and seventh grade mathematics students, results of the current study suggest two unique clusters of gifted students, those whose attitudes toward each of the constructs present in the Achievement-Orientation Model are positive and those who attitudes are negative. Significantly more gifted underachievers were found in the negative attitudes cluster and more gifted achievers in the positive attitudes cluster, $\chi^{2}(1)=15.86, p<.001$. Further, only two of the constructs present in the model distinguished gifted achievers from gifted underachievers, self-efficacy, $t(154)=-3.850$, $p<.001, d=.62$ and self-regulation, $t(154)=-3.113, p=.002, d=.50$. Finally, results of a path analysis call into question several of the relationships specified by the model. In particular, task meaningfulness only predicted student engagement and was not significantly related to self-regulation or student achievement. The findings of this study suggest the Achievement-Orientation Model may hold promise for the development of interventions to address gifted underachievement; however, future research should be conducted to continue work toward validating the model before this step is taken.
\end{abstract}




\section{ACKNOWLEDGEMENTS}

Thank you so much to the members of my dissertation committee: Claudia Flowers, for taking me on, being patient with me, and always checking email; Kelly Anderson, for mentoring me, sharing in my accomplishments, and helping me overcome my less than successful moments; Brenda Romanoff, for being a constant source of encouragement; Jeanneine Jones, for rekindling my love of middle school; and Paola Pilionieta, for making my dissertation Methods section ten times better. It would have been impossible for me to complete this task without your expertise and guidance. I would also like to thank the professors in the special education doctoral program who taught and mentored me during my time at UNC Charlotte. Thank you to my cohort BFFs, La'Shawndra Scroggins and Crystalynn Schnorr. You ladies are truly brilliant and two of the most supportive people I have ever known. Thank you to the district leaders and teachers who supported this study and made it possible. Thank you to Angel Lee for helping me along as I stumbled during the first year of the doctoral program. Thank you to my mother, Maria, who always lent a kind ear from hundreds of miles away, believed in me, and inspired me to believe in myself when inspiration was in short supply. Thank you to my father, Michael, who always put my education first when I was young and nurtured me through these past three years. Most importantly, thank you to my husband, Brian, and my two children, Ally and Conner. Without your love and support there would be no degree or dissertation. This final product is above all dedicated to you, my compassionate and understanding husband and two amazing children. 
TABLE OF CONTENTS

LIST OF TABLES

vi

LIST OF FIGURES Vii

CHAPTER 1: INTRODUCTION 1

$\begin{array}{ll}\text { Purpose } & 8\end{array}$

Significance of the Study $\quad 9$

$\begin{array}{ll}\text { Delimitations } & 10\end{array}$

Definition of Terms

CHAPTER 2: REVIEW OF THE LITERATURE 15

CHAPTER 3: METHODS $\quad 54$

$\begin{array}{ll}\text { CHAPTER 4: RESULTS } & 71\end{array}$

CHAPTER 5: DISCUSSION

$\begin{array}{ll}\text { REFERENCES } & 99\end{array}$

APPENDIX A: SCHOOL ATTITUDE ASSESSMENT SURVEY—REVISED 108

APPENDIX B: CHALLENGES TO SCHOLASTIC ACHIEVEMENT SURVEY 115

APPENDIX C: ENGAGEMENT VS. DISAFFECTION WITH LEARNING, 119 STUDENT-REPORT

APPENDIX D: COMBINED INSTRUMENT 124

APPENDIX E: SAMPLE AIG DIRECTOR SCRIPT 130

APPENDIX F: SAMPLE PRINCIPAL EMAIL 131

APPENDIX G: SAMPLE TEACHER SCRIPT 132

APPENDIX H: SURVEY SCRIPT 134

APPENDIX I: STUDENT DEMOGRAPHIC FORM 136 


\section{LIST OF TABLES}

TABLE 1: Definitions of giftedness

TABLE 2: Studies that use "discrepancy between potential and performance"

TABLE 3: Studies that use "predicted achievement versus actual achievement"

TABLE 4: Studies that use "development of potential"

TABLE 5: Studies that use the "universal definition" of gifted underachievement

TABLE 6: Demographics of participants

TABLE 7: SAAS—R subscales and sample items

TABLE 8: CSAS subscales and sample items

TABLE 9: EvsD subscales and sample items

TABLE 10: Means, standard deviations, skewness, kurtosis, and reliability coefficients of variables

TABLE 11: Sample sizes, means, and standard deviations for the four constructs based on the three cluster solution

TABLE 12: Sample sizes, means, and standard deviations for the four constructs based on the two cluster solution

TABLE 13: Independent samples $t$-test results for the two cluster solution

TABLE 14: Means and standard deviations for underachievers and achievers

TABLE 15: Unstandardized regression coefficients $(B)$, intercept, standardized regression coefficients $(\beta)$, semipartial correlations $\left(\mathrm{sr}_{\mathrm{i}}\right), t$-values and $p$-values

TABLE 16: Unstandardized regression coefficients $(B)$, intercept, standardized regression coefficients $(\beta)$, semipartial correlations $\left(\mathrm{sr}_{\mathrm{i}}\right), t$-values and $p$-values

TABLE 17: Unstandardized regression coefficients $(B)$, intercept, standardized regression coefficients $(\beta)$, semipartial correlations $\left(\mathrm{sr}_{\mathrm{i}}\right), t$-values and $p$-values 


\section{LIST OF FIGURES}

FIGURE 1: Achievement-Orientation Model 6

FIGURE 2: Diaz's model of gifted underachievement 37

FIGURE 3: Baker et al.’s model of gifted underachievement 38

$\begin{array}{ll}\text { FIGURE 4: Path analysis diagram } & 70\end{array}$

FIGURE 5: Path model with standardized regression coefficients, unexplained 82 variance, and $p$-values. 


\section{CHAPTER 1: INTRODUCTION}

The decision made by thousands of high school students to drop out of school each year represents a "silent epidemic" for the nation (Bridgeland, Delulio, Jr., \& Morison, 2006, p. 9). During the 2007-2008 school year, 613,379 students in grades 9 through 12 dropped out of high school, representing an overall event dropout rate of $4.1 \%$ across all 49 reporting states and the District of Columbia (Stillwell, 2010). In a largescale survey of 467 high school dropouts across the nation, $88 \%$ reported they in fact had passing grades, but dropped out of school due to boredom (Bridgeland et al., 2006).

The decision to drop out of school is often made prior to high school. Middle school academic performance and engagement are believed to predict whether or not a student will drop out of high school (Orthner et al., 2010). According to Eccles (2008), "For a substantial number of America's youth, early adolescence marks the beginning of a downward spiral that eventuates in academic failure [and] school dropout” (p. 1). Middle school students (ages 11-13), must make "decisions ... within the context of a complex social reality that presents each individual with a variety of choices" (Eccles, 2008, p. 6). School work often takes "a back seat" to spending time with friends, for example, as does being bullied or discriminated against, and social commitments. With regard to gifted and talented students, "being smart" is often sacrificed for maintaining a certain social appearance (Compton, 1982; Moore, Ford, \& Milner, 2005). Consequently, the groundwork is laid in middle school for the decision to drop out in high school (Zabloski \& Milacci, 2012). 
It has been estimated that gifted and talented students may comprise up to $5 \%$ of the high school dropout rate in this nation (Matthews, 2009). Given the statistic of 613,379 high school dropouts (Stillwell, 2010), this could mean that over 30,000 of these students may have IQs in the gifted and talented range. Although this figure is only an estimate and the precise number of high school dropouts who are gifted and talented remains unknown, the reasons gifted students choose to drop out of high school are not quite so elusive. Using data from the National Longitudinal Study of 1988 (NELS:88), Renzulli and Park (2002) conducted two studies, the first to acquire information about gifted students who drop out and the second to examine factors that influenced their decision to drop out. The most prevalent reasons for dropping out given by both male and female gifted students were not liking school and failing school (Renzulli \& Park, 2002).

A gifted and talented student underperforming in, and even failing, academic coursework is puzzling to say the least. For decades researchers have studied this phenomenon in an effort to help gifted students achieve their full potential and prevent potentially devastating consequences like dropping out. High school dropouts tend to be jobless (Sum et al., 2003). Those who do find employment earn on average $\$ 9,000$ less per year than their peers who graduated from high school (Doland, 2001). Further, there is a high societal cost to dropping out of school. It has been estimated that a high school dropout costs the country a total of $\$ 260,000$ over the course of his lifetime (Rouse, 2005).

Dropping out of school can be considered "an extreme manifestation of academic underachievement" (Matthews, 2006, p. 217). The most common term used to describe the phenomenon of a bright student failing to excel academically is gifted 
underachievement. While researchers have yet to agree upon one definition of gifted underachievement, the most commonly used definition is a discrepancy between ability and achievement, with ability typically defined by results from an IQ test and achievement measured by classroom performance, predominately grades (Reis \& McCoach, 2000).

Although gifted underachievers present a potentially devastating loss to society, educators generally do not perceive this group as being "at risk" (Colangelo, Kerr, Christensen, \& Maxey, 1993). Rather, the common misconception prevails that gifted students will make it on their own. This assumption, however, is completely fallacious, especially for gifted underachievers. Peterson and Colangelo (1996) examined the school records, grades 7-12, of a group of gifted students $(n=153)$. Findings revealed most students identified as gifted underachievers failed to achieve in all subject areas and their underachievement persisted for the duration of their secondary education. In a four-yearfollow-up study, Peterson (2000) found that of the original 153 participants who had attended college, only $52 \%$ graduated, compared to an $83 \%$ graduation rate among the achievers. Gifted underachievement, therefore, can be viewed as a chronic phenomenon (Colangelo et al.), one that most likely will not fix itself without appropriate interventions.

Middle school is believed to be a critical time for the onset of gifted underachievement (Peterson \& Colangelo, 1996). Surprisingly, the majority of gifted underachievers may have been considered academic achievers during their elementary school years (Peterson, 2001; Zabloski \& Milacci, 2012). Shaw and McCuen (1960), for example, found that the GPA of elementary-aged female gifted underachievers exceeded 
that of female gifted achievers prior to grade five. Attitudes toward school, especially for gifted girls, tend to become increasingly negative in middle school, and a decline is seen in overall achievement for both genders as students progress to grade seven (Lupart \& Pyryt, 1996).

Further, an unchallenging middle school curriculum may intensify gifted students' boredom and lead to disengagement and underachievement (Kanevesky \& Keighly, 2003). Conversely, middle school curriculum may represent an unexpected challenge for gifted students. Diaz (1998) found that gifted students who underachieve may begin to do so in middle school due to the effort and perseverance required to achieve academically at this level. Elementary school does not always pose a challenge to gifted students; therefore, they may not develop the skills needed to persevere through academic obstacles. The inability to successfully overcome new academic challenges may in turn lead to poor self-efficacy and consequently, underachievement. Commonly, gifted students may begin to question whether or not they are still "gifted" once they enter middle school. Underachievement is often a byproduct of this lack of self-confidence (Compton, 1982; Rayneri, Gerber, \& Wiley, 2006).

Though researchers have some idea of when gifted students begin to underachieve, why they underachieve remains unclear. Gifted underachievement may be symptomatic of several combinations of reasons. Reis and McCoach (2000) reviewed the literature on gifted underachievement and found relationships between achievement and academic self-concept, self-regulation, environmental perceptions (i.e., attitudes toward school and teachers), and goal valuation. 
Academic self-concept refers to how students perceive their academic abilities; it may be subdivided depending on whether the comparisons are made with regard to their peers' academic performance in the same subject area, or to their own academic performance in other subject areas. Students with poor overall academic self-concept are more likely to doubt their abilities and avoid engaging in tasks they consider beyond their skill level (McCoach \& Siegle, 2003a).

Self-regulation is a significant predictor of achievement. It consists of three components: (a) metacognitive strategies used to plan, monitor, and modify cognition (b) management and effort control on academic tasks, and (c) cognitive strategies used to learn, remember, and understand academic material (Pintrich \& DeGroot, 1990).

Environmental perceptions concern the level of support students perceive from those around them (i.e., teachers, peers, parents). Students are less likely to engage and be productive in environments they perceive as being less supportive (Rubenstein, Siegle, Reis, McCoach, \& Burton, 2012). Finally, Eccles and Wigfield (1995) confirmed goal valuation as a multidimensional construct consisting of intrinsic interest value (i.e., interest in a particular task), extrinsic utility value (i.e., importance of the task in relation to future goals), and attainment value (i.e., importance of being competent in a task). McCoach and Siegle (2003a) view goal valuation as the most important precursor to student motivation.

These factors all are present in a model created by Siegle and McCoach (2005) that theorizes why gifted student underachieve. According to their AchievementOrientation Model (see Figure 1), gifted achievers have the prerequisite abilities needed to achieve at high levels in school, value the goals of school, and find academic tasks 
meaningful (i.e., goal valuation); feel the school environment is supportive (i.e.,

environmental perceptions); and perceive they have the ability to perform academic tasks well (i.e., self-efficacy). These three factors, task meaningfulness, environmental perceptions, and self-efficacy, comprise motivation. If students' self-perceptions are positive on all three factors, according to the theory, they will self-regulate, and as a consequence they will engage and achieve at levels commensurate with their ability. However, Siegle and McCoach suggest that if students' attitudes are low on any one of these three factors, their motivation will be adversely affected, resulting in poor selfregulation, disengagement, and likely academic underachievement.

\section{Achievement-Orientation Model DelSiegle and D. Betsy McCoach}

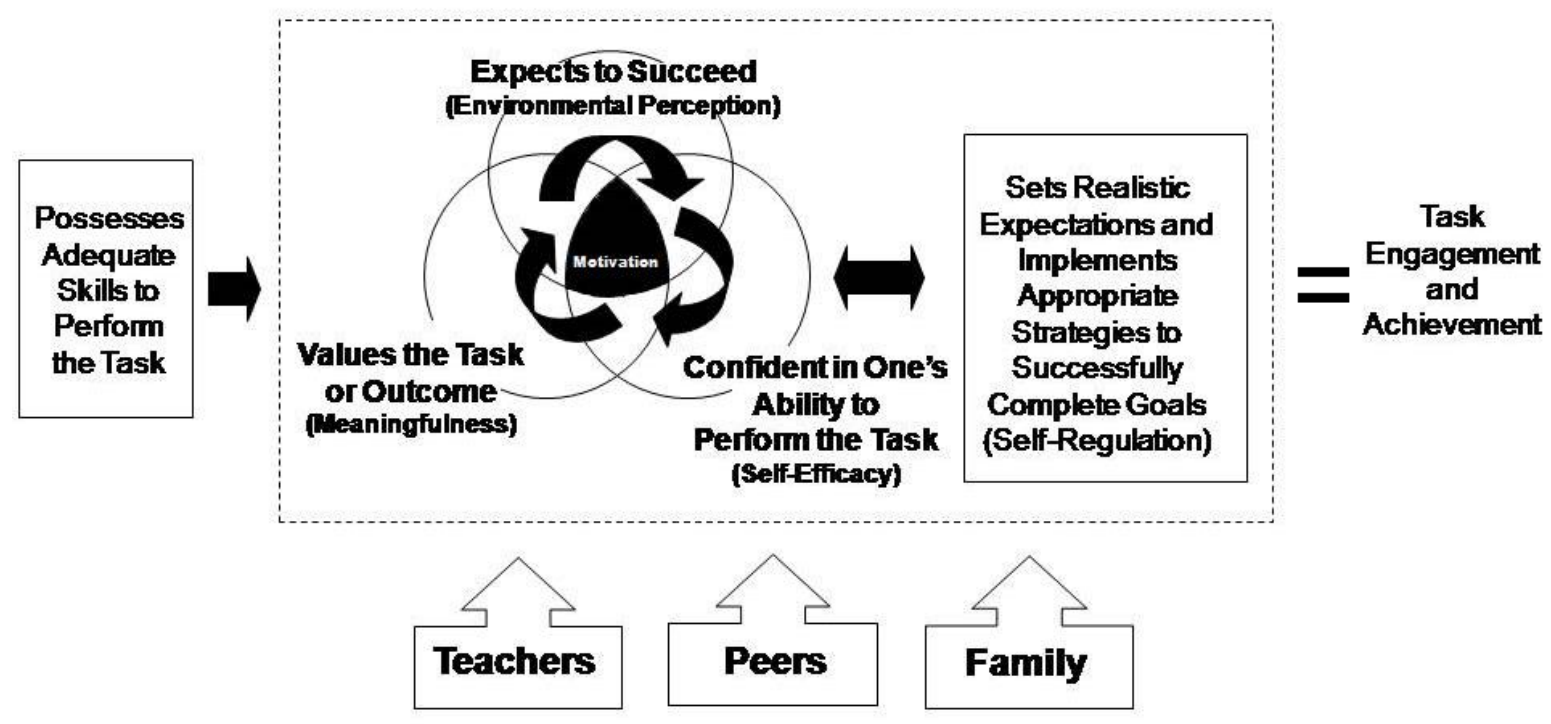

Figure 1. Achievement-Orientation Model

Prior to the development of the Achievement-Orientation Model, intervention studies aimed at reversing gifted underachievement either focused on counseling 
interventions (e.g., Broedel, Ohlsen, Proff, \& Southard, 1965) or on costly instructional interventions (Whitmore, 1986; Supplee, 1990). Most recently, however, two studies have used the Achievement-Orientation Model as the foundation for designing interventions aimed at reversing gifted underachievement.

Rubenstein (2011) experimentally tested an intervention, Project ATLAS (Autonomous Thinkers Learning as Scholars), with middle school gifted underachievers. The ATLAS intervention included students' assessment of their short- and long-term goals and individual instruction on how to propose differentiated class assignments to their teachers for the purpose of increasing their interest in class. In essence, the ATLAS intervention was based in the task meaningfulness factor of the Achievement-Orientation Model. Using a multiple-baseline single-subject design, visual inspection of the graphs did not indicate a functional relationship between the intervention and student engagement or student achievement in Rubenstein's study.

Second, Rubenstein, Siegle, Reis, McCoach, and Burton (2012) developed individualized interventions based on the components of the Achievement-Orientation Model. Middle school gifted underachievers were identified and then administered treatments based on the component of the Achievement-Orientation Model in which they demonstrated a deficit. These students were randomly assigned to either a control group or to an intervention group that targeted the source of their underachievement. Students' grades in reading and mathematics, on average, increased by a full letter grade over the course of the intervention; however, due to the small sample size, these changes were not statistically significant. A second analysis comparing the five different intervention strategies in use revealed a statistically and practically significant increase in students' 
grades over the 6 to 9 week intervention period, $t(45)=2.56, p=.014, d=.38$. Of all the treatment conditions, students in the goal valuation and environmental perceptions treatment groups demonstrated the greatest growth in academic grades.

Purpose

Based on these results, the Achievement-Orientation Model appears to hold promise for developing interventions that may reverse the pattern of gifted underachievement; however, the model itself has yet to be empirically validated. We know that taken separately, each of these constructs correlate with achievement; however, a flow of causality between each factor and achievement has never been established (McCoach \& Siegle, 2003a). Further, whether and how the constructs work together to influence achievement remains relatively unknown. It seems hasty to develop interventions based on a theoretical model that may not accurately capture the complex phenomenon of gifted underachievement. In light of these concerns, the primary purpose of the current study was to investigate the validity of the Achievement-Orientation Model for middle school students who have been identified as Academically or Intellectually Gifted (AIG) following the policies of their local district and North Carolina's state laws in this area.

Because task meaningfulness, self-efficacy, environmental perceptions, selfregulation, achievement, and engagement cannot be directly measured, they are considered latent variables. Subscale items from two direct measures, the School Attitude Assessment-Revised (SAAS-R) and the Challenges to Scholastic Achievement Scale (CSAS) were used to measure task meaningfulness, self-efficacy, environmental perceptions, and self-regulation (see Appendices A and B). The Engagement vs. 
Disaffection with Learning Support- student report (EvsD) was used to measure engagement (see Appendix C). Achievement was measured via student self-reported GPA (this is an item on the SAAS-R), based on students' previous year's math class, and their current math teacher's report of GPA based on grades from the first progress report. Research questions were as follows:

1. Using the Achievement-Orientation Model, what are the profiles of a gifted middle school student?

2. Using the Achievement-Orientation Model, what are the specific characteristics that identify an underachieving gifted middle school student?

3. Based on the Achievement-Orientation Model, is there a relationship between the motivation of gifted middle school students and selfregulation, engagement, and achievement?

Significance of the Study

According to a national needs assessment conducted in 1990, underachievement was considered to be the primary issue in the field of gifted education (Renzulli, Reid, \& Gubbins, 1992). Today, 20 years later, gifted underachievement is still a serious issue to parents and educators alike, with little research concerned with how to reverse it (Siegle $\&$ McCoach, 2009). Given that academic performance is one of the strongest predictors of students' decisions to drop out of school (Matthews, 2006), waiting until high school to identify underachievers and attempt to intervene is too late. Interventions designed to increase the engagement and achievement of gifted underachievers need to start in middle school. 
Although attempts have been made to develop such interventions (e.g., Rubenstein, 2011; Rubenstein et al., 2012) the theoretical underpinnings of these interventions have yet to be empirically validated. Validation of the AchievementOrientation Model is necessary in order to proceed with developing interventions based in this model that will successfully reverse the pattern of underachievement of gifted students. The results of this study may provide researchers with information they can use to address the frustrating loss of potential that underachievement represents. Results of this study may also provide students with a means of enabling and enhancing the development of their talents based on the specific source(s) of their underachievement. Delimitations

The scope of this study was limited to sixth and seventh grade students. Gifted underachievement appears to be most prevalent during students' middle school years; however, the transition from sixth to seventh grade is particularly critical. Students' feelings about their achievement are often especially vulnerable to internal and external threats such as social comparison and peer pressure (Middleton, Kaplan, \& Midgley, 2004) during the seventh grade year. By eighth grade, gifted underachievers often have been weeded out of gifted English and mathematics classes due to their lack of academic achievement in these areas; this is especially true in the area of mathematics. Most school districts in North Carolina no longer recognize the gifted label in their criteria for placement into eighth grade Algebra (which is the most advanced math class generally available in the middle school setting). Rather, teacher recommendation, grades, and standardized test scores play the largest role in determining if a student, whether gifted or 
unidentified, takes advanced mathematics coursework in eighth grade. Given these considerations, only sixth and seventh grade students were recruited for this study.

Further, the scope of this study was limited to just gifted students who underachieve, as opposed to academic underachievers in general. The AchievementOrientation Model was designed expressly to examine the relationship among factors that are believed to predict underachieving behaviors among gifted students. As this was the first study that attempted to validate the model, it was important to focus on the subpopulation of students this model was intended to depict; therefore, only students identified as Academically or Intellectually Gifted (AIG) according to district criteria were sampled.

This study was limited by its quantitative nature. Simply validating the model did not inform why low attitudes on a combination of factors clustered gifted students as underachievers. Qualitative inquiry would help illuminate the why in this study. Without qualitative data, the reasons why certain clusters of gifted achievers and underachievers exist will be left to speculation and future study.

Definition of Terms

The terms used in this study are presented and defined operationally in this section. These definitions are needed in order to contextualize the overall study and to enhance the generalizability of the results to other, similar settings.

Achievement. See underachiever.

Achievement-Orientation Model. The model (Siegle \&McCoach, 2005; see Figure 1) posits that gifted achievers have the innate ability needed to achieve at high levels in school, value the goals of school and find academic tasks meaningful (i.e., goal 
valuation); feel the school environment is supportive (i.e., environmental perceptions); and perceive they have the ability to perform academic tasks well (i.e., self-efficacy). These three factors, goal valuation, environmental perceptions, and self-efficacy comprise motivation. If students' self-perceptions are positive on all three factors, according to the theory, they will self-regulate, and as a consequence they will engage and achieve at levels commensurate with their ability. However, Siegle and McCoach (2005) suggest that if students' attitudes are low on any one of these three factors, their motivation will be adversely affected, resulting in poor self-regulation, disengagement, and likely academic underachievement.

Cluster analysis. Cluster analysis is a multivariate technique that is most traditionally used as an exploratory technique to classify objects based on common properties (Hair, Anderson, Tatham, \& Black, 1998). Resulting clusters, in turn, have high internal homogeneity and high external heterogeneity (Dixon, Lapsley \& Hanchon, 2004).

Engagement. Engagement has many proposed definitions, but for the purpose of this study, it is defined as a multi-dimensional construct consisting of cognitive (i.e., students' level of investment in learning), behavioral (i.e., participation in academic, social, and extracurricular activities), and emotional engagement (i.e., positive and negative reactions to the school environment; Fredericks et al., 2011; Frederick, Blumenfeld, \& Paris, 2004).

Giftedness. North Carolina law characterizes AIG (gifted) learners as being able to 
"perform or show the potential to perform at substantially high levels of accomplishment when compared with others of their age, experience, or environment. Academically or intellectually gifted students exhibit high performance capability in intellectual areas, specific academic fields, or in both intellectual areas and specific academic fields. Academically or intellectually gifted students require differentiated educational services beyond those ordinarily provided by the regular educational program. Outstanding abilities are present in students from all cultural groups, across all economic strata, and in all areas of human endeavor" (1996, 2nd Ex. Sess., c. 18, s. 18.24(f).).

State law requires local education agencies in North Carolina to develop local identification procedures within the scope of the state rule.

Endogenous variables. Variables with causal links (arrows) leading to them from other variables in the model. Endogenous variables have causes within the model.

Exogenous variables. Variables with no causal links (arrows) leading to them from other variables in the model. Exogenous variables have no causes within the model. Latent variables. Factors that cannot be directly observed (Tabachnick \& Fidell, 2007), but whose existence can be inferred through the measurement and analysis of their components.

Middle school. Schooling that targets the developmental and educational needs of the early adolescent learner. Since the dominant organizational structure for middle schools in the United States is grades 6-8, this study will utilize these grade constraints (McEwin \& Greene, 2011). 
Path Analysis. Path analysis is a type of structural equation modeling that tests hypotheses regarding direct and indirect causal effects between exogenous and endogenous variables (Kline, 2011).

SPSS. SPSS is a popular software package used for a variety of statistical analyses.

Underachiever. "Underachievers are students who exhibit a severe discrepancy between expected achievement (as measured by standardized achievement test scores or cognitive or intellectual ability assessments) and actual achievement (as measured by class grades and teacher evaluations)" (Reis \& McCoach, 2000, p. 157). Gifted underachievers for this study were sixth and seventh grade students whose math average was at least two letter grades below what was expected, in other words a ' $\mathrm{C}$ ' or lower on the traditional A-F grading scale commonly used in North Carolina middle schools. 


\section{CHAPTER TWO: REVIEW OF THE LITERATURE}

Most people who will attain success in their lives, however defined, are people who figure out who they are-what they have to offer themselves, others, and the world at large. They find ways of making the most of their diverse talents, and they find ways to live with their weaknesses (Sternberg, 1997a, p. 9).

The first section of this chapter attempts to answer the questions who is the typical sixth and seventh grader, what is giftedness, and what is gifted underachievement? While the first question lends itself to a straightforward answer, neither of the latter two questions have a clear answer. Researchers have debated the definitions of both the constructs of giftedness and underachievement for decades. The next section reviews the literature on the factors that influence gifted underachievement. Again, why gifted students underachieve is not easily understood. Researchers have proposed many reasons and some theoretical models to explain this complex phenomenon. In addition to individual factors, theoretical models that combine more than one factor will be discussed, with a special emphasis on the Achievement-Orientation Model. Finally, the third section reviews the literature on reversing gifted underachievement. It should come as no surprise that because the definition of gifted underachievement and why gifted students underachieve are debated, no clear answer exists for how to reverse gifted students' underachieving behaviors. However, examining the literature on the reversal of gifted underachievement sheds light on future directions 
researchers must take in order to better address this issue and thereby help gifted underachievers make the most of their diverse talents.

Who are Sixth and Seventh Grade Students?

Intellectual and Social Development

Adolescence is a period marked by major changes. Sixth and seventh grade students (ages 11 to13) must not only cope with changing physical characteristics and with physiological functions, but also psychological changes. With regard to the latter, adolescents' cognitive development often changes considerably in the sixth and seventh grades. Their cognition may begin to shift from concrete (i.e., logical thinking about things) to abstract (i.e., development of formal operations like higher-order reasoning). In other words, sixth and seventh grade students may experience a transitional state between thinking like a child in concrete terms and thinking like an adult in abstract terms (Strahan, L'Esperance, \& Van Hoose, 2009)

Further, a sense of self, that search for membership in the social word, typically starts to emerge in the sixth and seventh grades (Lerner, 2002). Early adolescents tend to define who they are based on how others perceive them. Early adolescents' views of themselves are fragile and malleable at this stage. Interactions with their social world can either improve or diminish their perceptions of themselves. Unfortunately, early adolescents often fall victim to what Strahan, L'Esperance, and Van Hoose (2009) refer to as the "big lie," which encourages young people to view themselves as inadequate if they differ from their peers. Early adolescents may compensate for these feelings of inadequacy in negative ways, such as maladaptive perfectionism, disengagement, risk taking, and "acting out." 
Early adolescents in sixth and seventh grades may also act like children sometimes and like adults other times. There are moments when sixth and seventh graders may want to be completely autonomous and have little adult interference, especially at school; however, there may also be moments when they need and seek out the support of an adult to be successful on a particular task. This is yet another type of transitional phase that early adolescents experience, vacillating between adult and childlike behaviors (Strahan, L’Esperance, \& Van Hoose, 2009).

It is important to note, however, that not all sixth and seventh grade students experience these types of transitions at the same age (Powell, 2011; Strahan et al., 2009). Gifted and talented students, for example, tend to be more cognitively advanced than their same-aged peers. They often possess a higher mental age than their chronological age. A term used to describe this phenomenon is asynchronous development (Davis, Rimm, \& Siegle, 2011). Some researchers believe "this asynchrony has social ramifications [for] gifted students" (Bailey, 2011, p. 209). Especially in middle school, gifted students “...may feel out-of-step with their social context. This feeling, coupled with... heightened awareness and understanding of their differences from their peers, can cause further dissonance and emotional stress" (Bailey, p. 209). Gifted students may not experience a transitional state between concrete and abstract thinking in sixth and seventh grade like many of their peers, and their “... ability to think more abstractly and complexly may translate to an earlier search for identity and individual values," again setting them apart from their peers (Bailey, p. 209). If teachers are unaware of this “dissonance and emotional stress," gifted students' performance in school could suffer. Therefore, it is critical that middle school teachers are trained not only in how to meet the 
social and emotional needs of young adolescents as a collective, but in how to meet the needs of gifted middle school students as well.

\section{Middle School Context}

Middle schools were created to provide a developmentally appropriate education for young adolescents ages 11 to 13. William Alexander, a leader in the middle school movement, believed that middle schools should include such components as a core curriculum, guidance programs, and exploratory education (Powell, 2011). Further, interdisciplinary teaming and advisory should be implemented to better meet the needs of young adolescents. With teaming, teachers work together, planning collaboratively, to address the strengths and weaknesses of students on their team. Similarly, advisory was developed with the individual needs of the young adolescent in mind; assigned teachers work with small groups of students and delve into their issues and concerns, building relationships based on mutual trust and respect (Thompson \& Homestead, 2004).

Middle school leaders believe that "For middle schools to be successful, their students must be successful; for students to be successful, the school's organization, curriculum, pedagogy, and programs must be based upon the developmental readiness needs of young adolescents" (NMSA, 2003, p. 1). Successful middle level schools adhere to the 16 characteristics proposed in the Association for Middle Level Education's (2010) position paper, This We Believe: Keys to Educating Young Adolescents. These characteristics are interdependent and must be implemented together.

Successful middle schools are characterized by: (a) Educators who value young adolescents and are prepared to teach them; (b) Students and teachers who are engaged in active, purposeful learning; (c) Curriculum that is challenging, exploratory, integrative, and relevant; (d) Educators who use multiple learning and teaching approaches; (d) 
Varied and ongoing assessments that advance learning as well as measure it; (e) A shared vision developed by all stakeholders that guides every decision; (f) Leaders who are committed to and knowledgeable about adolescents, educational research, and best practices; (g) Leaders who demonstrate courage and collaboration; (h) Ongoing professional development that reflects best educational practices; (i) Organizational structures that foster purposeful learning and meaningful relationships; (j) A school environment that is inviting, safe, inclusive, and supportive of all; (k) Adult advocates who guide every student's academic and personal development; (1) Comprehensive guidance and support services that meet the needs of young adolescents; (m) Health and wellness that are supported in curricula, school-wide programs, and related policies; (n) Active involvement of families in the education of their children; and (o) The inclusion of the community and business partners in school affairs (AMLE, 2010).

However, not all middle schools may adhere to this philosophy. Research suggests that early adolescent development is characterized by increases in the need for autonomy, peer relationships, a social identity, and a capacity for abstract thinking. Given psychological characteristics interrelate with contextual influences to influence development and achievement in school, a mismatch in school environment can be detrimental to students' development. Eccles et al. (1993) suggest there are ...two trajectories: one a developmental trajectory of early adolescent growth, the other a trajectory of environmental change across the school years. We believe there will be positive motivational consequences when these two trajectories are in synchrony, that is, when the environment is both responsive to the changing needs of the individual and offers the kinds of stimulation that will propel continued positive growth" (p. 92). 
These trajectories may not always be in synchrony in all middle schools, which can lead to a decline in the motivation and academic performance of young adolescents.

At the core of middle school philosophy is the caring teacher who knows and understands the needs of young adolescents. These teachers play a critical role in the middle school context. Teacher attitudes and behaviors have a great bearing on adolescents' behavior and development. Poor self-efficacy, for example, can be enhanced by a caring teacher who builds a student up about his ability to master a particular academic subject. Successful middle schools provide early adolescents with plenty of opportunities for positive teacher-student interactions (e.g., advisory) and allow teachers from different subject areas to collaborate (e.g., interdisciplinary teaming) to make learning more meaningful and engaging for students (Learner, 2002).

With regard to gifted students, a mismatch between individual needs and gifted programming options is too often the case. Pull-out programming (i.e., students are taken out of their classroom for one or more hours a week and given additional instruction) is often the preferred method of delivering enriched instruction to gifted students; however, it has been criticized as being expensive and unrealistic. The benefits of pull-out programming depend on how many contact hours the gifted teacher has with her students and whether or not the general education teacher is able or willing to share planning with the gifted education teacher. Being "pulled out" of class may be very damaging to gifted students socially since they might not want to appear "smart" in front of their friends (Bernal, 2003). The latter is also a concern of ability grouped classes, another popular form of providing gifted services to middle school students. Gifted students may want to stay with their friends and not go to the "smart" class. They may be teased by their peers 
and made to feel socially inadequate because of their advanced intellectual ability (Peterson \& Ray, 2006). A result of this teasing may be dropping out of gifted programming altogether, a common occurrence in middle school (Compton, 1982; Moore et al., 2005; Zabloski \& Milacci, 2012).

\section{Summary}

Young adolescents are in a state of transition physically, psychologically, and contextually. The typical sixth and seventh grader's cognitive development often changes considerably in the sixth and seventh grade from concrete thinking to abstract thinking. Further, he/she may constantly vacillate between a desire to be autonomous and a need for adult support and attention. These transitional changes, however, do not necessarily depict all sixth and seventh grade students. Gifted students, in particular, tend to be very precocious and develop asynchcronously. They may already be thinking in abstract terms, for example, in elementary school. This asynchronous development may cause them discomfort as they attempt to find themselves amidst their same-aged peers in middle school.

What all sixth and seventh grade students must contend with is the "big lie" (Strahan et al., 2009), believing they are inadequate if they are different from their peers. Although many middle schools adhere to a philosophy that promotes a developmentally appropriate education for young adolescents, sometimes a mismatch in personenvironment fit can occur when students' developmental trajectory is not in synchrony with this environment change. Consequently, disengagement and poor academic achievement may result. 


\section{What is Giftedness?}

Giftedness is not an easy term to define (Crepau-Hobson \& Bianco, 2011); its definition is continuously evolving. Giftedness once was equated with a high full-scale IQ score. Terman (1925) defined giftedness as the top $1 \%$ of general intelligence $(g)$, measured by an IQ test comparable to the Stanford-Binet Intelligence Test. In more recent decades, researchers have proposed less restrictive definitions of giftedness. These definitions recognize attributes in addition to intellectual ability (McCoach, Kehle, Bray, \& Siegle, 2001). Descriptions of the most notable of these definitions are provided in Table 1. To date, a single agreed-upon definition or theory of giftedness does not exist.

Table 1: Definitions of giftedness

\begin{tabular}{lcl}
\hline \multicolumn{1}{c}{ Author } & Date & Definition of Giftedness \\
\hline Renzulli & 1978 & Gifted students are capable of developing a composite set \\
& & of traits that includes task commitment, above-average \\
& ability, and creativity. \\
Tannenbaum & 1983 & Five factors constitute giftedness: (a) $g$, (b) special ability, \\
& & (c) affective factors (d) environmental factors, and (e) \\
& chance factors.
\end{tabular}


Table 1 (Continued)

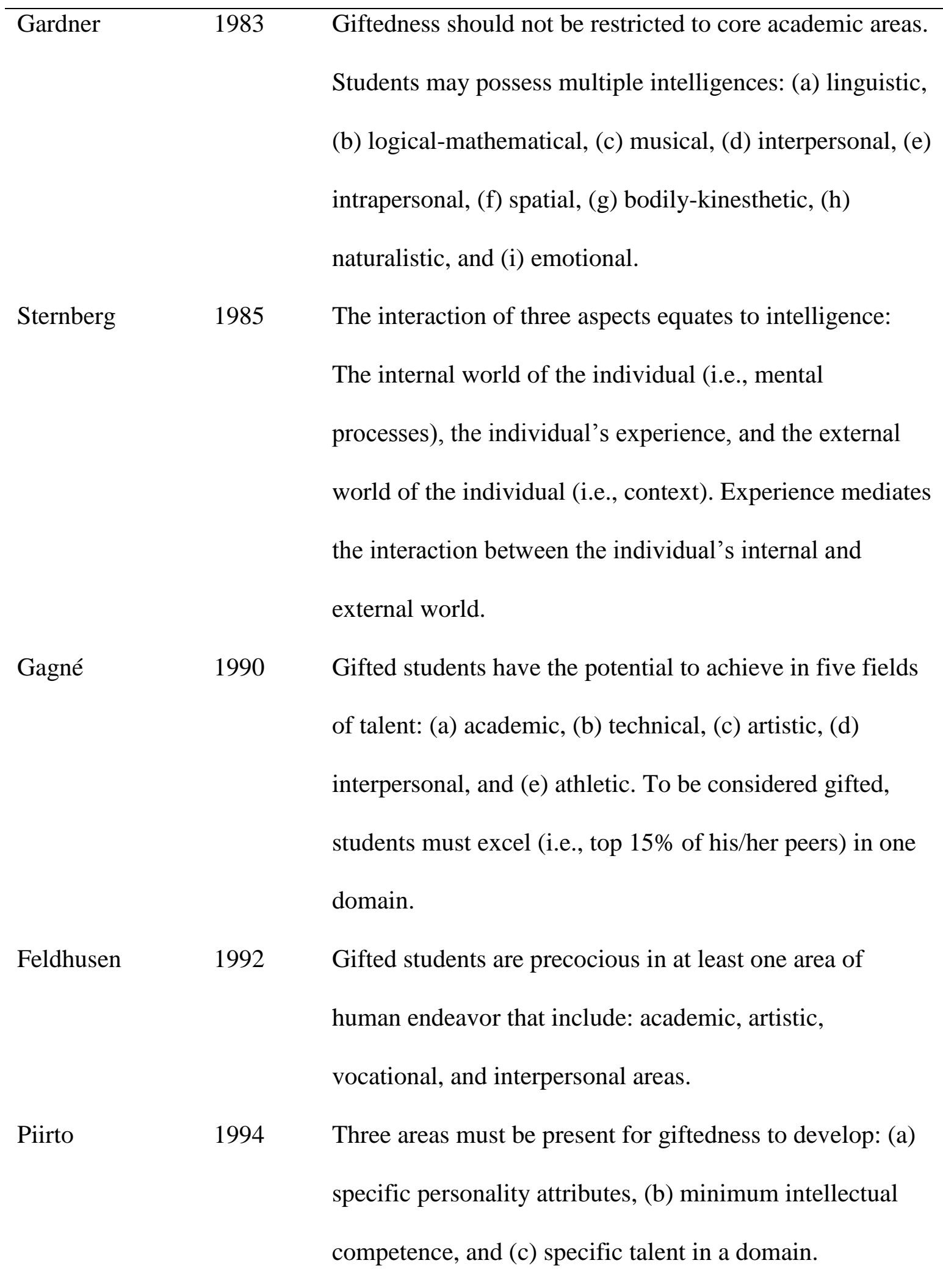


Federal and State Definitions

Although a universal definition of giftedness does not exist, the federal government provides one of the most inclusive definitions.

The term 'gifted and talented', when used with respect to students, children, or youth, means students, children, or youth who give evidence of high achievement capability in areas such as intellectual, creative, artistic, or leadership capacity, or in specific academic fields, and who need services or activities not ordinarily provided by the school in order to fully develop those capabilities (NCLB, 2002, p. 544).

Whereas federal law recognizes the special needs of gifted students, it does not require schools to identify or offer services for these students. Nonetheless, many states (e.g., North Carolina) have integrated this federal definition into their laws, and many school districts have made attempts to use this definition to identify and offer special programming for gifted students (Volker, Lopata, \& Cook-Cottone, 2006). In North Carolina, for example, Article 9B of the North Carolina General Statutes states:

... academically or intellectually gifted students perform or show the potential to perform at substantially high levels of accomplishment when compared with others of their age, experience, or environment. Academically or intellectually gifted students exhibit high performance capability in intellectual areas, specific academic fields, or in both intellectual areas and specific academic fields. Academically or intellectually gifted students require differentiated educational services beyond those ordinarily provided by the regular educational program. Outstanding abilities are present in students from all cultural groups, across all 
economic strata, and in all areas of human endeavor. (1996, 2nd Ex. Sess., c. 18, s. $18.24(\mathrm{f})$.)

Twenty states either do not have a mandate for gifted education or have a mandate that is not funded at all. In addition to having a very inclusive definition of giftedness, North Carolina both mandates and partially funds gifted programming (NAGC, 2006).

\section{What is Gifted Underachievement?}

Similar to the challenges of defining giftedness, for decades researchers have been unable to agree upon a common definition of gifted underachievement (Dowdall \& Colangelo, 1983; Reis \& McCoach, 2000). Unfortunately, it is difficult to develop interventions to address gifted underachievement given the varied definitions of what it actually is. Certain definitions only capture a particular subpopulation of gifted students. According to Reis and McCoach (2000), various definitions become problematic when gifted students cannot reliably be identified as underachievers. Consequently, identification is tied to the definition of gifted underachievement (Dowdall \& Colangelo, 1983). Defining this construct, therefore, is crucial in order to identify, first, who these students are and second, to provide interventions that address the factor(s) contributing to their underachievement.

Gifted underachievement definitions fall in three categories: (a) discrepancy between potential and performance; (b) predicted achievement versus actual achievement; and (c) development of potential (Reis \& McCoach, 2000). Reis and McCoach (2000) introduced a universal definition that collapses these three categories into one workable definition. A discussion of these three categories and the universal definition proposed by Reis and McCoach follows. 
Discrepancy between Potential and Performance

In the gifted education literature, the most prominent approach to defining gifted underachievement involves a discrepancy between potential and performance. The term "potential" typically refers to "ability" and is measured by an Intelligence Quotient (IQ) test, such as the WISC or Stanford-Binet. Since there is no federal mandate for gifted education, there is no predetermined IQ cut-off point to qualify for gifted programming; this varies across states and even districts. Consequently "potential" is inconsistently defined (Reis \& McCoach, 2000).

"Performance" is used interchangeably with "achievement," and its definition is equally troublesome. "Achievement" is most often measured by scores on standardized achievement tests (e.g., Iowa Test of Basic Skills, Stanford Achievement Tests) and by subject-specific grades. Although standardized achievement tests are more reliable than grades, they do not necessarily capture what a student has learned during a particular academic year. Conversely, grades are unreliable due to inherent teacher bias; however, grades tend to capture more adequately a student's learning experience in a specific classroom (Reis \& McCoach, 2000).

Despite these limitations, researchers have used this approach to defining gifted underachievement for decades. Studies utilizing this definition are represented in Table 2. 
Table 2: Studies that use "discrepancy between potential and performance"

\begin{tabular}{lll}
\hline Author(s) & Date & Gifted Underachievement Criteria \\
\hline Broedel, Ohlsen, Proff, \& & 1965 & Gifted students ranked in the top ten \\
Southhard & percent of their peers using the \\
& California Test of Mental Maturity and \\
& at the ninth percentile or below, with \\
& regard to GPA. \\
Whitmore & Gifted students with either high aptitude \\
& scores or high achievement scores who \\
& performed poorly in schoolwork as \\
& evidenced by low grades. \\
& Students demonstrating a discrepancy \\
& between potential and actual \\
& & \\
& &
\end{tabular}


Table 2 (Continued)

\begin{tabular}{ll}
\hline Emerick 1992 & Gifted students who demonstrated \\
& intellectual giftedness through \\
& standardized achievement test scores \\
& (90th+ percentile) or scores on tests of \\
& general aptitude (125+ IQ) or other \\
& indicators of potential for above-average \\
& performance. Underachievement was \\
& demonstrated by evidence of average or \\
& below-average academic performance \\
& (e.g., grades, observations, test scores). \\
& Gifted students who scored at or above \\
& the $95^{\text {th }}$ percentile on the composite \\
& score of the American College Testing \\
Colangelo et al. & Program (ACT), but who also had a \\
Peterson \& Colangelo & GPA of 2.25 or lower. \\
& Students identified for gifted \\
& programming who had GPAs less than \\
& 3.35. \\
\hline 1996 &
\end{tabular}


Table 2 (Continued)

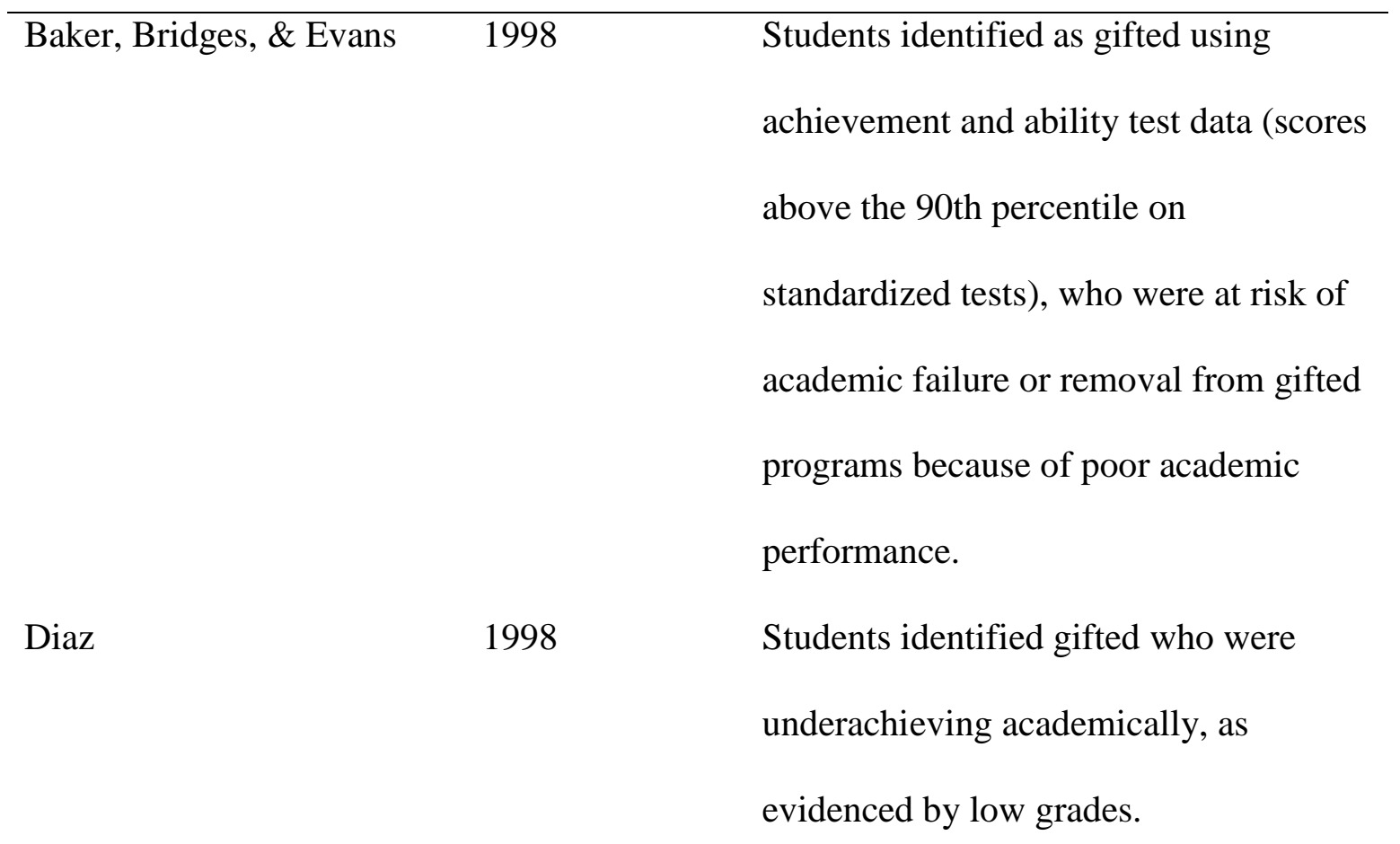

Predicted Achievement versus Actual Achievement

A few researchers define gifted underachievement as a discrepancy between predicted achievement and actual achievement. Underachievement, in this case, is viewed as a regression equation. Students who perform more poorly than expected on measures of achievement (i.e., at least 1 standard deviation below predicted) based on measures of ability are classified as gifted underachievers (Reis \& McCoach, 2000). Studies utilizing this definition are represented in Table 3. 
Table 3: Studies that use "predicted achievement versus actual achievement"

\begin{tabular}{|c|c|c|}
\hline Author(s) & Date & Gifted Underachievement Criteria \\
\hline Davis \& Connell & 1985 & $\begin{array}{l}\text { Gifted underachievers were defined as having IQs } \\
>125 \text { and having achievement scores which fell } \\
\text { at least } 1 \text { standard error of prediction below the } \\
\text { achievement score predicted by their IQ in a } \\
\text { regression analysis. }\end{array}$ \\
\hline Green & 1988 & $\begin{array}{l}\text { Gifted students who demonstrated at least a one } \\
\text { year difference between expected and actual } \\
\text { performance on a standardized achievement test. }\end{array}$ \\
\hline Redding & 1990 & $\begin{array}{l}\text { The underachievers were those whose predicted } \\
\text { GPA (based on their WISC-R score) was at least } \\
1.0 \text { standard error of estimate higher than their } \\
\text { actual GPA during the previous school year. }\end{array}$ \\
\hline Lupart \& Pyryt & 1996 & $\begin{array}{l}\text { Whether or not a student is a gifted underachiever } \\
\text { is determined by the following ana1yses: (a) The } \\
\text { correlation between IQ and achievement, and (b) } \\
\text { estimation of the expected IQ in relation to } \\
\text { achievement for the student using the standard } \\
\text { error of estimate. Underachievers are students } \\
\text { with a discrepancy beyond one standard error of } \\
\text { estimate. }\end{array}$ \\
\hline
\end{tabular}


Development of Potential

A less prominent theme in the literature defines gifted underachievement as simply a failure to self-actualize. This definition of gifted underachievement fails to take any kind of external criteria into account (e.g., grades, test scores). Rather, gifted underachievers are viewed as individuals who, for whatever reasons, are unable to reach their full potential (Reis \& McCoach, 2000). Studies that utilize this definition of gifted underachievement are provided in Table 4.

Table 4: Studies that use "development of potential"

\begin{tabular}{lll}
\hline Author(s) & Date & Gifted Underachievement Criteria \\
\hline Richert & 1991 & Students who fail to achieve in any of the areas \\
& needed to manifest giftedness (e.g., ability, \\
& creativity, motivation). \\
Rimm & Gifted students who are not performing up to their \\
& ability. \\
\hline
\end{tabular}

\section{Universal Definition}

Although several definitions have been proposed for gifted underachievement, the majority of these definitions share a common theme; students must demonstrate a discrepancy between potential and performance. The aforementioned studies, however, did not universally operationalize the magnitude and exact nature of this discrepancy. Therefore, Reis and McCoach (2000) proposed the following universal definition for gifted underachievement: 
Underachievers are students who exhibit a severe discrepancy between expected achievement (as measured by standardized achievement test scores or cognitive or intellectual ability assessments) and actual achievement (as measured by class grades and teacher evaluations). To be classified as an underachiever, the discrepancy between expected and actual achievement must not be the direct result of a diagnosed learning disability and must persist over an extended period of time... Ideally, the researcher would standardize both the predictor and the criterion variables and would identify as underachievers those students whose actual achievement is at least one standard deviation below their expected achievement level. (p. 157)

Although imperfect (Reis \& McCoach, 2000), this universal definition of gifted underachievement has gained immense popularity in the field of gifted education since its introduction. Studies utilizing this definition are provided in Table 5.

Table 5: Studies that use the "universal definition" of gifted underachievement

\begin{tabular}{lll}
\hline Author(s) & Date & Gifted Underachievement Criteria \\
\hline Schultz & Students with an IQ two or more standard \\
& deviations above the mean and/or $95^{\text {th }}$ \\
& percentile achievement test scores who earned \\
& a 2.75 GPA or below (on a 4.00 point scale) \\
& in science coursework averaged over any \\
& three grading periods.
\end{tabular}


Table 5 (Continued)

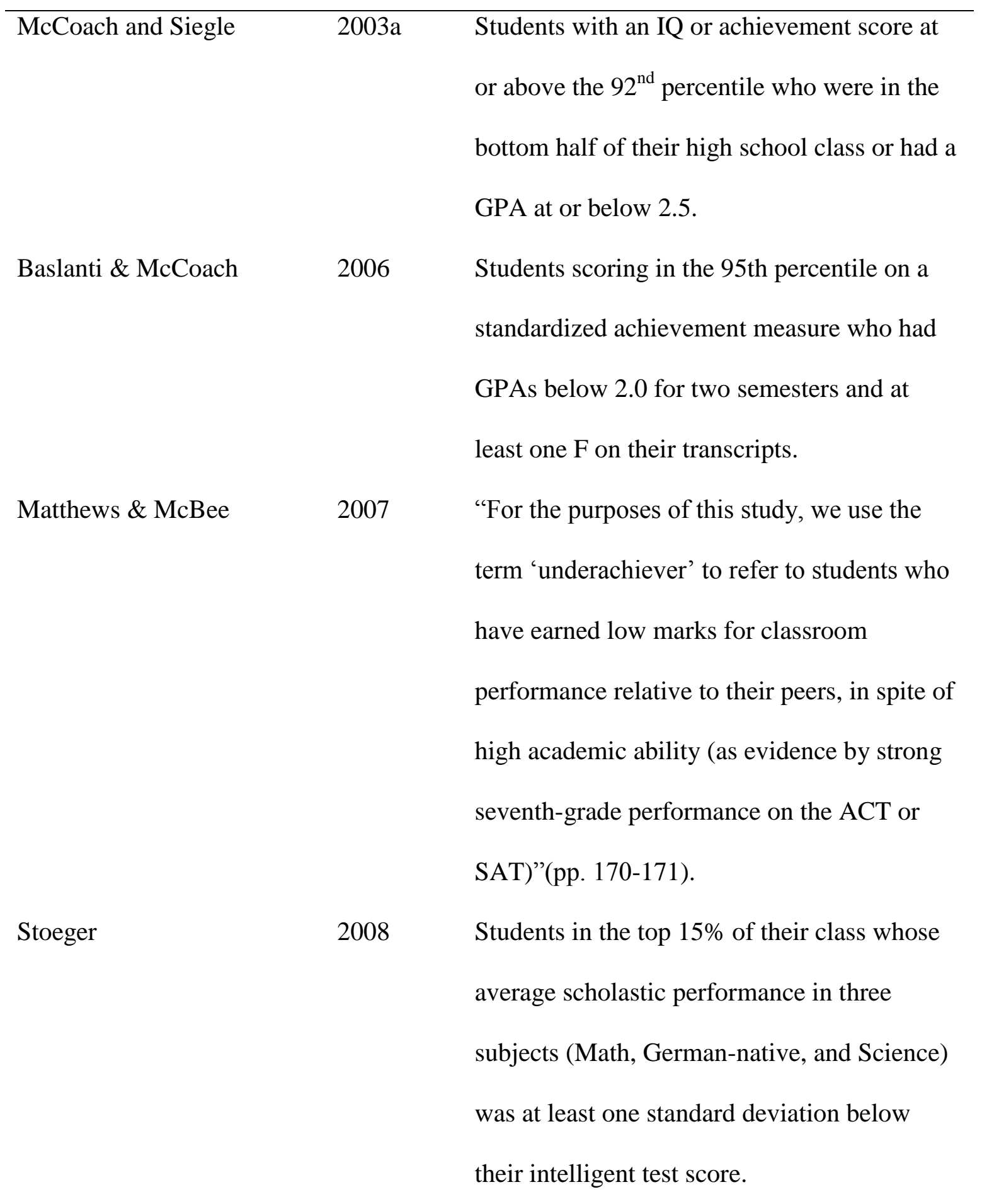




\section{Summary}

Definitions of giftedness have come a long way since Terman. Most definitions recognize attributes in addition to general intelligence such as task commitment, creativity, and emotional intelligence. Although researchers appear to be more aware of how complex the construct of giftedness is, they still fail to agree upon a common definition. Gifted underachievement, therefore, is even more difficult to define, given the constructs of giftedness and underachievement both must be considered. Researchers have proposed definitions of gifted underachievement that fall in three categories. These categories, however, all appear to share a discrepancy between potential and performance in common. Given this commonality, Reis and McCoach (2000) proposed a universal definition of gifted underachievement that provides more specificity: "Underachievers are students who exhibit a severe discrepancy between expected achievement (as measured by standardized achievement test scores or cognitive or intellectual ability assessments) and actual achievement (as measured by class grades and teacher evaluations)" (p. 157). Since its introduction, this definition has gained acceptance in the gifted community and continues to be used today.

\section{Why Gifted Students Underachieve}

Most researchers in gifted education concur that gifted underachievement is symptomatic of a number of causes (Dowdall \& Colangelo, 1982; Reis \& McCoach, 2000). To simply say a common set of specific causes are antecedent to the underachieving behavior of every gifted child would be a gross inaccuracy. For decades researchers have studied why gifted students underachieve. Based on an extensive review of the gifted underachievement literature, two broad themes emerge. Gifted students either underachieve because of individual factors (e.g., low self-esteem) or because of 
environmental factors (e.g., home issues). Not surprisingly, the two sets of factors tend to interact with one another. A mismatch in learning environment, for example, may lead to the development of poor self-regulation skills. Or, an uncaring adult may cause a child to think he is not smart.

Balduf (2009) found gifted university students attributed their underachievement to individual issues (i.e., time management and self-discipline). Further, Kanoy, Johnson, and Kanoy (1980) found poor self-concept, with regard to their intellectual and school status, as a major factor impacting the achievement of gifted students. This latter finding, however, has recently been challenged by McCoach and Siegle (2003a) and Baslanti and McCoach (2006), who claim academic self-concept is not a significant factor contributing to the underachievement of gifted students.

Environmental factors may also play a crucial role in the academic underachievement of gifted students. Negative home and school environments contributed to the onset of participants' underachievement in Peterson's (2001) study of gifted adults who reversed their pattern of underachievement. Parents and teachers were the primary influences impacting the underachieving behaviors of participants when they were adolescents. Gifted females, especially, experienced a great deal of family conflict that in retrospect contributed to their underachievement. In particular, important adults in their lives were believed to be under-involved and have negative attitudes toward their schooling. Conversely, Green et al. (1988) found underachievement of gifted students was not correlated with environmental factors like dysfunction within a family.

A mismatch in learning environment may also contribute to the underachievement of gifted students. Similar to the findings of Kanevsky and Keighly (2003), Schultz 
(2002) found lack of choice, unchallenging material, and the absence of a caring teacher negatively impacted gifted students’ achievement. Similarly, Hébert (2001) noted inappropriate curricular experiences and issues in the home environment as factors leading to students' underachievement.

Individual and environmental factors negatively impacted the participants in a study conducted by Diaz (1998). Diaz found that inappropriate learning experiences in students' elementary school years played a decisive role in their underachievement in middle and high school. When students were appropriately challenged later in their education, they did not have the academic or affective skills needed to persevere. Family and community difficulties further complicated this issue. Compounded, these issues led to negative academic self-perceptions, disengagement from learning, and underachievement.

Diaz (1998) created a model to visually represent factors contributing to academic underachievement (See Figure 2). In the center of the model are mismatched early learning experiences, believed by Diaz to be the primary cause of students' underachievement. Other contributing factors surround the core of the model, negative environmental influences outside of school (e.g., family issues). A byproduct of these experiences is internal turmoil, which leads to academic underachievement. 


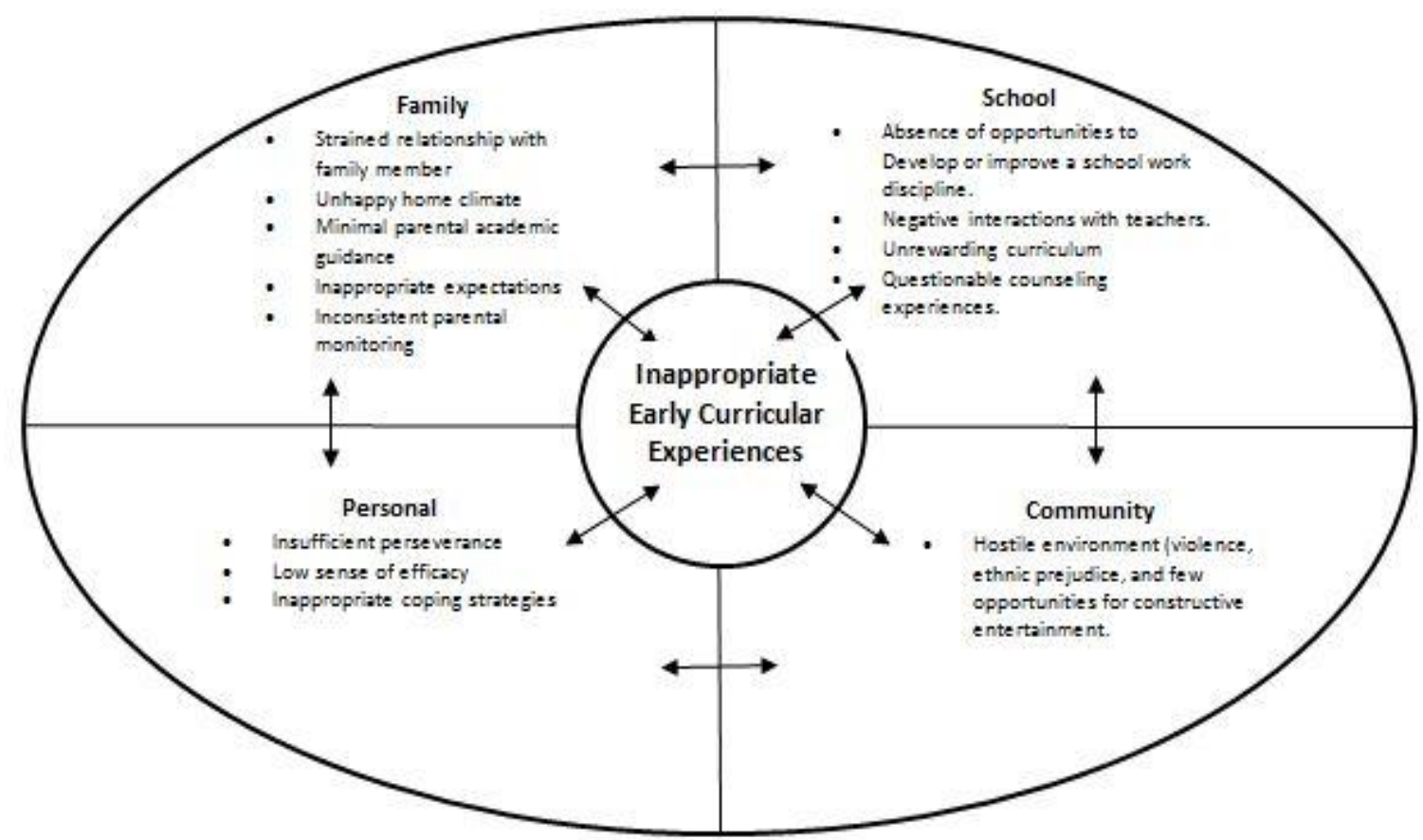

Figure 2. Diaz's model of gifted underachievement.

Baker, Bridger, and Evans (1998) also constructed a model to visually represent why gifted students underachieve (See Figure 3). Their combined etiology model was comprised of organizational and study skills (individual factor), parenting skills (environmental factor), and academic quality (environmental factor). Data investigating the model were statistically significant $(p=.000)$, correctly classifying $86 \%$ of the cases. All of the three predictors contributed significantly to the model, suggesting academic underachievement is caused by both individual and environmental influences, similar to the findings of Diaz (1998). 
COMBINED ETIOLOGY MODEL

- derives from ecological systems theory

- premise: underachievement is best predicted using a multimodal approach

\begin{tabular}{|c|c|c|c|c|}
\hline $\begin{array}{c}\text { Lack of Organizational } \\
\text { Study Skills }\end{array}$ & $\begin{array}{c}\text { Poor Parenting } \\
\text { Skills }\end{array}$ & $\begin{array}{c}\text { Poor Academic } \\
\text { Quality }\end{array}$ & - & Underachievement \\
\hline
\end{tabular}

Figure 3. Baker et al.'s model of gifted underachievement.

The Achievement-Orientation Model

Most recently, Siegle and McCoach (2005) created a model that theorizes why gifted students underachieve in an effort to develop individualized interventions for reversing gifted underachievement (see Figure 1). According to their AchievementOrientation Model, gifted achievers have the prerequisite abilities needed to achieve at high levels in school, value the goals of school, and find academic tasks meaningful (i.e., goal valuation); feel the school environment is supportive (i.e., environmental perceptions); and perceive they have the ability to perform academic tasks well (i.e., selfefficacy). These three factors, task meaningfulness, environmental perceptions, and selfefficacy, comprise motivation. If students' self-perceptions are positive on all three factors, according to the theory, they will self-regulate, and as a consequence they will engage and achieve at levels commensurate with their ability. However, Siegle and McCoach suggest that if students' attitudes are low on any one of these three factors, their motivation will be adversely affected, resulting in poor self-regulation, disengagement, and likely academic underachievement.

The Achievement-Orientation Model is based on four theories: (a) Self-Efficacy Theory, (b) Attribution Theory, (c) Expectancy-Value Theory, and (d) PersonEnvironment Fit Theory. A brief discussion of these theories follows. 
Self-Efficacy Theory. Self-efficacy is a person's belief that they have the ability to accomplish a task (Bandura, 1977). Efficacy expectations refer to a person's conviction that they can successfully accomplish a task (e.g., an exam) and thereby achieve a desired outcome (e.g., a perfect grade). Outcome expectancy, on the other hand, refers specifically to the behavior needed to accomplish the task that will lead to a desired outcome. A student, for example, may know certain behaviors will lead to a desired result; however, he may doubt whether or not he can successfully execute those behaviors. Given this doubt, the student may choose not to attempt those behaviors (e.g., one-on-one tutoring with the teacher) and fail to achieve the desired outcome (e.g., a perfect test grade). Why a student may decide against one-on-one tutoring with the teacher, for example, has to do with coping. Individuals will avoid settings that they believe threaten their coping skills. The student may fear "looking stupid" in front of the teacher or being exposed in some way. Students tend to choose behavioral settings that are unintimidating and make them feel safe; they will naturally avoid settings and behaviors that increase their vulnerability (Bandura, 1977). The decision to underachieve is perceived as the less threatening alternative.

Further, four components make up an individual's expectations of personal efficacy: (a) performance accomplishments, (b) vicarious experiences, (d) verbal persuasion, and (e) physiological states. Performance accomplishments increase mastery expectations, whereas failures decrease them. Seeing others perform activities perceived as threatening without facing adverse consequences (i.e., vicarious experiences) also increase mastery expectations; "if she can do it, I can do it." Verbal persuasion may also raise mastery expectations. If a student can be convinced they can successfully cope with 
certain stresses, they are more likely to persist and attempt a particular task. Finally, stressful situations may lead to negative physiological states and decrease a student's mastery expectations. Altering stressful situations (e.g., test taking), making them less emotionally taxing, may have the opposite desired effect (Bandura, 1977).

Attribution Theory. Attribution theory concerns students' perceptions of why certain events occurred (Weiner, 1972). Students, for example, may attribute a failing test grade to their lack of time spent studying, or they may attribute it to a teacher disliking them. The allocation of responsibility will lead to different behavior on the part of the student. In the former case, the student may study harder for the next exam, while in the subsequent case, he may decide against studying at all because he "can't win" in that particular class; the teacher is out to get him. How a student perceives these events may be due to myriad environmental factors (e.g., home issues, prior success and failure experiences) and/or personal predisposition.

The perceived causes of achievement outcomes are typically related either to locus of control or stability. Locus of control may be internal or external. With internal locus of control, a student attributes his success or failure to ability or effort, whereas with external locus of control, success or failure is attributed to luck or bias. With regard to stability, causes such as ability and bias are often perceived by the student as fixed and unchangeable. Effort and luck, on the other hand, are more malleable and can change. Expectancy of success is generally believed to be more related to stability of causal attributions than locus of control (Weiner, Nierenberg, \& Goldstein, 1974). If a student believes a teacher dislikes him or is "out to get him," he most likely also believes there is 
nothing he can do to bolster his academic performance in that class. This consequently leads to academic underachievement.

Expectancy-Value Theory. Eccles and Wigfield (1995) proposed a three-factor model for understanding why students become motivated to engage in and successfully complete academic tasks. They theorized students must find intrinsic, attainment, and utility value (i.e., the components of goal valuation) in a task to be motivated to engage in it. Intrinsic value is defined as how interested a student is in a task, while attainment value relates to perceptions of the importance of doing well on a task. Utility value refers to how central the student believes a task is to his/her future goals.

Students who value academic goals are motivated to engage in academic tasks and achieve their full potential. Conversely, students who do not see intrinsic, attainment, or utility value in academic goals have no reason to put forth the effort to achieve academically (McCoach \& Siegle, 2003a). Attainment value has been found to be low among gifted female underachievers, in particular (Callahan, Cunningham, \& Plucker, 1994). Kramer (1991), for example, found that gifted female underachievers in middle school attributed their successes to hard work or luck; they did not believe they actually had the natural ability to do well on assigned tasks.

Goal valuation in particular is believed to lay the groundwork for increasing motivation in gifted underachievers. In a study of 178 gifted high school students, McCoach and Siegle (2003a) found low goal valuation was a strong predictor of underachievement. Results indicated a strong correlation between gifted underachievers' goal valuation and their motivation/self-regulation. This finding further substantiates Eccles and Wigfield's (1995) theory that students must first value the goals of school 
before they can become motivated to achieve. Other studies using a measure developed by McCoach \& Siegle (2003b) also have found low goal valuation to be predictive of underachievement (Matthews \& McBee, 2007; Suldo, Shaffer, \& Shaunessy, 2008).

Person-Environment Fit Theory. Person-Environment Fit Theory (French, Rodgers, \& Cobb, 1974) is rooted in person-environment interaction theory (Lewin, 1935). The theory states that outcomes result from an interaction between individuals and their environment. Person-fit is difficult to operationalize because individual characteristics and environment characteristics may not share commensurate dimensions. However, if this can be achieved, goodness of fit is defined as a discrepancy between person and environment (Jansen \& Kristoff-Brown, 2006).

In understanding Person-Environment Fit Theory, it is important to distinguish between different measures of fit and the components of this theory. For example, objective and subjective measures of fit must be differentiated, as well as abilitiesenvironmental demand and needs-environmental supply. Objective and subjective fit are easily distinguished. Objective fit deals with facts about an environment, while subjective fit concerns a person's perceptions of their environment. A student, for example, may perceive his environment as unsupportive. Facts to support this assessment may include the teacher's refusal to tutor after school or questions not being allowed during class (Caplan \& Van Harrison, 1993).

Demands-abilities fit deals with whether a person has the abilities that fit demands of a work role. For example, a student may want to please his teacher, even if his teacher is unsupportive, and therefore, goes above and beyond expectations on assignments and always participates in class discussion. The student, in this case, is most interested in 
satisfying the needs of others (i.e., his teacher) and has the ability to do so. Conversely, needs-supplies fit concerns a person's desire to satisfy his own needs. For example, a teacher may not provide enough task clarity; therefore, the student has to constantly ask the teacher to clarify instructions before he will attempt the task at hand (Caplan \&Van Harrison, 1993).

When there is a discrepancy between person and environment, underachievement can occur. If a student perceives his environment as unsupportive, he may choose to underachieve, or he may not develop the skills necessary to reach his full academic potential. Students' perceptions may not be accurate; however, student performance may be affected negatively nonetheless. Students must believe that those around them, whether at home or school, want them to succeed. Academic underachievement is likely to result when students stop believing this (Peterson, 2001).

\section{Summary}

Much like the very definition of gifted underachievement, the exact reasons why gifted students underachieve are unclear. Upon reviewing the literature on gifted underachievement, it appears individual and environmental factors play a decisive role in gifted students' underachievement. These factors are represented in three different theoretical models that seek to explain the phenomenon of gifted underachievement. The most recent of these three models, the Achievement-Orientation Model, posits students' attitudes must be positive in three areas (i.e., self-efficacy, environmental perceptions, and task meaningfulness) in order for self-regulation, achievement, and engagement to occur. A student's belief in their ability can be considered an individual factor; however, this factor may definitely interact with environmental perceptions and task 
meaningfulness. For example, if the academic environment is unsupportive and/or uninteresting, a student may experience low levels of self-efficacy (Diaz, 1998). It is interesting to note that the three rings encapsulating these factors in the AchievementOrientation Model overlap, suggesting interaction. Similarly, Baker et al. found a model comprised of both individual and environmental factors best predicted gifted underachievement, again suggesting the salience of these two dominant overarching constructs.

The Reversal of Gifted Underachievement

Effective interventions to help reverse the trend of underachievement in gifted students have been inconsistent and inconclusive (McCoach \& Siegle, 2003). Unfortunately, "no prescription or formula can be written that is appropriate for all underachieving students" (Baum, Renzulli, \& Hebert, 1995, p. 235). In fact, reversing the underachievement pattern of gifted students has met with limited success in part because many "researchers [have] failed to understand the individual sufficiently and [have] failed to investigate systematically all aspects of the problem" (Emerick, 1992, p. 140). Despite several unsuccessful attempts to reverse gifted underachievement, studies have paved the way for future research by demonstrating the need for a systematic and theoretical approach to combating this silent epidemic.

In one of the first studies aimed at reversing gifted underachievement, Broedel et al. (1960) implemented a group counseling intervention with 29 gifted ninth grade students who placed in the $9^{\text {th }}$ percentile or lower in GPA their eighth grade year of school. The intervention focused on increasing the affective and academic growth of participants over an eight week treatment period. Using a pre-post-test control group 
design, results indicated statistically significant gains in student acceptance of self and others; however, with regard to academic growth, the grades of students in the treatment condition worsened over time. Overall, the study failed to demonstrate group counseling as a viable way to improve the academic performance of gifted underachievers.

Whitmore (1980), in her seminal work, successfully reversed the pattern of underachievement for many students by placing them in a self-contained program for gifted underachievers. The Cupertino Program for highly gifted underachievers, a fulltime therapeutic program, developed the academic and social skills of students with high IQs who scored 1-2 years below grade level on tests of basic skills. In the regular classroom setting, these students rarely completed work and were nonresponsive to efforts made to motivate them to achieve. Further, all participants at the time of referral were labeled emotionally and behaviorally disturbed (EBD). The program sought to increase self-acceptance, provide meaningful curriculum opportunities, and provide students with the chance to embrace success. Twenty-six primary and intermediate students participated in the Cupertino Program. As a result of their one to two year participation, almost all of the students were placed in gifted education programs and became high achievers.

Supplee (1990) also developed a special program for gifted underachievers. The program, a part-time class, focused on bolstering students' affective and academic growth. The effectiveness of the program was assessed through 12 case studies. Overall, students reported improved self-perceptions, sense of control, and appreciation for unique learning styles. Based on the work of Whitmore (1980) and Supplee, it appears as though curricular interventions may hold promise for reversing gifted underachievement; 
however, these types of interventions tend to be costly and they therefore lack feasibility in the regular school system setting.

Several studies have examined factors gifted students believe contribute or could contribute to the reversal of their underachievement. Emerick (1992) retrospectively examined the factors that reversed the underachievement pattern of 10 gifted students ranging in age from 14 to 20 years old. Analysis of qualitative data acquired from questionnaires and interviews revealed six factors contributing to the students' reversal of underachievement. Factors included: (a) out-of-school interests/activities, (b) parents, (c) the class, (d) goals associated with grades, (e) the teacher, and (f) self. Although the participants noted six factors as crucial to the reversal of their underachievement, they all highlighted the actions of one teacher as the most influential factor in their decision to become achievers.

Peterson (2001) conducted a study to determine what factors gifted adults who were once underachievers perceived as contributing to the reversal of their underachievement. Thirty-one participants completed a questionnaire concerning their experiences as high school students. Results indicated that developmental changes (e.g., maturity), curricular changes, relocation of home, and a specific teacher were involved in the reversal of these participants' underachievement. Peterson highlighted the importance of specific environmental factors (e.g., home, school) in reversing the pattern of gifted underachievement.

Using a case study design, Kanevsky and Keighly (2003) interviewed 10 individuals, ages 15 to 18 years old, who were identified gifted, became academic underachievers, and who had dropped out of school or been suspended from school at 
least once. Based on these interviews, Kanevsky and Keighly concluded that interventions to reverse underachievement must focus on the five C's: (a) control, (b) choice, (c) challenge, (d) complexity, and (e) caring. The extent to which each of the factors was available to the participants in school determined whether or not they disengaged from learning. Similar to the findings of Emerick (1992), the experience students had with a caring teacher had a powerful positive impact on their academic achievement.

Further, Balduf (2009) interviewed seven underachieving college freshmen about the interventions they felt could reverse their underachievement. Unlike in previous studies, these participants looked mainly to themselves when considering the factors that could reverse their underachieving behaviors. They felt that changing their own attitudes toward their education and improving their behaviors (i.e., studying, metacognitive strategies) would increase their motivation and subsequently, reverse their pattern of underachievement.

In addition to retrospective studies concerning the reversal of gifted underachievement, several studies have examined the effects of a particular intervention on the underachievement behaviors of gifted students. Using a multiple case study design, Baum, Renzulli, and Hebert (1995) investigated the effects of Type III enrichment on the underachievement of 17 preadolescent students. Type III Enrichment provides students with the opportunity to investigate a problem of interest to them. Students, as investigators, collect data, analyze problems, and apply research strategies to produce creative culminating products. Fourteen of the 17 students in this study made positive academic gains, and these gains continued through the following year. Positive 
attention from a teacher, learning self-regulation strategies, and the opportunity to work in an area of interest were among the factors that helped these students become achievers.

More recently, using a pretest-posttest control group design, Stoeger and Ziegler (2008) implemented a self-regulation intervention with 36 fourth grade gifted

underachievers in mathematics. Dependent measures were (a) time management, (b) selfefficacy, (c) helplessness, (d) mathematical aspirations, (e) persistence, (f) academic achievement, and (g) self-reflective learning behaviors. Statistically significant training effects were found for time management, $F(1,30)=2.82$, p=.05 and self-efficacy, $F(1$, $30)=2.82, p=.05$. The training did not have a statistically significant effect on any of the other measures, however, including students' academic achievement.

Although less common, one study was located that experimentally tested an intervention with underachieving university students. Morisano et al. (2010) assessed the effectiveness of a computerized goal-setting program on the GPA and retention rates of underachieving university students whose GPAs had fallen below a 3.0. Participants' post-intervention GPAs were significantly higher than their pre-intervention GPAs. No statistically significant differences in GPA were identified for the control group. A planned comparison of post-intervention GPA between treatment and control groups indicated significantly greater GPAs for students in the treatment group. Retention was operationalized as not dropping below nine credits. All students in the treatment group remained at nine credits or above, whereas $20 \%$ of students in the control group dropped below nine credits and two withdrew from school. The retention-rate difference between groups was statistically significant. The results of this study demonstrate the potential goal-setting interventions have for reversing student underachievement. 
Most recently, studies have attempted to use the Achievement-Orientation Model as a theoretical foundation for developing interventions to address gifted students' underachievement. Rubenstein (2011) experimentally tested an intervention, Project ATLAS (Autonomous Thinkers Learning as Scholars), with middle school gifted underachievers. The ATLAS intervention included students' assessment of their shortand long-term goals and individual instruction on how to propose differentiated class assignments to their teachers, for the purpose of in increasing their interest in class. Using a multiple-baseline single-subject design, visual inspection of the graphs did not indicate a functional relationship between the intervention and student engagement or student achievement in Rubenstein's study.

In a related study, Rubenstein et al. (2012) developed individualized interventions based on the components of the Achievement-Orientation Model. Middle school gifted underachievers were identified and then administered treatments based on the component of the Achievement-Orientation Model in which they demonstrated a deficit. These students were randomly assigned to either a control group or to an intervention group that targeted the source of their underachievement. Students' grades in reading and mathematics, on average, increased by a full letter grade over the course of the intervention; however, due to the small sample size, these changes were not statistically significant. A second analysis comparing the five different intervention strategies in use revealed a statistically and practically significant increase in students' grades over the 6 to 9 week intervention period, $t(45)=2.56, p=.014, d=.38$. Of all the treatment conditions, students in the goal valuation and environmental perceptions treatment groups demonstrated the greatest growth in academic grades. 


\section{Summary}

Early interventions to reverse gifted underachievement used counseling or curricular modifications. Although the latter met with success, these types of interventions are often considered expensive and impractical; school districts would have to fund part or full-time classes just for gifted underachievers. Following the work of Whitmore and Supplee, research concerning the reversal of gifted underachievement has failed to test interventions using experimental methodology. The majority of studies, in fact, used qualitative methodology, attempting to understand the factors that individuals considered paramount to the reversal of their underachievement reversal. Recently, researchers have attempted to test gifted underachievement interventions experimentally, but these attempts have met with limited success. Rather than simply dismiss these studies as unsuccessful, however, it is important to investigate the theoretical underpinnings of these studies further, to potentially strengthen interventions for gifted underachievers in the future.

\section{Chapter Summary}

This review of the literature has provided a foundation for this study. First, the typical sixth and seventh grade student was described, as well as the middle school environment. Second, giftedness and gifted underachievement were defined. Third, factors contributing to gifted underachievement and theoretical models proposed to explain gifted underachievement were discussed. Fourth, potential strategies for reversing gifted underachievement were examined. With regard to whom the typical sixth and grade student is and what the typical middle environment looks like, the foundation for underachievement is often laid as early adolescents' attempt to reconcile their quest for 
identity with a mismatched learning environment. In terms of definitions of giftedness, since this study is based in the state of North Carolina, the definition of giftedness provided by article 9B of the North Carolina General Statutes will be used. Further, given that the vast majority of researchers agree gifted underachievement represents a discrepancy between potential and performance, Reis and McCoach's (2000) corresponding definition of gifted underachievement will be used for this study. Specifically, gifted underachievers will be defined operationally as students whose expected achievement (i.e., gifted students would be expected to earn an 'A' in their coursework) is severely discrepant (i.e., at least two letter grades below) from their actual achievement (i.e., student and teacher-reported GPA in mathematics).

The literature on why gifted students underachieve is nonexperimental, meaning causal inferences cannot be made from these studies. Although establishing a theory as to why gifted students underachieve seems like a logical first step before developing potentially costly interventions, the theories proposed in the literature are severely limited. For example, Diaz's (1998) theory was based on a sample of six students of Puerto Rican descent. Suffice to say, these findings are not generalizable. Further, the theory is exploratory in nature and has never been confirmed by structural equation modeling techniques like Path Analysis. The theory proposed by Baker et al. (1998), was tested with a sample of 56 gifted students using logistic regression, an exploratory method of data analysis. Inadequate power precluded exploration of potentially important variables. The authors suggested larger samples for future research.

To avoid some of the shortcomings of prior research, the current study included 156 participants from two diverse school districts, a much larger sample that will lead to 
more generalizable results. Finally, the Achievement-Orientation model, although supported by a strong theoretical framework, has never been tested. Therefore, the current study provided a test of this model.

Literature concerning the reversal of gifted underachievement, much like research about why gifted students underachieve, is predominately nonexperimental; however, important information about factors that may potentially reverse underachievement can be ascertained from these studies. The caring teacher, for example, was a recurring factor in a number of studies (e.g., Kanevesky \& Keighly, 2003; Peterson, 2001, Baum et al., 1995). This factor, therefore, should be investigated further. With regard to the current study, the role of the teacher in contributing to students' underachievement was examined through the environmental perceptions construct of the Achievement-Orientation model.

Although it is tempting to assume that individual factors, in isolation, contribute to the reversal of gifted students' underachievement, Rubenstein (2011) cautions that the complex interplay (i.e., interaction effects) between factors must be taken into consideration. For example, attitudes toward environmental perceptions and task meaningfulness may be equally important in determining whether a gifted child achieves or underachieves. The current study addressed this important concern through Cluster Analysis. Based on the Achievement-Orientation Model, there may be up to seven different clusters (or profiles) of gifted underachievers. The next chapter will explain in greater depth the methods used to conduct this study.

The findings of this study shed light not only on why gifted students underachieve, but also offer profiles of what different gifted achievers and 
underachievers look like statistically with regard to the Achievement-Orientation Model constructs. 


\section{CHAPTER 3: METHODS}

Purpose and Research Questions

The Achievement-Orientation Model appears to hold promise for developing interventions that may reverse the pattern of gifted underachievement; however, the model itself has yet to be empirically validated. Taken separately, each of the model's four constructs (i.e., self-efficacy, environmental perceptions, task meaningfulness, and self-regulation) correlate with achievement (McCoach \& Siegle, 2003a); however, whether and how the constructs work together to influence achievement (i.e., their interaction effects) remains relatively unknown. It seems hasty to develop interventions based on a theoretical model that may not accurately capture the complex phenomenon of gifted underachievement. In light of these concerns, the primary purpose of the current study was to investigate the validity of the Achievement-Orientation Model for middle school students who have been identified as Academically or Intellectually Gifted (AIG) following the policies of their local district and state laws in this area.

Because self-efficacy, environmental perceptions, task meaningfulness, selfregulation, achievement, and engagement cannot be directly measured, they are considered latent variables. Subscale items from the School Attitude Assessment-Revised (SAAS-R) were used to measure task meaningfulness and self-efficacy. Subscale items from the Challenges to Scholastic Achievement Scale (CSAS) were used to measure environmental perceptions and self-regulation (see Appendices A and B). Subscale items from the Engagement vs. Disaffection with Learning Support-student report (EvsD)were 
used to measure engagement (see Appendix C). See Appendix D for the version of the instrument that was administered to students; subscales from the different instruments have been combined. Achievement was measured via student self-reported GPA (this is an item on the SAAS-R), based on students' current math class, and their current math teacher's report of GPA based on grades from the most recent progress report.

Research questions were as follows:

1. Using the Achievement-Orientation Model, what are the profiles of a gifted middle school student?

2. Using the Achievement-Orientation Model, what are the specific characteristics that identify an underachieving gifted middle school student?

3. Based on the Achievement-Orientation Model, is there a relationship between the motivation of gifted middle school students and selfregulation, engagement, and achievement?

Participants

Convenience sampling was used for this study. Participants consisted of 156 sixth and seventh grade students in Academically and/or Intellectually Gifted (AIG) mathematics classes in two school districts in North Carolina. Students in these classes were either AIG in mathematics, as predetermined by the district's criteria for gifted services, or placed in an AIG mathematics setting due to their potential to achieve at high levels in mathematics.

Research suggests the pattern of underachievement is strongest in sixth and seventh grades (e.g., Lupart \& Pyryt, 1996; Middleton, Kaplan, \& Midgley, 2004). 
Placement in eighth grade Algebra is in large part based on teacher recommendation. As a consequence, underachievers typically are not selected for this advanced math placement at the eighth grade level; therefore, eighth grade AIG math students were excluded from the current study. See Table 6 for participant demographic characteristics.

Table 6: Demographics of participants

\begin{tabular}{|c|c|c|}
\hline Characteristics & $N$ & $\%$ \\
\hline \multicolumn{3}{|l|}{ Gender } \\
\hline Male & 71 & 45.5 \\
\hline Female & 85 & 54.5 \\
\hline \multicolumn{3}{|l|}{ Ethnicity } \\
\hline Caucasian & 110 & 70.5 \\
\hline African American & 14 & 9.0 \\
\hline Latino/a & 12 & 7.7 \\
\hline Asian & 5 & 3.2 \\
\hline Other & 12 & 7.7 \\
\hline \multicolumn{3}{|l|}{ Grade } \\
\hline Six & 64 & 41.0 \\
\hline Seven & 92 & 59.0 \\
\hline \multicolumn{3}{|l|}{ Gifted Status } \\
\hline Math only & 30 & 19.2 \\
\hline Reading only & 8 & 5.1 \\
\hline Math and Reading & 90 & 57.7 \\
\hline Not identified & 23 & 14.7 \\
\hline \multirow[t]{2}{*}{ Age } & $\underline{M}$ & $\underline{\text { Range }}$ \\
\hline & $\overline{11.7}$ & $10-13$ \\
\hline
\end{tabular}

\section{Setting}

School systems in North Carolina were contacted for this study. Specifically, Kannapolis City Schools and Wake County Schools agreed to participate. Middle schools in the selected school systems were included in the study if they use homogeneous ability 
grouping of AIG students for mathematics. Further, the researcher monitored demographic characteristics of chosen middle schools and determined the representativeness of the sample. Although a representative sample of each school system was ideal, no participants who met the inclusion criteria were excluded.

North Carolina state legislation mandates that gifted students must be identified and served by public schools. How to identify and serve gifted students, however, is left to the discretion of each local education agency (LEA), as individual districts may have specific programming needs depending on their student population. LEAs must still abide by state legislation and use the AIG program standards in the development of their AIG programs. Each LEA creates a local AIG plan based on these standards. This plan outlines the LEA's policies and practices with regard to identifying and serving gifted students in their district.

Based on 2010 North Carolina Department of Public Instruction AIG Child Count data, 169,087 students were identified Academically/Intellectually gifted in the state of North Carolina, $12 \%$ of the total North Carolina student population. Of the identified gifted students, $51 \%$ were female and $49 \%$ were male. Further, $76 \%$ were White, $11 \%$ were Black, $4 \%$ were Hispanic, 5\% were Asian, $3 \%$ were multiracial, and less than $1 \%$ were Native American.

Measurement

Since task meaningfulness, environmental perceptions, self-efficacy, selfregulation, achievement, and engagement are latent variables, data that directly measure these constructs were collected. Subscale items from the School Attitude AssessmentRevised (SAAS-R) was used to measure task meaningfulness (TM) and self-efficacy 
(SE). Subscale items from the Challenges to Scholastic Achievement Scale (CSAS) was used to measure environmental perceptions (EP) and self-regulation (SR). The Engagement vs. Disaffection with Learning Support-student report (EvsD) was used to measure engagement. Achievement was measured via student self-reported GPA (this is an item on the SAAS-R) based on students' previous year's math class, together with their current math teacher's report of GPA based on grades from the first progress report.

SAAS-R (McCoach \& Siegle, 2003b). The SAAS-R measures five factors, identified as students' (a) Academic Self-Perceptions (i.e., self-efficacy), (b) Attitude Toward Teachers (i.e., environmental perceptions), (c) Attitudes Toward School (i.e., environmental perceptions), (d) Goal Valuation (i.e., task meaningfulness), and (e) Motivation/Self-Regulation. Table 7 breaks down each subscale of the SAAS-R and provides selected sample items from this instrument.

Table 7: SAAS-R subscales and sample items

\begin{tabular}{clc}
\hline Subscale & $\begin{array}{c}\text { Number of } \\
\text { Total Items }\end{array}$ & Sample Item \\
\hline Academic Self-Perceptions & 7 & I am smart in school. \\
Attitudes Toward Teachers & 7 & My teachers care about me. \\
\hline
\end{tabular}


Table 7 (Continued)

\begin{tabular}{|c|c|c|}
\hline Attitudes Toward School & 5 & This school is a good match for me. \\
\hline Goal Valuation & 6 & Doing well in school is one of my goals. \\
\hline Motivation/Self-Regulation & 10 & I am self-motivated to do my schoolwork. \\
\hline
\end{tabular}

Respondents rate agreement with each of the 35 SAAS-R items using a 7-point Likert-type scale ranging from 1 (strongly disagree) to 7 (strongly agree). The FleschKincaid formula used to calculate readability indicates that the SAAS-R directions and items are at a reading level of 5.1 (Suldo, Shaffer, \& Shaunessy, 2007) and therefore are appropriate for middle school students. The instrument takes approximately 15 minutes to administer.

Each subscale of the instrument has an internal consistency reliability coefficient of at least .80 (McCoach \& Siegle, 2003b). Further, scores on the SAAS-R demonstrate evidence of adequate content and criterion-related validity. Content validity was assessed through a panel of 18 experts. The panel provided two ratings for each item. First, items were categorized into their respective constructs. Next, experts rated confidence in their classification on a 5-point Likert-type scale. At least $80 \%$ agreement between the two ratings among the panel was needed for an item to be retained (McCoach, 2002).

Criterion-related validity was examined through two studies with high school students. First, McCoach and Siegle (2003a) investigated whether the SAAS-R distinguished a national sample of 178 high school gifted underachievers from gifted achievers. Findings indicated that the underachieving group reported more negative attitudes toward school on all SAAS-R scales except Academic Self-Perceptions. The Motivation/Self-Regulation and Goal Valuation factor scores were the strongest 
predictors of group membership. A second study examined whether the SAAS-R could distinguish 244 high achieving students from low-achieving students in one high school (McCoach \& Siegle, 2001). Results demonstrated high-achieving students reported more positive attitudes within each of the five constructs than low-achieving students did.

Construct validity of the SAAS-R was demonstrated in the form of significant correlations between SAAS-R scales and other indicators theoretically related to each scale. Further, construct validity was established between all SAAS-R scales and students' school satisfaction. Discriminant validity was supported by smaller and/or nonsignificant relations between perceptions of school climate and attitudes regarding the value of schooling and motivation to self-regulate academic behavior, as well as by nonsignificant associations between academic self-perceptions and students' behavior in and out of school (Suldo et al., 2007).

CSAS (McCoach, Picho, \& Baslanti, in press). The CSAS, also developed by McCoach, is based on the SAAS-R and measures negative manifestations of constructs related to underachievement. In other words, the items on the CSAS are indicative of negative attitudes or behaviors and therefore, represent underachievement as opposed to achievement (McCoach et al., in press).

The CSAS measures student attitudes toward five factors: (a) Unregulated Study Behavior, (b) Negative Environmental Perceptions, (d) Disdains the Value of School, (e) Negative Attitudes Toward Teachers and Classes, and (f) Negative Self-Concept. Table 8 breaks down each subscale of the CSAS and provides sample survey items. Given factors for SEM should be based on at least 3 items each, the CSAS is sufficient in this respect. Further, just like the SAAS-R, respondents rate agreement with each of the 42 items 
using a 7-point Likert-type scale ranging from 1 (strongly disagree) to 7 (strongly agree; McCoach et al., in press). The instrument takes approximately 15-20 minutes to administer.

Table 8: CSAS subscales and sample items

\begin{tabular}{lll}
\hline \multicolumn{1}{c}{ Subscale } & $\begin{array}{c}\text { Number of } \\
\text { Total Items }\end{array}$ & \multicolumn{1}{c}{ Sample Item } \\
\hline Unregulated Study Behavior & 10 & I have poor study habits. \\
$\begin{array}{l}\text { Negative Environmental } \\
\text { Perceptions }\end{array}$ & 13 & $\begin{array}{l}\text { I think that I would be a better student if I } \\
\text { could go to a different school. }\end{array}$ \\
$\begin{array}{l}\text { Disdains the Value of } \\
\text { School }\end{array}$ & 8 & Grades don't mean anything to me. \\
$\begin{array}{l}\text { Negative Attitudes Toward } \\
\text { Teachers }\end{array}$ & 5 & I have bad relationships with my teachers. \\
Negative Self-Concept & 6 & I can't seem to get good grades in school. \\
\hline
\end{tabular}

Content validity for this instrument was assessed through a panel of eight content experts. Experts were asked to evaluate their certainty that the item measured a particular construct on a 1-4 scale, where $1=$ completely unsure and $4=$ very sure. Additionally, the experts were asked to assess the relevance of the item to the construct, where 1=completely irrelevant and 3=highly relevant (McCoach et al., in press).

Several analyses were conducted to demonstrate construct validity. First, an exploratory factor analysis was performed. Next, Cronbach's alpha was computed as a measure of internal consistency reliability analysis. Finally, correlations among the subscales, the students' self-reported GPAs, and their self-reported homework time were computed and compared to the mean scores of high, average and low GPA students. With 
regard to reliability, the results of the EFA identified 5 factors with reliability estimates for the 5 subscales ranging from .86 to.91 (McCoach et al., in press).

EvsD. The EvsD (Skinner, Kindermann, \& Furrer, 2009) contains 24 items in four different subscales. Behavioral engagement (5 items) is defined as putting effort forth in initiating and participating in learning. Behavioral disaffection (5 items) is the opposite, a lack of effort and withdrawal from learning activities. Emotional engagement (5 items) is indicative of students' desire to be involved in learning activities. Emotional disaffection (9 items), conversely, captures students' feelings of disengagement during learning activities.

Skinner, Kindermann, and Furrer (2009) found internal reliability coefficients ranging from .61 to .85 based on a sample of students in grades three through six. Combining behavioral and emotional engagement items produced higher levels of internal consistency, .79 and .86. Interindividual stability was reported to be high (Fredericks et al., 2011). In light of these findings, only the emotional and behavioral engagement scales of the EvsD will be used.

Respondents rate agreement with each of the 24 EvsD items using a 4-point Likert-type scale ranging from 1 (not at all true) to 4 (very true). The instrument takes about 20-30 minutes to complete (Fredericks et al., 2011). Table 9 breaks down each subscale of the EvsD and provides sample survey items. 
Table 9: EvsD subscales and sample items

\begin{tabular}{lll}
\hline \multicolumn{1}{c}{ Subscale } & $\begin{array}{c}\text { Number of } \\
\text { Total Items }\end{array}$ & \multicolumn{1}{c}{ Sample Item } \\
\hline Behavioral Engagement & 5 & When I'm in class, I listen very carefully. \\
Behavioral Disaffection & 5 & $\begin{array}{l}\text { When I'm in class, I just act like I'm } \\
\text { working. }\end{array}$ \\
Emotional Engagement & 5 & $\begin{array}{l}\text { I enjoy learning new things in class. } \\
\text { When we work on something in class, I feel } \\
\text { Emotional Disaffection }\end{array}$ \\
& 9 & \\
\hline
\end{tabular}

Construct validity was evidenced through results of confirmatory factor analyses (CFA). CFA results found a four-factor model distinguished adequately between the four constructs (i.e., behavioral engagement, behavioral disaffection, emotional engagement, and emotional disaffection). Subscales correlated as anticipated; behavioral and emotional subscales correlated positively, and engagement and disaffection subscales correlated negatively. Age-grade patterns were also found for elementary and middle school students (Skinner et al., 2009). Middle school students demonstrated lower levels of engagement than students in the upper grades of elementary school (Fredericks et al., 2011; Skinner, Marchand, Furrer, \& Kindermann, 2008).

Implementation

Student and School Recruitment. School systems in North Carolina were contacted for this study (i.e., Kannapolis City Schools and Wake County Schools). Research procedures for approval were completed for districts once approval was received from the University of North Carolina at Charlotte's Institutional Review Board. 
The Academically/Intellectually Gifted (AIG) Directors of the systems were contacted directly via phone to determine which middle schools in the district met the inclusion criteria for the study (see Appendix E for sample script). Middle schools had to use homogeneous ability grouping of AIG students for mathematics. Further, the researcher monitored demographic characteristics of middle schools and determined the representativeness of the sample.

Once contact was made with the districts' AIG Directors, principals at individual schools were contacted via email (See Appendix F for sample email).

All AIG mathematics students in $6^{\text {th }}$ and $7^{\text {th }}$ grade whose parents signed informed consent were administered the survey. Informed consent letters were sent home in the students' AIG mathematics class. The students' AIG mathematics teacher was responsible for passing out and collecting informed consent letters (see Appendix G for sample teacher script). iTunes gift cards were raffled off to students (one per class) once the surveys were completed.

Survey Administration Procedures. The classroom AIG mathematics teacher administered the survey to her students at a time convenient for him/her so as not to interfere with instructional time. The AIG teacher was visited by the researcher and supplied all of the necessary forms. All forms were paper. The researcher went over the survey script and forms with the teacher (See Appendices H and I for survey script and demographic information form). The researcher returned to collect all forms. Teachers needed to follow these steps:

- Be sure there is adequate space between students to protect student privacy

- Distribute survey forms (Demographic information, survey) to students 
- Teachers were reminded to ensure students have written their student ID\# in the appropriate place on the demographic information form and student survey form. They were asked to please have a list of student ID\#s readily available in case students did not know their ID\#.

- Parents may have chosen to have their child not take the survey. If so, students worked on another quiet activity.

- Teachers were asked to read all of the script (see Appendix H) to students as it contained information that had to be presented to students. The script needed to be read before the survey started.

- Teachers were asked to pass out and collect assent forms at the appropriate time.

- Teachers/survey administrators were reminded to refrain from wandering around the room during the survey administration to help assure student anonymity.

- Teachers were asked not to rush students as not to affect the quality of the survey results. Although the survey is estimated to take 30 minutes to complete, they were asked to allow up to $10-15$ extra minutes if needed.

Collection of GPA. Teachers needed to provide two critical pieces of information for students taking the survey in their AIG mathematics classes: Grade Point Average (GPA) and number of grades GPA is based on. GPA was based on students' first progress report grade in the current AIG mathematics teacher's class. GPA was supplied as a percentage out of 100 possible points. In addition to GPA, teachers were asked to provide the number of grades the current GPA was based on; this was to ensure the GPA was representative of students' actual performance in the class. In the case the number of grades was less than 10, the researcher would ask the teacher to provide a GPA based on 
the first report card; this step did not need to be taken. The latter would also occur if the first progress reporting period's grades were based on academic review from the previous year's mathematics class; again, this was not necessary as the material was not review. The researcher discussed this with the teacher when she visited his/her classes and made a determination at that point in time. The teacher was also asked to create his/her own spreadsheet for the information requested. This was a handwritten or a printed copy that the researcher picked up at the end the study.

Finally, student ID\#s were used to match students. All forms asked students to supply their ID\#. The teacher ensured students provided the correct student ID\#. Teachers also provided the required information (i.e., GPA, number of grades GPA is determined by) based on student ID\#.

Identification of Gifted Underachievers. Discrepancy between potential and performance (Reis \& McCoach, 2000) was used to classify students as underachievers. Potential was determined by gifted status or placement in an advanced level mathematics class, while performance was determined by the overall grade received in the current mathematics class. To determine if a discrepancy existed, a cut-off point of a " $\mathrm{C}$ " average or lower was chosen to identify gifted underachievers. Although a "C" average may not seem severely discrepant, for highly gifted students, grades that might seem acceptable for the typical student population, are often considered low for students with exceptionally high IQ scores (Matthews \& McBee, 2007).

\section{Data Analysis}

Research Question 1: Using the Achievement-Orientation Model, what are the profiles of a gifted middle school student? 


\section{Hierarchical Cluster Analysis}

To answer research question 1, data was analyzed using a hierarchical cluster analysis. Cluster analysis is a multivariate technique that is most traditionally as an exploratory technique to classify objects based on common properties (Hair, Anderson, Tatham, \& Black, 1998). Resulting clusters in turn have high internal homogeneity and high external heterogeneity (Dixon, Lapsley \& Hanchon, 2004). Clusters can be formed using two different methods, hierarchical and nonhierarchical. Hierarchical cluster grouping was used for this study as it is desirable when only small numbers of observations are available. Hierarchical clustering procedures entail the construction of a hierarchy of a treelike structure. Using agglomerative methods commonly referred to as buildup methods, each item is treated as its own cluster and then the two closest clusters (using a preselected measure of distance) are combined into one cluster. This process is continued until all items are grouped into one large cluster. Although there are five types of agglomerative algorithms used to develop clusters, this study used average linkage, which takes average distance from all individuals in one cluster to all individuals in another cluster. For interval scale data, the preselected measure of distance can be one of two choices, Euclidean distance or squared Euclidean distance. The latter was used for this study (Hair et al., 1998).

It is recommended that several procedures be used when choosing the final cluster solution because there are no absolute criteria for evaluating cluster solutions. First, using SPSS software, the proximity coefficients obtained from the agglomeration schedule were examined for increases in value. Since larger coefficients suggest more distance between clusters, identifying the point of high proximity coefficients in turn suggests the 
optimal number of clusters have been formed. Next, the dendrogram was visually inspected in order to identify the optimal number of cluster solutions (Hair et al., 1998). A series of independent $t$-tests with a Bonferroni adjustment were used to determine the profiles of the clusters.

Research Question 2: Using the Achievement-Orientation Model, what are the specific characteristics that identify an underachieving gifted middle school student?

\section{Independent Samples T-Test}

To answer research question 2 , data were analyzed using a series of independent $t$-tests. A Bonferroni adjustment was made to accommodate the use of multiple tests. The $t$-test is a parametric test used to determine if the mean scores of two groups are significantly different given a specified probability level. $T$-tests compare the actual difference between group means with the difference that would be expected by chance. This study used a series of independent samples $t$-tests to determine if a significant difference existed between the means of two independent samples, gifted achievers and gifted underachievers for the different constructs in the model. Three assumptions must be met prior to running the independent samples $t$-test: (a) the two groups must consist of random, independent samples, (b) the samples must be normally distributed, and (c) the assumption of homogeneity of variance must not be violated, although SPSS corrects for this violation (Gay, Mills, \& Airasian, 2009).

\section{Mann-Whitney U}

To answer research question 2, a Mann-Whitney $U$ was also run to confirm the results of the independent samples $t$-test since the data were not normally distributed. Similar to the independent samples $t$-test, the Mann-Whitney U Test is used to compare 
differences between two independent groups when the dependent variable is interval but not normally distributed. It is the nonparametric alternative to the independent samples $t$ test. The Mann-Whitney U Test also assumes independent samples and requires the dependent variable to be either ordinal, interval, or ratio. Samples, however, do not need to be normally distributed (Gay, Mills, \& Airasian, 2009).

Research Question 3: Based on the Achievement-Orientation Model, is there a relationship between the motivation of gifted middle school students and self-regulation, engagement, and achievement?

Path Analysis

To answer research question 3, data were analyzed using path analysis. Path analysis test hypotheses regarding direct and indirect causal effects between exogenous and endogenous variables. For this model, task meaningfulness, self-efficacy, and environmental perceptions were exogenous variables as they were not caused by anything in the model. Achievement and engagement were endogenous variables as they were directly influenced by other variables in the model. Self-regulation acted as both an endogenous and exogenous variable (see Figure 4 for path diagram). SPSS 19 was used to conduct the path analysis using a series of multiple regression analyses. The effect of the mediator was tested using a series of Sobel tests. 


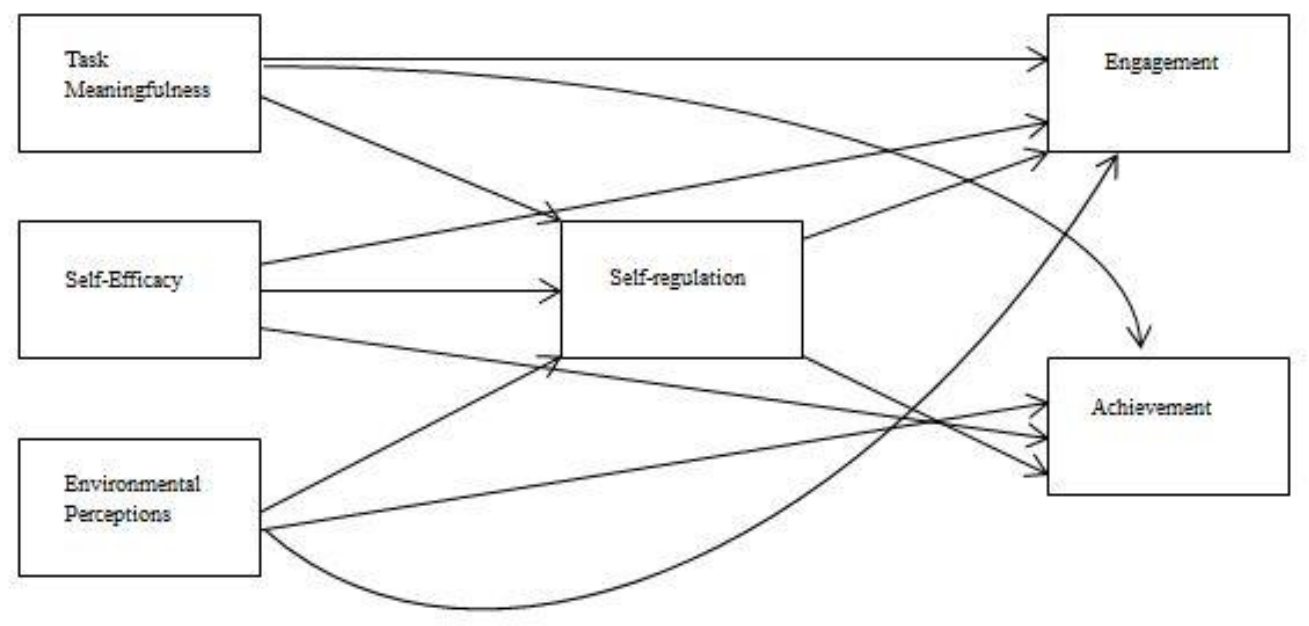

Figure 4. Path analysis diagram 


\section{CHAPTER 4: RESULTS}

This chapter describes the results of the data analyses used to examine the research questions. SPSS 19 was used for all analyses. The following statistical procedures were used in this study: First, response rate, data entry accuracy, and scoring procedures are discussed. Second, descriptive statistics of all of the variables are presented. Third, results of data screening procedures and examination of assumptions are discussed. Fourth and finally, each research question is addressed.

\section{Sample}

A convenience sample of sixth and seventh grade AIG math students at middle schools in two school districts in a southeastern state was used for this study. AIG directors at both school districts were contacted at the beginning of the study and each agreed to participate. The AIG directors contacted schools within their respective districts to gauge interest in the study. Two middle schools in school district 1 agreed to participate (the total number of middle schools in that district) and one middle school in school district 2 agreed to participate in the study.

Response Rate. Approximately 288 surveys were distributed to students across both school districts. Students' parents agreed to their child's participation in the study via informed consent. A total of 156 students participated in the study for an overall response rate of $60 \%$. 
Data Entry. The researcher entered data for all 156 surveys in SPSS. Ten percent of the surveys entered (i.e., 15 surveys) were checked for data entry reliability by an external rater. There was $100 \%$ agreement between the initial data entry and the external rater.

\section{Variables}

Given that all items on a survey can only be analyzed if they are worded either all positively or all negatively (i.e., one direction), it was necessary to reverse code all items from the CSAS, which features negatively worded items. This is accomplished in SPSS by recoding negatively worded items for each subscale into the same or different variables. All items in the environmental perceptions and self-regulation subscales from the CSAS were reverse coded. Mean values for all subscale items were used to calculate the total score. For all of the subscales of the SAAS-R and CSAS, a 1 is the minimum score and a 7 is the maximum score. For the EvsD, the measure of engagement, a 1 is the minimum score and a 4 is the maximum score.

Means, standard deviations, skewness, kurtosis, and reliability coefficients prior to data screening are reported in Table 10. Task meaningfulness had the highest mean value $(M=6.77)$, a common critique of the task meaningfulness subscales of both the SAAS-R and CSAS. Self-regulation had both the lowest mean value $(M=5.49)$ and most variability ( $S D=1.27$ ) of all the subscales. Underachievers' mean GPA was 84.44, which is considered a ' $\mathrm{C}$ ' average in both the school districts sampled in this study. Potentially problematic skewness and kurtosis were noted for task meaningfulness, environmental perceptions, and student-reported GPA. Cronbach's alpha reliability coefficients ranged from .83 to .93 , indicating an acceptable internal consistency in the measures. 
Table 10: Means, standard deviations, skewness, kurtosis, and reliability coefficients of variables

\begin{tabular}{lccccc}
\hline Variable & Mean & SD & Skewness & Kurtosis & $\begin{array}{l}\text { Cronbach's } \\
\text { Alpha }\end{array}$ \\
\hline Self-Efficacy & 5.94 & .67 & -.93 & 1.04 & .85 \\
Task Meaningfulness & 6.77 & .42 & -2.45 & 6.54 & .89 \\
$\begin{array}{l}\text { Environmental } \\
\text { Perceptions }\end{array}$ & 6.25 & .74 & -1.35 & 1.73 & .93 \\
Self-Regulation & 5.49 & 1.27 & -.96 & .16 & .91 \\
Engagement & 3.45 & .37 & -.74 & .39 & .83 \\
Teacher-Reported GPA & 93.37 & 5.11 & -1.09 & 1.04 & \\
Student-Reported GPA & 91.43 & 5.07 & -2.35 & 9.19 & \\
Underachiever & 84.44 & 3.79 & -.63 & .70 & \\
Achiever & 95.55 & 3.16 & -.32 & -.64 & \\
\hline
\end{tabular}

\section{Data Analyses}

Prior to conducting the necessary analyses to answer the research questions, data were screened for multivariate normality and the presence of univariate and multivariate outliers. Variables are considered reasonably close to normal if their skewness and kurtosis have values between -1.0 and +1 .0. Problematic skewness and kurtosis were found for task meaningfulness and environmental perceptions. A logarithmic transformation was performed to improve normality of these variables; however, the transformation was unable to improve normality. Upon inspection of box plots, it was determined that two of the variables, task meaningfulness and environmental perceptions, 
possessed numerous univariate outliers, but the outliers were retained in the analyses. Although Mahalanobis distance was less than a significance level of .001 for six of the cases, upon inspection of the data, it was decided to retain these multivariate outliers as analyses would not be adversely affected.

Homogeneity of the variance-covariance matrices was assessed using Box's $M$ test. A nonsignificant Box's $M$ test guarantees robustness. Box's M was found to be statistically significant, indicating potential problems with the analysis. Linear relations among all pairs of dependent variables were inspected via scatterplots. Based on this inspection, linear relations could not be assumed between all pairs of variables. Multicollinearity diagnostics revealed tolerance levels close to 1, suggesting absence of multicollinearity.

Research Questions

Research Question 1: Using the Achievement-Orientation Model, what are the profiles of a gifted middle school student?

Hierarchical cluster grouping in SPSS was used to answer this research question. The average linkage method was chosen for linking the clusters and squared Euclidian distance was used as the distance measure. Survey items representing each of the four constructs (i.e., task meaningfulness, self-efficacy, environmental perceptions, and selfregulation) were the data used to form the clusters. Results of the cluster analysis and an examination of the incremental increase in proximity coefficients suggested that a three cluster solution was most reasonable. Inspection of the dendrogram confirmed a three cluster solution; however, upon inspection of descriptive statistics (See Table 11), it appeared that one of the clusters, cluster 2, only had 3 participants. The three cluster 
solution should be interpreted with caution because of the instability of the descriptive statistics for the cluster with only three students. Therefore, a two cluster solution was also examined. Sample sizes, means and standard deviations for the four constructs based on the two cluster solution are presented in Table 12.

Table 11: Sample sizes, means and standard deviations for the four constructs based on the three cluster solution

\begin{tabular}{lllll}
\hline & Clusters & $N$ & Mean & SD \\
& & & & \\
\hline \multirow{2}{*}{ Self-Efficacy } & 1 & 27 & 5.34 & .64 \\
& 2 & 3 & 3.95 & .21 \\
& 3 & 126 & 6.12 & .50 \\
Task Meaningfulness & 1 & & & \\
& 2 & 27 & 6.58 & .51 \\
& 3 & 3 & 5.05 & .25 \\
Environmental & 1 & 126 & 6.85 & .27 \\
Perceptions & 2 & 27 & 5.21 & .87 \\
& 3 & 3 & 5.79 & .86 \\
Self-Regulation & 1 & 126 & 6.48 & .47 \\
& 2 & & & \\
& 3 & 27 & 3.42 & .97 \\
& & 126 & 5.95 & .80 \\
\hline
\end{tabular}


Table 12: Sample sizes, means and standard deviations for the four constructs based on the two cluster solution

\begin{tabular}{lllll}
\hline & Clusters & $N$ & Mean & $S D$ \\
\hline Self-Efficacy & 1 & 30 & 5.20 & .74 \\
& 2 & 126 & 6.13 & .50 \\
Task Meaningfulness & 1 & & & \\
& 2 & 30 & 6.43 & .68 \\
& & 126 & 6.85 & .27 \\
Environmental & 1 & & & \\
Perceptions & 2 & 30 & 5.27 & .87 \\
& & 126 & 6.49 & .47 \\
Self-Regulation & 1 & & & \\
& 2 & 30 & 3.58 & 1.07 \\
& & 126 & 5.95 & .80 \\
\hline
\end{tabular}

A series of independent $t$-tests with a Bonferroni adjustment were run to determine the profiles of the two clusters. The Bonferroni adjustment helps prevent against Type I error when a series of univariate tests are run. The Bonferroni adjustment was calculated by dividing the selected alpha level, in this case .05 , by the number of tests (i.e., 4). The new alpha level that each test had to meet in order to qualify as statistically significant was .013. If the test for homogeneity of variance was significant, the adjusted $t$-test was used to reduce potential bias. Statistically significant differences were found when comparing the two clusters' attitudes on all of the variables. See Table 13 for results from the independent samples $t$-test. Cluster 1 is characterized by less positive attitudes toward their self-efficacy, the meaningfulness of tasks, their school environment, and their self-regulation skills. Interestingly, this group is comprised of $40 \%$ underachieving gifted students. Cluster 2 , on the other hand, has higher means for 
all variables and is comprised of predominately achieving gifted students, $90 \%$ achieving versus only $10 \%$ underachieving students. A crosstabs was calculated to examine whether the two clusters differed with respect to the percentage of underachievers and achievers. $\chi^{2}(1)=15.86, p<.001$, indicating Cluster 1 contained significantly more underachievers than Cluster 2, and Cluster 2 contained significantly more achievers than Cluster 1.

Table 13: Independent samples $t$-test results for the two cluster solution

\begin{tabular}{lcccc}
\hline & $d f$ & $t$ & p-value & $d$ \\
\hline Self-Efficacy* & 35.64 & -6.4 & $<.001$ & -2.14 \\
Task Meaningfulness* & 31.36 & -3.31 & .002 & -1.18 \\
Environmental Perceptions* & & & & \\
& 33.12 & -7.38 & $<.001$ & -2.56 \\
Self-Regulation & & & & -2.19 \\
\hline
\end{tabular}

*Equal variances not assumed

Research Question 2: Using the Achievement-Orientation Model, what are the specific characteristics that identify an underachieving gifted middle school student?

Given the violation of several multivariate assumptions and unbalanced sample size in each group, the decision was made to run a series of independent $t$-tests with a Bonferroni adjustment as opposed to a multivariate analysis of variance. The independent samples $t$-tests were conducted to compare underachievers' and achievers' attitudes toward task meaningfulness, self-efficacy, environmental perceptions, and selfregulation. The Bonferroni adjustment helps prevent against Type I error when a series of 
univariate tests are run. The Bonferroni adjustment was calculated by dividing the selected alpha level, in this case .05 , by the number of tests (i.e., 4). The new alpha level that each test had to meet in order to qualify as statistically significant was .014.

Statistically significant differences were found when comparing underachievers' and achievers' self-efficacy, $t(154)=-3.850, p<.001, d=.62$ and self-regulation, $t(154)=$ $-3.113, p=.002, d=.50$. Statistically significant differences between underachievers and achievers were not found for environmental perceptions, $t(154)=-2.031, p=.044, d=.33$, and task meaningfulness, $t(27)=-1.480, p=.170, d=.57$. Underachievers had lower mean scores on all of the variables. Effects sizes were medium for self-efficacy and selfregulation. Means and standard deviations are reported in Table 14.

Table 14: Means and standard deviations for underachievers and achievers

\begin{tabular}{lllll}
\hline & Underachiever & $N$ & $M$ & $S D$ \\
\hline \multirow{2}{*}{ Self-Efficacy } & Yes & 25 & 5.49 & .76 \\
& No & 131 & 6.03 & .61 \\
Task Meaningfulness & Yes & 25 & 6.62 & .62 \\
& No & 131 & 6.80 & .36 \\
Environmental Perceptions & Yes & 25 & 5.98 & .77 \\
& No & 131 & 6.30 & .73 \\
Self-Regulation & Yes & 25 & 4.78 & 1.47 \\
& No & 131 & 5.62 & 1.18 \\
\hline
\end{tabular}

Given the violation of the assumption of normality, a nonparametric test, the Mann-Whitney U with a Bonferonni adjustment, was run to confirm the results of the Independent Samples T-Tests. Similar to the results of the Independent Samples $t$-tests, 
statistically significant differences were found for self-efficacy $(p=.001)$ and selfregulation $(p=.008)$. Statistically significant differences were not found for environmental perceptions $(p=.034)$ and task meaningfulness $(p=.166)$.

Research Question 3: Based on the Achievement-Orientation Model, is there a relationship between the motivation of gifted middle school students and self-regulation, engagement, and achievement?

A path analysis using three multiple regressions was conducted to examine this research question. In the first multiple regression (a) task meaningfulness, (b) environmental perceptions, and (c) self-efficacy were used to predict self-regulation. In the second multiple regression (a) task meaningfulness, (b) environmental perceptions, (c) self-efficacy, and (d) self-regulation were used to predict achievement. In the third and final multiple regression (a) task meaningfulness, (b) environmental perceptions, (c) self-efficacy, and (d) self-regulation were used to predict engagement. Analysis was performed using SPSS Linear Regression.

The variance accounted for in the first multiple regression was $\left(R^{2}\right)$ equals .44 (adjusted $\left.R^{2}=.43\right)$, which was significantly different from zero $(F=40.5, p \leq .001)$. Two of the three independent variables contributed significantly to the prediction of selfregulation; these variables were self-efficacy and environmental perceptions. Environmental perceptions had the largest positive standardized beta and semipartial correlation coefficient. Self-efficacy had a similar positive standardized beta and semipartial correlation coefficient. While task meaningfulness was hypothesized to be positively related to self-regulation, it was not statistically significant. The 
unstandardized regression coefficients $(B)$ and intercept, the standardized regression coefficients $(\beta)$, and semipartial correlations $\left(s r_{\mathrm{i}}\right)$ are reported in Table 15.

Table 15: Unstandardized regression coefficients (B), intercept, standardized regression coefficients $(\beta)$, semipartial correlations $\left(\mathrm{sr}_{\mathrm{i}}\right), t$-values, and $p$-values

\begin{tabular}{llllll}
\hline IVs & $B$ & $\beta$ & $s r_{\mathrm{i}}$ & $t$-value & $p$-value \\
\hline Intercept & -4.35 & & & -3.35 & $p=001$ \\
Task Meaningfulness & .27 & .089 & .107 & 1.32 & $p=.186$ \\
Self-Efficacy & .428 & .225 & .251 & 3.19 & $p=.002$ \\
Environmental Perceptions & .875 & .512 & .537 & 7.85 & $p=.000$ \\
\hline
\end{tabular}

The variance accounted for in the second multiple regression was $\left(R^{2}\right)$ equals .44 (adjusted $\left.R^{2}=.43\right)$, which was significantly different from zero $(F=40.5, p \leq .001)$. Two of the four independent variables contributed significantly to the prediction of achievement; these variables were self-efficacy and self-regulation. Self-efficacy and self-regulation both had the largest positive standardized betas and semipartial correlation coefficients. While environmental perceptions and task meaningfulness were hypothesized to be positively related to achievement, these variables were not statistically significant. The unstandardized regression coefficients $(B)$ and intercept, the standardized regression coefficients $(\beta)$, and semipartial correlations $\left(s r_{\mathrm{i}}\right)$ are reported in Table 16. 
Table 16: Unstandardized regression coefficients (B), intercept, standardized regression coefficients $(\beta)$, semipartial correlations $\left(\mathrm{sr}_{\mathrm{i}}\right), t$-values, and $p$-values

\begin{tabular}{llllll}
\hline IVs & $B$ & $\beta$ & $s r_{\mathrm{i}}$ & $t$-value & $p$-value \\
\hline Intercept & 87.61 & & & 12.92 & $p=.000$ \\
Task Meaningfulness & -1.24 & -.103 & -.098 & -1.20 & $p=.230$ \\
Self-Efficacy & 1.89 & .249 & .216 & 2.71 & $p=.007$ \\
Environmental Perceptions & -.340 & -.050 & -.041 & -.510 & $p=.611$ \\
Self-Regulation & .905 & .226 & .177 & 2.21 & $p=.029$ \\
\hline
\end{tabular}

The variance accounted for in the third multiple regression was $\left(R^{2}\right)$ equals .46 (adjusted $\left.R^{2}=.44\right)$, which was significantly different from zero $(F=31.65, p<.001)$. All of the four predictors contributed significantly to the prediction of engagement; these variables were self-efficacy, task meaningfulness, environmental perceptions, and selfregulation. The unstandardized regression coefficients $(B)$ and intercept, the standardized regression coefficients $(\beta)$, and semipartial correlations $\left(s r_{\mathrm{i}}\right)$ are reported in Table 17 . See Figure 5 for path diagram with standardized regression coefficients and $p$-values.

Table 17: Unstandardized regression coefficients (B), intercept, standardized regression coefficients $(\beta)$, semipartial correlations $\left(\mathrm{sr}_{\mathrm{i}}\right), t$-values, and $p$-values

\begin{tabular}{llllll}
\hline IVs & $B$ & $\beta$ & $s r_{\mathrm{i}}$ & $t$-value & $p$-value \\
\hline Intercept & .366 & & & .950 & $p=.344$ \\
Task Meaningfulness & .210 & .241 & .281 & 3.59 & $p=.000$ \\
Self-Efficacy & .083 & .151 & .168 & 2.09 & $p=.038$ \\
Environmental Perceptions & .116 & .235 & .242 & 3.06 & $p=.003$ \\
Self-Regulation & .081 & .279 & .271 & 3.46 & $p=.001$ \\
\hline
\end{tabular}




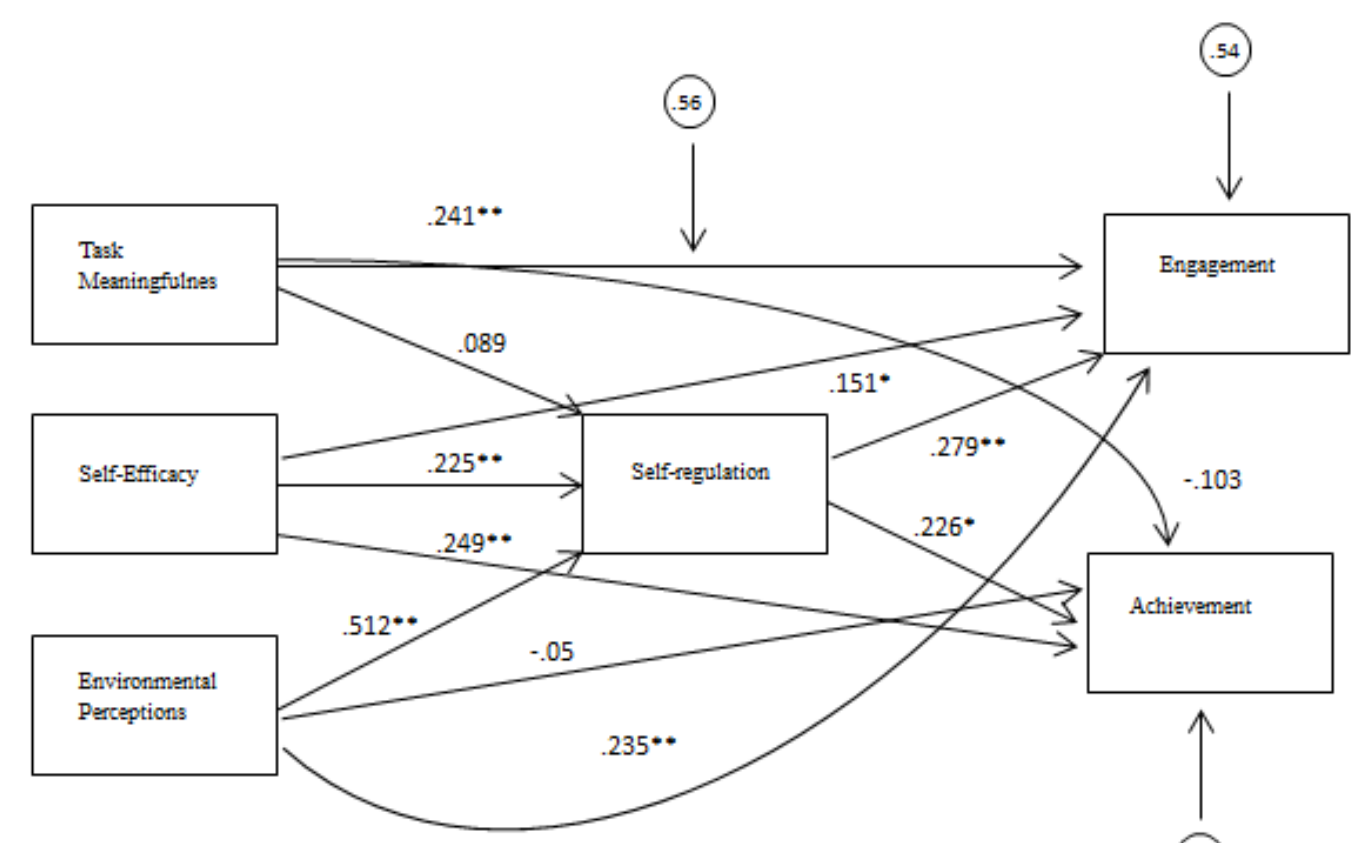

(.56)

Figure 5. Path model with standardized regression coefficients, unexplained variance, and $p$-values.

$*=p<.05, * *=p<.01$.

Sobel tests were run to examine the hypothesis that self-regulation mediates the relationship between the independent variables (i.e., task meaningfulness, environmental perceptions, and self-efficacy) and the dependent variables (i.e., achievement and engagement) in the Achievement-Orientation Model. An online statistics calculator was used to compute the Sobel tests using regression coefficients and standard error for regression coefficients. For example, to test whether self-regulation mediated the relationship between task meaningfulness and engagement, the regression coefficient and standard error for task meaningfulness as a predictor of self-regulation and for selfregulation as a predictor of engagement were entered into the formula. Results indicated 
that self-regulation mediated all of the relationships between the independent variables and dependent variables except for task meaningfulness. Results of the Sobel tests are presented in Table 18.

Table 18: Sobel tests

\begin{tabular}{llc}
\hline Relationship & $\begin{array}{l}\text { Sobel } \\
\text { Statistic }\end{array}$ & p-level \\
\hline Task Meaningfulness $\rightarrow$ Self-Regulation $\rightarrow$ Engagement & 1.28 & $p=.100$ \\
Task Meaningfulness $\rightarrow$ Self-Regulation $\rightarrow$ Achievement & 1.15 & $p=.124$ \\
Self-Efficacy $\rightarrow$ Self-Regulation $\rightarrow$ Engagement & 2.55 & $p=.005$ \\
Self-Efficacy $\rightarrow$ Self-Regulation $\rightarrow$ Achievement & 1.84 & $p=.033$ \\
Environmental Perceptions $\rightarrow$ Self-Regulation $\rightarrow$ Engagement & 3.58 & $p<.001$ \\
Environmental Perceptions $\rightarrow$ Self-Regulation $\rightarrow$ Achievement & 2.14 & $p=.032$ \\
\hline
\end{tabular}

\section{Summary}

With regard to the first research question, a two cluster solution was suggested.

Cluster 1 was characterized by less positive attitudes toward their self-efficacy, the meaningfulness of tasks, their school environment, and their self-regulation skills. Interestingly, this group was comprised of $40 \%$ underachieving gifted students. Cluster 2, on the other hand, had more positive attitudes toward all of the variables and was comprised of predominately achieving gifted students, $90 \%$ achieving versus only $10 \%$ underachieving students. Crosstabs analysis indicated Cluster 1 had significantly more underachieving gifted students than Cluster 2, and Cluster 2 had significantly more achieving gifted students than Cluster 1 . 
For the second research question, statistically significant differences were found for self-efficacy and self-regulation, suggesting gifted underachievers have poorer selfefficacy and self-regulation skills than gifted achievers. Statistically significant differences were not found for environmental perceptions and task meaningfulness.

Finally, for the third research question, in the first regression analysis two of the three independent variables contributed significantly to the prediction of self-regulation; these variables were self-efficacy and environmental perceptions. In the second regression analysis, only two of the four independent variables contributed significantly to the prediction of achievement; these variables were self-efficacy and self-regulation. In the third and final regression analysis, all of the independent variables contributed significantly to the prediction of engagement. With the regard to self-regulation as a mediator, Sobel tests indicated self-regulation mediated all of the relationships between the independent variables and dependent variables except for task meaningfulness. 


\section{CHAPTER 5: DISCUSSION}

The primary purpose of this research study was to investigate the validity of the Achievement-Orientation Model for a population of middle school students who have been identified as Academically or Intellectually Gifted (AIG) following the policies of their local district and North Carolina's state laws in this area. The following research questions guided this investigation:

1. Using the Achievement-Orientation Model, what are the profiles of a gifted middle school student?

2. Using the Achievement-Orientation Model, what are the specific characteristics that identify an underachieving gifted middle school student?

3. Based on the Achievement-Orientation Model, is there a relationship between the motivation of gifted middle school students and selfregulation, engagement, and achievement?

Siegle and McCoach (2005) developed the Achievement-Orientation Model in order to explain why gifted students achieve and underachieve in school. According to their Achievement-Orientation Model, gifted achievers have the prerequisite abilities needed to achieve at high levels in school, value the goals of school, and find academic tasks meaningful (i.e., goal valuation); feel the school environment is supportive (i.e., environmental perceptions); and perceive they have the ability to perform academic tasks 
well (i.e., self-efficacy). These three factors, goal valuation, environmental perceptions, and self-efficacy, comprise motivation. If students' self-perceptions are positive on all three factors, according to the theory, they will self-regulate, and as a consequence they will engage and achieve at levels commensurate with their ability. However, Siegle and McCoach suggest that if students' attitudes are low on any one of these three factors, their motivation will be adversely affected, resulting in poor self-regulation, disengagement, and likely academic underachievement.

Prior to the development of the Achievement-Orientation Model, intervention studies aimed at reversing gifted underachievement either focused on counseling interventions (e.g., Broedel et al., 1965) or on costly instructional interventions (Whitmore, 1986; Supplee, 1990). The Achievement-Orientation Model holds promise for the development of interventions that can potentially reverse underachievement. If educators, for example, know which factor(s) an underachieving student has poor attitudes toward, they can systematically target the underlying cause(s) of the students' underachievement and potentially help the student to become an achiever in school. Interventions have been developed based on the Achievement-Orientation Model (Rubenstein, 2011; Siegle, Reis, McCoach, and Burton, 2012); however these interventions have met with limited success.

The Achievement-Orientation Model, although grounded in research, has never been empirically validated. This current study investigated the validity of the Achievement-Orientation Model for gifted middle school students. Sixth and seventh grade students were selected for participation in this study because middle school is believed to be a critical time for the onset of gifted underachievement (Peterson \& 
Colangelo, 1996). Although results of this study lend support to the validity of the Achievement-Orientation Model for middle school students, whether or not interventions should be developed to treat underachievement based on the constructs in the model is still questionable. More research is needed to determine the validity of the AchievementOrientation Model. A discussion of the results of this study follows.

Findings

Research Question 1: Using the Achievement-Orientation Model, what are the profiles of a gifted middle school student?

In the current study, the profiles of underachieving and achieving students appeared to be different with respect to the Achievement-Orientation Model constructs. Underachieving gifted students in sixth and seventh grade tended to have more negative attitudes toward all of the constructs in the Achievement-Orientation Model and achieving gifted students tended to have more positive attitudes toward all of the constructs; however, the small overall sample size precludes generalization. Of particular interest is that $60 \%$ of the students who clustered in the "negative attitudes" group were gifted achievers, suggesting gifted achievers in sixth and seventh grade may still be able to persevere academically despite lacking motivation and self-regulation skills. This finding suggests gifted achievers may not possess positive attitudes toward all of the constructs present in the model (McCoach \& Siegle, 2005). In contrast, cluster 2, the "positive attitudes" group, and the cluster with the largest membership, was comprised of 90\% gifted achievers, lending support to McCoach and Siegle's (2005) contention that gifted achievers tend to be both motivated and able to self-regulate. Further, cluster 1, the "negative attitudes" group consisted of significantly more underachievers than cluster 2, 
again lending support to the theory that gifted underachievers tend to possess more negative attitudes toward the constructs in the model.

Research Question 2: Using the Achievement-Orientation Model, what are the specific characteristics that identify an underachieving gifted middle school student?

Previous research has found that gifted underachievers and achievers differ with regard to factors that comprise the Achievement-Orientation Model (McCoach \& Siegle, 2001; McCoach \& Siegle, 2003a). For example, McCoach and Siegle (2003a) found gifted achievers and underachievers differed considerably in their goal valuation (i.e., task meaningfulness) mean scores. Results from the current study, however, found no statistically significant difference between the mean scores of gifted underachievers and achievers with regard to the task meaningfulness construct. This finding is troubling given the theoretical expectation that task meaningfulness is the precursor to motivation for gifted underachievers (McCoach \& Siegle, 2003a). However, as noted by the creators of the CSAS, the mean score for the goal valuation subscale is extremely high (McCoach et al., in press). It may be the case that the subscale is not sensitive enough to detect students who underachieve due to poor attitudes toward the meaningfulness of tasks and the value of goals.

Also, in contrast to the findings of McCoach and Siegle (2003a), mean scores of students on the academic self-perceptions (i.e., self-efficacy) subscale did differ significantly in this study, with gifted underachievers having significantly lower mean scores than gifted achievers. It is interesting to note that McCoach and Siegle sampled high school students for their study. Because the sample for this study consisted of middle school students, it could be that students in this age group who underachieve have 
more negative perceptions with regard to their self-efficacy. Early adolescents' views of themselves are fragile and malleable. They are susceptible to the "big lie," the myth which encourages early adolescents to view themselves as inadequate if they differ from their peers (Strahan, L’Esperance, \&Van Hoose, 2009). Gifted underachievers most definitely differ from their gifted peers with regard to grades. Consequently, they may view themselves as inadequate and fall victim to the "big lie." This finding is supported by earlier research where gifted underachievers and gifted achievers were found to differ with regard to self-efficacy; gifted underachievers had poorer self-efficacy than gifted achievers (Diaz, 1998; Dowdall \& Colangelo, 1982; McCoach and Siegle, 2001; Supplee, 1990; Whitmore, 1980).

Similar to findings from previous research, there was no statistically significant difference found for the mean scores of gifted achievers and underachievers on the environmental perceptions factor (McCoach \& Siegle, 2003a), suggesting that gifted underachievers in sixth and seventh grades may actually underachieve despite having positive attitudes toward their teachers and school environment. Given that middle schools are intentionally designed to be supportive and student-centered (AMLE, 2010; Powell, 2011), it is not surprising that these students may regard their environment positively and underachieve for other reasons. Findings from the current study also suggest gifted underachievers have poorer self-regulation skills than gifted achievers, a finding supported by the research of McCoach and Siegle (2001, 2003a).

Research Question 3: Is there a relationship of the specific characteristics of underachieving gifted middle school students to self-regulation, engagement, and achievement in the Achievement-Orientation Model? 
The Achievement-Orientation Model posits that task meaningfulness, environmental perceptions, and self-efficacy directly affect students' self-regulation. In other words, students who possess positive attitudes towards these three variables will self-regulate in school. Conversely, students whose attitudes are low toward any one of the three variables will not self-regulate in school. Only two of three independent variables in the first regression analysis predicted self-regulation; these variable were self-efficacy and environmental perceptions. Surprisingly, task meaningfulness did not have a direct effect on students' self-regulation, suggesting a weak relationship between these variables. In other words, gifted students may still be able to self-regulate in school despite not finding meaning in the task at hand. This may be due to the commonly held belief that gifted students already possess adequate self-regulation skills and therefore are able to persevere nonetheless (Rubenstein et al., 2012).

However, students' attitudes toward their self-efficacy and environment directly affect their ability to self-regulate. In other words, students who believe in their ability will find a way to successfully complete the task at hand; they may set goals and/or learn how to control their emotions better. Similarly, students who perceive their environment as supportive will seek help from peers and teachers and will utilize additional resources. Conversely, students with poor self-efficacy and less favorable environmental perceptions, as theorized by the Achievement-Orientation Model, likely will struggle with self-regulation.

In the second multiple regression analysis, only two of four independent variables contributed significantly to the prediction of achievement; these variables were selfefficacy and self-regulation. With regard to self-regulation, it appears reasonable that 
students with poor self-regulation skills would struggle to achieve academically. Similarly, it is not surprising that students who do not believe in their ability to be successful at completing a task may fail to achieve academically. Surprisingly, attitudes toward environment did not predict gifted students' achievement, suggesting gifted students may be able to persevere despite holding less favorable attitudes toward their school environment. Perhaps most interesting are the results of the third regression analysis; all of the variables in the model predicted student engagement. In other words, gifted students may be able to achieve despite poor attitudes toward certain variables in the model (e.g., environmental perceptions), but they will not be engaged in what they are doing.

Finally, the Achievement-Orientation Model posits that self-regulation mediates all of the relationships between the independent variables and dependent variables in the model. For example, it is not enough for gifted students to have positive academic selfperceptions; they must also be able to self-regulate in order to achieve and engage in school. Results of this study, for the most part, support this theory; however, selfregulation did not mediate the relationship between task meaningfulness and achievement or between task meaningfulness and engagement.

\section{Conclusions}

Gifted students appear to have two unique profiles based on the AchievementOrientation Model. Gifted underachievers tended to have negative attitudes toward all of the constructs in the model, while gifted achievers' attitudes tended to have more positive attitudes toward all of the constructs in the model. Not surprisingly, gifted underachievers and gifted achievers were found to have different characteristics based on the constructs 
in the Achievement-Orientation Model. In particular, gifted underachievers had negative perceptions of their self-efficacy and ability to self-regulate when compared to their achieving peers. Finally, results of the path analysis indicate all of the suggested relationships between constructs in the model may not exist. For example, task meaningfulness did not predict self-regulation or achievement. Further, self-regulation did not mediate the relationship between task meaningfulness and engagement or task meaningfulness and achievement. There potentially could be an issue with how this construct is measured; however, the results of this study challenge the theoretical expectation that task meaningfulness is crucial to gifted students' self-regulation, achievement, and engagement.

\section{Limitations}

The sample size was one limitation of this study. The sample consisted of 156 gifted students, only 24 of whom were determined to be gifted underachievers. The original intent was to collect a minimum sample of 200 students in order to have enough power to conduct the analyses; however, given the difficulty of acquiring district and individual school approval to conduct this study, this number was determined to be acceptable and the analyses to be conducted were modified accordingly based on this smaller sample size. Further, although 156 gifted achievers and 24 gifted underachievers may seem severely unevenly distributed across each group, other studies of gifted underachievement have utilized similar group compositions (e.g., Baker et al., 1998; McCoach \& Siegle, 2003a). A larger sample size, however, would most likely lead to the identification of more underachieving gifted students. 
A second possible limitation of this study could be the use of cluster analysis. Cluster analysis is often described as "descriptive, atheoretical, and noninferential" (Hair et al., 1998, p. 474) because it lacks a statistical foundation. It is, therefore, used primarily as an exploratory technique. Given the sample size obtained for the present study, an exploratory technique was judged to be appropriate in this case. Further, the selection of a cluster solution is subjective in nature. Inspection of graphs is often used to make a final determination. Finally, cluster analysis will always create clusters, regardless of whether or not they truly represent real patterns in the data. Future studies should consider the use of latent class analysis for validating the AchievementOrientation Model because of the statistical foundation this analysis provides.

A third limitation of this study could be the sampling of only sixth and seventh grade gifted mathematics students. Although middle school is believed to be when the groundwork for underachievement is laid (Peterson \& Colangelo, 1996), and mathematics classes tend to be more homogenous with regard to instruction, the sample size could have been made substantially larger with the inclusion of elementary school students or even high school students, or even with the inclusion of gifted students in middle school language arts classes. Future studies should examine the validity of the Achievement-Orientation Model for elementary school students and/or high school students as well.

A final limitation of this study is the lack of prior research on the AchievementOrientation Model. This is the first study that has attempted to validate this model. Although underachievement interventions based on this model have already been 
developed and tested, the results reported for these studies suggest these efforts have met with little success (Rubenstein et al., 2012; Rubenstein, 2011).

\section{Suggestions for Future Research}

The results of this study demonstrate that gifted achievers and underachievers do differ on some of the factors present in the Achievement-Orientation Model and that several of the theorized relationships in the model do exist; however, the AchievementOrientation Model cannot be validated based on the results of this study alone. Several suggestions for future research follow.

A larger sample size should be used in future studies. As gifted underachievers only represent a small fraction of the gifted population, it is necessary to sample a larger overall population, perhaps at least 250 to 500 gifted students, in order to obtain a sufficient sample of underachieving learners.

Another suggestion for future research is to use latent class analysis with a larger sample of gifted students, as opposed to cluster analysis. Latent class analysis (Lazarsfeld \& Henry, 1968) is an exploratory multivariate technique that is commonly used to classify individuals into a set of latent classes based on direct measures such as survey items. After cases are classified, additional variables may be used to predict class membership. The number of classes is not predetermined in latent class analysis and can be exhaustive; however, models are typically estimated between one and four clusters initially. A one-class model is initially fit to the data, and the number of classes are systematically increased until a model is generated that meaningfully distinguishes classes and yields a good statistical fit. Latent class analysis can be viewed as an improved version of cluster analysis because it has a statistical foundation. 
A third suggestion for future research involves how each of the constructs in the model is measured. This study chose to use subscale items from the SAAS-R and the CSAS to measure the constructs in the model. It might be interesting to use items from other reliable and valid measures of the same constructs. For example, the SelfRegulation Questionnaire- Academic (Ryan \& Connell, 1989) could be used to measure self-regulation. Further, items from the Learning Climate Questionnaire (Williams \& Deci, 1996) might be used to measure environmental perceptions. Although the measures used in this study are valid and reliable, other measures of the same constructs could potentially lead to different findings or validate the findings of this study.

A fourth suggestion for future research would be to test the validity of the Achievement-Orientation Model with elementary school gifted students and/or high school gifted students. Although middle school is believed to coincide with the onset of academic underachievement, gifted students, especially males, sometimes also underachieve in elementary school. Further, the cycle of underachievement does not end in high school. High school students may still be able to benefit from interventions based on the Achievement-Orientation Model. Therefore, the validity of the model should be tested with high school gifted students as well.

A fifth suggestion for future research would be to expand upon the current model. The model created by Siegle and McCoach (2005) does not fully capture the influence of peers and family on the motivation, self-regulation, achievement, and engagement of students. For the young adolescent, peer relationships alone may account for the decision to underachieve in school (Strahan et al., 2009). Further, as suggested by many researchers in gifted education (e.g., Baker et al., 1998; Diaz, 1998; Peterson, 2001) 
issues at home can directly impact gifted students' achievement. The AchievementOrientation Model could potentially be strengthened by the inclusion of these factors.

A final suggestion for future research is to test the practical significance of the model. Qualitative research concerning how students, teachers, and parents view the validity of the Achievement Orientation Model could definitely provide insight into whether the model as a whole and the individual factors in the model make practical sense. For example, it would be interesting to see how stakeholders view the task meaningfulness construct, a construct that is believed to be theoretically significant but may not be practically significant in the eyes of students, teachers, and parents. Further, does the model account for all of the reasons gifted students underachieve? Could home environment, for example, also account for gifted students' underachievement? These are questions that could be answered through qualitative inquiry.

\section{Implications for Practice}

Based on the findings of this study, middle school teachers of gifted students in the districts surveyed should be made aware that students' attitudes toward their school environment and the meaningfulness of tasks were generally positive. Self-regulation and self-efficacy, on the other hand, were more problematic for gifted students, especially gifted underachievers. Therefore, more professional development should be offered to educate middle school teachers about how to improve gifted students' self-regulation skills and self-efficacy in school. For example. Siegle and McCoach have developed materials online to support the development of self-regulatory skills and self-efficacy in gifted underachievers. These materials could potentially be used in professional development opportunities for educators. 
Although interventions have been developed based on the AchievementOrientation Model, teachers should know that the model is fairly new and needs further validation; they should not expect interventions based on the constructs in the model to be the "magical cures" that will reverse their students' pattern of underachievement. Teachers must further understand that gifted underachievement is a complex phenomenon and intervention research is still in its infancy. More research is needed before teachers commit themselves to potentially time-intensive interventions.

\section{Significance}

Although the Achievement-Orientation Model holds promise for the development of interventions to ameliorate gifted underachievement, it probably is too early to begin this work. In the future, the Achievement-Orientation Model may be used to develop interventions to address underachievement; however, first, more research is needed to validate the model. Although little research exists concerning the AchievementOrientation Model, this study suggests the model is a step in the right direction toward understanding why gifted middle school students underachieve in school. Although all of the relationships in the model could not be validated by this study alone, several of the theorized relationships did appear to exist. Future studies should continue to build off of the findings of this study. Once the validity of the Achievement-Orientation Model is established, interventions can then be developed and subjected to rigorous testing. This study is the first of its kind and its intent is to pave the way for this important work to be done.

\section{Summary}

Gifted underachievement represents a frustrating loss of potential for society. Currently, the Achievement-Orientation Model is one of the best theoretical models for 
understanding why gifted students underachieve. It is plausible to expect that such a model, grounded in theory, would be well-suited for the development of interventions to address the problem of underachievement; however, interventions based on the Achievement-Orientation Model have met with limited success. Validating the model seems a necessary step before developing and implementing additionally potentially time-intensive interventions. The purpose of this study was to conduct a preliminary validation of the Achievement-Orientation Model for gifted middle school students. These findings suggest the Achievement-Orientation Model, in part, explains the complex relationships that undergird why gifted students underachieve; however, more research must be conducted to further validate the model. Understanding the underlying theory of the model will help practitioners develop effective interventions in the future. 


\section{REFERENCES}

Association for Middle Level Education (2010). This we believe: Keys to educating young adolescents. Columbus, $\mathrm{OH}$ : Author.

Bailey, C. (2011). An examination of the relationships between ego development, Dabrowski's theory of positive disintegration, and the behavioral characteristics of gifted adolescents. Gifted Child Quarterly, 55(3), 208-222. doi:10.1177/0016986211412180

Baker, J. A., Bridger, R., \& Evans, K. (1998). Models of underachievement among gifted preadolescents: The role of personal, family, and school factors. Gifted Child Quarterly, 42, 5-14.

Balduf, M. (2009). Underachievement among college students. Journal of Advanced Academics, 20, 274-294.

Bandura, A. (1977). Self-efficacy: Toward a unifying theory of behavioral change. Psychological Review, 84, 191-215. doi:10.1037/0033-295X.84.2.191

Baslanti, U., \& McCoach, D. (2006). Factors related to the underachievement of university students in turkey. Roeper Review, 28, 210-215.

Baum, S. M., Renzulli, J. S., \& Hebert, T. P. (1995b). Reversing underachievement: Creative productivity as a systematic intervention. Gifted Child Quarterly, 39, 224-235.

Bernal, E.M. (2003). To no longer educate the gifted: Programming for gifted students beyond the era of inclusionism. Gifted Child Quarterly, 47, 183-191.

Bridgeland, J. M., Dilulio, J. J., \& Morison, K. B. (2006, March). The silent epidemic: Perspectives of high school dropouts. Retrieved from http://www.civicenterprises.net/pdfs/thesilentepidemic3-06.pdf

Broedel, J., Ohlsen, M., Proff, F., \& Southhard, C. (1965). The effects of group counseling on gifted underachieving adolescents. In M. Kornrich (Ed.), Underachievement (pp. 514-528). Springfield, IL: Charles C. Thomas.

Callahan, C. M., Cunningham, C. M., \& Plucker, J. A. (1994). Foundations for the future: The socio-emotional development of gifted, adolescent women. Roeper Review, 17, 99-105.

Caplan, R. D., \& Van Harrison, R. (1993). Person-Environment Fit theory: Some history, recent developments, and future directions. Journal of Social Issues, 49, 253-275. 
Colangelo, N., Kerr, B., Christensen, P., \& Maxey, J. (1993). A comparison of gifted underachievers and gifted high achievers. Gifted Child Quarterly, 37, 155-160.

Compton, M. F. (1982). The gifted underachiever in the middle school. Roeper Review, 4(4), 23-25.

Crepeau-Hobson, F., \& Bianco, M. (2011). Identification of gifted students with learning disabilities in a response-to-intervention era. Psychology in the Schools, 48, 102109. doi: 10.1002/pits.20528

Davis, H. B., \& Connell, J. P. (1985). The effect of aptitude and achievement status on the self-system. Gifted Child Quarterly, 29, 131-136.

Davis, G. A., Rimm, S. B., \& Siegle, D. (2011). Education of the gifted and talented (6th ed.). Boston, MA: Pearson.

Diaz, E. I. (1998). Perceived factors influencing the academic underachievement of talented students of Puerto Rican descent. Gifted Child Quarterly, 42, 105-122.

Doland, E. (2001). Give yourself the gift of a degree: Employment Policy Foundation, Washington, D.C.

Dowdall, C. B., \& Colangelo, N. (1982). Underachieving gifted students: Review and implications. Gifted Child Quarterly, 26, 179-184.

Eccles, J. S. (2008). Can middle school reform increase high school graduation rates? (Report No. 12). Retrieved from http://www.cdrp.ucsb.edu/researchreport12.pdf

Eccles, J. S., Midgley, C., Wigfield, A., Buchanan, C. M., Reuman, D., Flanagan, C., \& MacIver, D. (1993). Development during adolescence: The impact of stageenvironment fit on adolescents' experiences in schools and families. American Psychologist, 48, 90-101.

Eccles, J. S., \& Wigfield, A. (1995). In the mind of the actor: The structure of adolescents' achievement task values and expectancy-related beliefs. Personality and Social Psychology Bulletin, 21, 215-225.

Emerick, L. J. (1992). Academic underachievement among the gifted: Students' perceptions of factors that reverse the pattern. Gifted Child Quarterly, 36, 140146.

Feldhusen, J. (1992). Talent identification and development in education (TIDE). Sarasota, FL: Center for Creative Learning. 
Fredricks, J. A., Blumenfeld, P. C., \& Paris, A. (2004). School engagement: potential of the concept: state of the evidence. Review of Educational Research, 74, 59-119.

Fredricks, J., McColskey, W., Meli, J., Mordica, J., Montrosse, B., \& Mooney, K. (2011). Measuring student engagement in upper elementary through high school: a description of 21 instruments. (Issues \& Answers Report, REL 2011-No. 098). Washington, DC: U.S. Department of Education, Institute of Education Sciences, National Center for Education Evaluation and Regional Assistance, Regional Educational Laboratory Southeast. Retrieved from http://ies.ed.gov/ncee/edlabs/regions/southeast/pdf/REL_2011098.pdf

French, J. R. P., Jr., Rodgers, W., \& Cobb, S. (1974). Adjustment as person-environment fit. In G. V. Coelho, D. A. Hamburg, t J. E. Adams (Eds.), Coping and adaptation. New York: Basic Books.

Gagne, E (1995). From giftedness to talent: A developmental model and its impact on the language of the field. Roeper Review, 18, 103-111.

Gardner, H. (1983). Frames of mind. New York: Basic Books

Green, K., Fine, M. J., \& Tollefson, N. (1988). Family systems characteristics and underachieving gifted males. Gifted Child Quarterly, 32, 267-272.

Gay, L. R., Mills, G. E., \& Airasian, P. (2009). Educational research: Competencies for analysis and applications. Upper Saddle River, NJ: Pearson.

Hebert, T. P., \& Olenchak, F. (2000). Mentors for gifted underachieving males: Developing potential and realizing promise. Gifted Child Quarterly, 44, 196.

Jansen, K. J., \& Kristof-Brown, A. (2006). Toward a multidimensional theory of PersonEnvironment Fit. Journal of Managerial Issues, 18, 193-212.

Kanevsky, L., \& Keighley, T. (2003). To produce or not to produce? Understanding boredom and the honor in underachievement. Roeper Review, 26, 20-28.

Kanoy, R. C., Johnson, B. W., \& Kanoy, K. W. (1980). Locus of control and self-concept in achieving and underachieving bright elementary students. Psychology in the Schools, 17, 395-399.

Kramer, L. R. (1991). The social construction of ability perceptions: An ethnographic study of gifted adolescent girls. Journal of Early Adolescence, 11, 340-362.

Lazarsfeld, P. F., \& Henry, N. W. (1968). Latent structure analysis. Boston: Houghton Mifflin. 
Lerner, R. M. (2002). Adolescence: Development, diversity, context, and application. Upper Saddle, NJ: Pearson.

Lewin, K. (1935). A dynamic theory of personality: Selected papers. New York, NY: McGraw-Hill

Lupart, J. L., \& Pyryt, M. C. (1996). "Hidden gifted" students: Underachiever prevalence and profile. Journal for the Education of the Gifted, 20, 36-53.

Matthews, M. S. (2009). Gifted learners who drop out: Prevalence and prevention. In L. V. Shavinina (Ed.), The international handbook on giftedness (pp. 527-536). New York: Springer Science.

Matthews, M. (2006). Gifted students dropping out: recent findings from a southeastern state. Roeper Review, 28, 216-223.

Matthews, M. S., \& McBee, M. T. (2007). School factors and the underachievement of gifted students in a talent search program. Gifted Child Quarterly, 51, 167-181.

Mccoach, D. B., Picho, K., \& Baslanti, U. (in press). Development and validation of the Challenges to Scholastic Achievement (CSAS) scale.

McCoach, D. B., Kehle, T. J., Bray, M. A., \& Siegle, D. (2001). Best practice for the identification of gifted students with learning disabilities. Psychology in the Schools, 38, 403-411.

McCoach, D. B., \& Siegle, D. (2001). A comparison of high achievers' and low achievers' attitudes, perceptions, and motivations. Academic Exchange Quarterly, $5,71-76$.

McCoach, D. (2002). A validation study of the school attitude assessment survey. Measurement and Evaluation in Counseling and Development, 35, 66-77.

McCoach, D. B., \& Siegle, D. (2003a). Factors that differentiate underachieving gifted students from high-achieving gifted students. Gifted Child Quarterly, 47, 144154.

McCoach, D. B., \& Siegle, D. (2003b). The School Attitude Assessment Survey-Revised: A new instrument to identify academically able students who underachieve.

Educational and Psychological Measurement, 63, 414-429. doi:10.1177/0013164403063003005

Mccutcheon AL (1987). Latent Class Analysis. Sage University Paper Series on Quantitative Applications in the Social Sciences. Beverly Hills: Sage. 
McEwin, K. C., \& Greene, M. W. (2011). The status of programs and practices in America's middle schools: Results from two national studies. Retrieved from http://www.amle.org/portals/0/pdf/research/Research_from_the_Field/Status_Pro grams_Practices_AMLE.pdf

Middleton, M. J., Kaplan, A., \& Midgley, C. (2004). The change in middle school students' achievement goals in mathematics over time. Social Psychology of Education, 7, 189-311.

Moore, J., Ford, D. Y., \& Milner, H. (2005). Recruitment is not enough: Retaining African American students in gifted education. Gifted Child Quarterly, 49, 51-67.

Morisano, D., Hirsh, J. B., Peterson, J. B., Pihl, R. O., \& Shore, B. M. (2010). Personal goal setting improves academic performance in university students. Journal of Applied Psychology, 95, 255-264.

National Association for Gifted Children and Council of State Directors of Programs for the Gifted. (2009). The 2008-2009 state of the states gifted and talented education report. Washington, DC: Author.

North Carolina General Statute $\S 115 C-150.5$, Elementary and Secondary Education, Chapter 115C, Article 9b (1996). North Carolina. Retrieved from http://www.gtcybersource.org/StatePolicyDetails.aspx?StateCode=10028\&NavID=4_0\#Legisla tionAndPolicies

No Child Left Behind Act 2001, 22 U.S.C. § 9101 (2002).

Orthner, D., Akos, P., Rose, R., Jones-Sanpei, H., Mercado, M., \& Woolley, M. (2010). CareerStart: a middle school student engagement and academic achievement program. Children \& Schools, 32, 223-234.

Peterson, J. S. (2000). A follow-up study of one group of achievers and underachievers four years after high school graduation. Roeper Review, 22, 217-224.

Peterson, J. S. (2001). Successful adults who were once adolescent underachievers. Gifted Child Quarterly, 45, 215-229.

Peterson, J. S., \& Colangelo, N. (1996). Gifted achievers and underachievers: A comparison of patterns found in school files. Journal of Counseling and Development, 74, 399-406.

Peterson, J., \& Ray, K. E. (2006). Bullying Among the Gifted: The subjective experience. Gifted Child Quarterly, 50, 252-269. 
Pintrich, P. R., \& de Groot, E. V. (1990). Motivational and self-regulated learning components of classroom academic performance. Journal of Educational Psychology, 82, 33-40. doi:10.1037/0022-0663.82.1.33

Piirto, J. (1994). Talented children and adults: their development and education. New York: Macmillan College Publishing Company

Powell, S.D. (2011). Introduction to middle school. Boston, MA: Pearson.

Rayneri, L. J., Gerber, B. L., \& Wiley, L. P. (2006). The relationship between classroom environment and the learning style preferences of gifted middle school students and impact on levels of performance. Gifted Child Quarterly, 50, 104-118.

Redding, R. E. (1990). Learning preferences and skill patterns among underachieving gifted adolescents. Gifted Child Quarterly, 34, 72-75.

Reis, S. M., \& McCoach, D. B. (2000). The underachievement of gifted students: What do we know and where do we go? Gifted Child Quarterly, 44, 152-170.

Renzulli, J. (1978). What makes giftedness? Reexamining a definition. Phi Delta Kappan, 261, 180-184.

Renzulli, J. S., \& Park, S. (2002). Giftedness and high school dropouts: Personal, family, and school related factors. Storrs, CT: The National Research Center on the Gifted and Talented.

Renzulli, J. S., Baum, S. M., Hebert, T., \& McCluskey, K. W. (1999). Reversing underachievement through enrichment: Reclaiming children and youth. Journal of Emotional and Behavioral Problems, 7, 217-23.

Richert, E. S. (1991). Patterns of underachievement among gifted students. In J. H. Borland (Series Ed.) \& M. Bireley \& J. Genshaft (Vol. Eds.), Understanding the gifted adolescent, (pp. 139-162). New York: Teachers College Press.

Rimm, S. (1997a). An underachievement epidemic. Educational Leadership, 54(7), 1822.

Rouse, C. E. (2005). Labor market consequences of an inadequate education. Paper prepared for the symposium on the Social Costs of Inadequate Education, Teachers College Columbia University, October 2005.

Rubenstein, L. D. (2011). Project ATLAS: Empowering academically underachieving gifted students. University of Connecticut. 
Rubenstein, L. D., Siegle, D., Reis, S. M., McCoach, D. B., \& Burton, M. G. (2012). A complex quest: The development and research of underachievement interventions for gifted students. Psychology in the Schools, 49, 678-694.

Ryan, R. M., \& Connell, J. P. (1989). Perceived locus of causality and internalization: Examining reasons for acting in two domains. Journal of Personality and Social Psychology, 57, 746-761.

Samuelson, K. M., \& Dayton, C. (2010). Latent class analysis. In G. R. Hancock \& R. O. Mueller (Eds.), The reviewer's guide to quantitative methods in the social sciences (173-184). New York, NY: Routledge.

Schultz, R. (2002). Understanding giftedness and underachievement: At the edge of possibility. Gifted Child Quarterly, 46, 193-208. doi:10.1177/001698620204600304

Shaw, M. C., \& McCuen, J. T. (1960). The onset of academic underachievement in bright children. Journal of Educational Psychology, 51, 103-108. doi:10.1037/h0043137

Siegle, D., \& McCoach D. B. (2005). Motivating gifted students. Waco, TX: Prufrock Press.

Skinner, E. A., Kindermann, T. A., \& Furrer, C. J. (2009). A motivational perspective on engagement and disaffection: conceptualization and assessment of children's behavioral and emotional participation in academic activities in the classroom. Educational and Psychological Measurement, 69, 493-525.

Skinner, E. A., Marchand, G., Furrer, C., and Kindermann, T. (2008). Engagement and disaffection in the classroom: part of a larger motivational dynamic. Journal of Educational Psychology, 100, 765-781.

Sternberg, R. J. (1997a, June). Developing your child's successful intelligence. Teaching for High Potential, 8-10.

Sternberg, R. (1985). Beyond IQ: A triarchic theory of human intelligence. Cambridge, MA: Cambridge University Press.

Strahan, D., L'Esperance, M., and Van Hoose, J. (2009). Promoting harmony: Young Adolescent Development and Classroom Practices. Westerville, $\mathrm{OH}$ : National Middle School Association.

Stillwell, R. (2010). Public school graduates and dropouts from the common core of data: School Year 2007-08 (NCES 2010-341). National Center for Education Statistics, Institute of Education Sciences, U.S. Department of Education. Washington, D.C.: U.S. Retrieved from http://nces.ed.gov/pubsearch/pubsinfo.asp?pubid=2010341. 
Stoeger, H. (2008). Deficits in fine motor skill as an important factor in the identification of gifted underachievers in primary school. Psychology Science, 2, 134-146.

Suldo, S. M., Shaffer, E. J., \& Shaunessy, E. (2008). An independent investigation of the validity of the School Attitude Assessment Survey-Revised. Journal of Psychoeducational Assessment, 26(1), 69-82. doi:10.1177/0734282907303089

Summ A., Khatiwada, I., Pond, N., Trub'skyy, M., Fogg, N., \& Palma, S. (2003). Left behind in the labor market: Labor market problems of the nations out-of-school, young adult populations. Boston, MA: Center for Labor Market Studies, Northeastern University.

Supplee, P. L. (1990). Reaching the gifted underachiever. New York, NY: Teachers College Press.

Tabachnick, B. G., \& Fidell L. S. (2007). Using multivariate statistics. Boston: Pearson.

Tannenbaum, A. J. (1983). Gifted children: Psychological and educational perspectives. New York: Macmillan Publishing Company.

Terman, L. M. (1925). Mental and physical traits of a thousand gifted children. Stanford, CA: Stanford University Press.

Thompson, K.F. \& Homestead, E. (2004a). Middle school organization through the 1970s, 1980s, and 1990s. Middle School Journal, 35(3), 70-74.

Volker, M. A., Lopata, C., \& Cook-Cottone, C. (2006). Assessment of children with intellectual giftedness and reading disabilities. Psychology in the Schools, 43, 855-869. doi: 10.1002/pits.20193

Weiner, B. (1972). Attribution theory, achievement motivation, and the educational process. Review of Educational Research, 42, 203-215. doi:10.2307/1170017

Weiner, B., Nierenberg, R., \& Goldstein, M. (1976). Social learning (locus of control) versus attributional (causal stability) interpretations of expectancy of success. Journal of Personality, 44(1), 52-68. doi:10.1111/j.1467-6494.1976.tb00583.x

Williams, G. C., \& Deci, E. L. (1996). Internalization of biopsychosocial values by medical students: A test of self-determination theory. Journal or Personality and Social Psychology, 70, 767-779.

Whitmore, J. R. (1980). Giftedness, conflict, and underachievement. Boston: Allyn and Bacon. 
Whitmore, J. R. (1986). Understanding a lack of motivation to excel. Gifted Child Quarterly, 30, 66-69.

Yang, X., Shaftel, J., Glassnapp, D., \& Poggio, J. (2005). Qualitative or quantitative differences? Latent class analysis of mathematical ability for special education students. The Journal of Special Education, 38, 194-207.

Zabloski, J., \& Milacci, F. (2012). Gifted dropouts: Phenomenological case studies of rural gifted students. Journal of Ethnographic \& Qualitative Research, 6, 175-190 


\title{
APPENDIX A: SCHOOL ATTITUDE ASSESSMENT SURVEY-REVISED
}

\author{
School Attitude Assessment Survey-Revised \\ (c) D. B. McCoach, University of Connecticut, 2002
}

Instructions: This survey should take approximately 5 minutes to complete. Please make sure you have answered all questions for Part I (35 questions total) and Part II (2 questions total).

Part I: Please rate how strongly you agree or disagree with the following statements. In answering each question, use a range from (1) to (7) where (1) stands for strongly disagree and (7) stands for strongly agree. Please circle only one response choice per question.

\begin{tabular}{|c|c|c|c|c|c|c|c|}
\hline Statement & $\begin{array}{l}\text { Strongly } \\
\text { Disagree }\end{array}$ & Disagree & $\begin{array}{l}\text { Slightly } \\
\text { Disagree }\end{array}$ & $\begin{array}{l}\text { Neither } \\
\text { agree nor } \\
\text { disagree }\end{array}$ & $\begin{array}{l}\text { Slightly } \\
\text { Agree }\end{array}$ & Agree & $\begin{array}{c}\text { Strongly } \\
\text { Agree }\end{array}$ \\
\hline $\begin{array}{l}\text { 1. My classes } \\
\text { are } \\
\text { interesting. }\end{array}$ & 1 & 2 & 3 & 4 & 5 & 6 & 7 \\
\hline $\begin{array}{l}\text { 2. I am } \\
\text { intelligent. }\end{array}$ & 1 & 2 & 3 & 4 & 5 & 6 & 7 \\
\hline $\begin{array}{l}\text { 3. I can learn } \\
\text { new ideas } \\
\text { quickly in } \\
\text { school. }\end{array}$ & 1 & 2 & 3 & 4 & 5 & 6 & 7 \\
\hline $\begin{array}{l}\text { 4. I check my } \\
\text { assignments } \\
\text { before I turn } \\
\text { them in. }\end{array}$ & 1 & 2 & 3 & 4 & 5 & 6 & 7 \\
\hline $\begin{array}{l}\text { 5. I am smart } \\
\text { in school. }\end{array}$ & 1 & 2 & 3 & 4 & 5 & 6 & 7 \\
\hline $\begin{array}{l}6 . \text { I am glad } \\
\text { that I go to } \\
\text { this school. }\end{array}$ & 1 & 2 & 3 & 4 & 5 & 6 & 7 \\
\hline $\begin{array}{l}\text { 7. This is a } \\
\text { good school. }\end{array}$ & 1 & 2 & 3 & 4 & 5 & 6 & 7 \\
\hline $\begin{array}{l}\text { 8. I work hard } \\
\text { at school. }\end{array}$ & 1 & 2 & 3 & 4 & 5 & 6 & 7 \\
\hline $\begin{array}{l}\text { 9. I relate well } \\
\text { to my } \\
\text { teachers. }\end{array}$ & 1 & 2 & 3 & 4 & 5 & 6 & 7 \\
\hline
\end{tabular}


10. I am self-

$$
2
$$

3

4

5

7

motivated to

do my

schoolwork.

11. I am good

at learning

new things in

school.

12. This

1

2

3

4

5

7

school is a

good match

for me.

13. School is

2

3

4

5

7

easy for me.

14. I like my

1

2

3

4

5

7

teachers.

15. I want to

1

2

3

4

5

7

get good

grades in

school.

16. My

1

2

3

4

5

7

teachers make

learning

interesting.

17. My

teachers care

about me.

18. Doing

1

2

3

4

5

7

well in

school is

importan

$t$ for my

future

career

goals.

19. I like this

1

2

3

4

5

6

7

school.

20. I can

1

2

3

4

5

6 
grasp

complex

concepts in

school.

21. Doing

1

2

3

4

5

7

well in school

is one of my

goals.

22. I am

capable of

getting

straight A's.

23. I am

1

proud of this

school.

24. I complete

1

1

2

3

4

5

7

my

schoolwork

regularly.

25. It's

1

2

3

4

5

6

7

important to

get good

grades in

school.

26. I am

about my

schoolwork.

27. I use a

1

2

3

4

5

6

7

strategies to

learn new

material.

28. I want to

1

2

3

4

5

6

do my best in

school.

29. It is

1

2

3

4

5

6

7

important for

me to do well

in school.

30. I spend a

1

2

3

4

5

6

7

lot of time on

my 
schoolwork.

\begin{tabular}{|c|c|c|c|c|c|c|}
\hline $\begin{array}{l}\text { 31. Most of } \\
\text { the teachers at } \\
\text { this school are } \\
\text { good teachers. }\end{array}$ & 1 & 2 & 3 & 4 & 5 & 6 \\
\hline $\begin{array}{l}\text { 32. I am a } \\
\text { responsible } \\
\text { student. }\end{array}$ & 1 & 2 & 3 & 4 & 5 & 6 \\
\hline $\begin{array}{l}\text { 33. I put a lot } \\
\text { of effort into } \\
\text { my } \\
\text { schoolwork. }\end{array}$ & 1 & 2 & 3 & 4 & 5 & 6 \\
\hline $\begin{array}{l}\text { 34. I like my } \\
\text { classes. }\end{array}$ & 1 & 2 & 3 & 4 & 5 & 6 \\
\hline $\begin{array}{l}35 . \text { I } \\
\text { concentrate } \\
\text { on my } \\
\text { schoolwork. }\end{array}$ & 1 & 2 & 3 & 4 & 5 & 6 \\
\hline
\end{tabular}

PART II: Please choose only one response choice per question.

1. What is your cumulative GPA? What are your average grades?
4.0 or higher (All A's)
2.5 to 2.99 (More B's than C's)
3.75 to 3.99 (Mostly A's)
2.0 to 2.49 (More C's than B's)
3.5 to 3.74 (More A's than B's)
1.5 to 1.99 (More C's than D's)
3.25 to 3.49 (More B's than A's)
1.0 to 1.49 (More D's than C's)
3.0 to 3.24 (Mostly B's, some A's and C's)
less than 1.0 (Mostly D's and F's)

2. On average, how much time per week do you spend doing homework?

Less than 1 hour

From 10 hours to less than 15 hours

From 1 hour to less than 3 hours From 15 hours to less than 20 hours

From 3 hours to less than 5 hours From 20 hours to less than 25 hours 
From 5 hours to less than 10 hours 25 hours or more Thank you for your time! 
School Attitude Assessment Survey-Revised

(C) D. B. McCoach, University of Connecticut, 2002

\section{Scoring Rubric/Codebook}

Academic Self-Perceptions: 7 Questions

Q2, Q3, Q5, Q11, Q13, Q20, Q22

Use mean scores.

Mean:5.7

Standard deviation $=.9$

Above 5.4 = Average/Normal

4.8 to $5.4=$ Low average

3.5 to $4.8=$ Low

Below $3.5=$ Very low

Attitudes toward teachers (and classes): 7 Questions

Q1, Q9, Q14, Q16, Q17, Q31, Q34

Mean:5.3

Standard deviation $=1.1$

Above $4.7=$ Average/Normal

4.0 to $4.7=$ Low average

2.5 to $4.0=$ Low

Below $2.5=$ Very low 
Attitudes toward school: 5 questions

Q6, Q7, Q12, Q19, Q23

Mean: 5.1

Standard deviation $=1.4$

Above $4.4=$ Average/Normal

3.6 to $4.4=$ Low average

1.5 to $3.6=$ Low

Below $1.5=$ Very low

Goal Valuation: 6 Questions

Q15, Q18, Q21, Q25, Q28, Q29

Mean: 6.3

Standard deviation $=1.0$

Above $6.0=$ Average $/$ Normal

5.0 to $6.0=$ Low average

3.5 to $5.0=$ Low

Below $3.5=$ Very low

Motivation/Self-Regulation: 10 questions

Q4, Q8, Q10, Q24, Q26, Q27, Q30, Q32, Q33, Q35

Mean: 5.1

Standard deviation $=1.3$

Above $4.7=$ Average/Normal

3.7 to $4.7=$ Low average

1.6 to $3.7=$ Low

Below 1.6 $=$ Very low 


\section{APPENDIX B: CHALLENGES TO SCHOLASTIC ACHIEVEMENT SURVEY}

\section{CHALLENGES TO SCHOLASTIC ACHIEVEMENT SURVEY (CSAS-R) @ 2011}

Instructions: This survey should take approximately 5 minutes to complete.

PART I: Please rate how strongly you agree or disagree with the following statements. In answering each question, use a range from (1) to (7) where (1) stands for strongly disagree and (7) stands for strongly agree. Please circle only one response choice per question.

\begin{tabular}{|c|c|c|c|c|c|c|c|}
\hline & 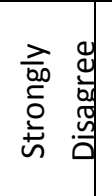 & 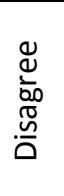 & 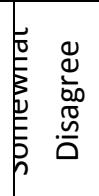 & 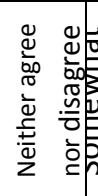 & 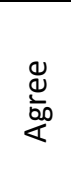 & 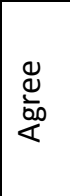 & 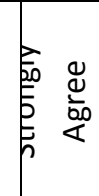 \\
\hline 1. Getting $A^{\prime} s$ is very difficult for me. & 1 & 2 & 3 & 4 & 5 & 6 & 7 \\
\hline 2. No one in this school supports me. & 1 & 2 & 3 & 4 & 5 & 6 & 7 \\
\hline 3. I am not motivated to study for exams. & 1 & 2 & 3 & 4 & 5 & 6 & 7 \\
\hline 4. I am not smart in school. & 1 & 2 & 3 & 4 & 5 & 6 & 7 \\
\hline 5. School is of no value to me. & 1 & 2 & 3 & 4 & 5 & 6 & 7 \\
\hline 6. I have poor study habits. & 1 & 2 & 3 & 4 & 5 & 6 & 7 \\
\hline 7. Teachers in this school do not treat me fairly. & 1 & 2 & 3 & 4 & 5 & 6 & 7 \\
\hline 8. School will not help me with my future plans. & 1 & 2 & 3 & 4 & 5 & 6 & 7 \\
\hline 9. Most teachers here are bad teachers. & 1 & 2 & 3 & 4 & 5 & 6 & 7 \\
\hline 10. People like me can't do well in a school like this. & 1 & 2 & 3 & 4 & 5 & 6 & 7 \\
\hline 11. I have trouble keeping track of my assignments. & 1 & 2 & 3 & 4 & 5 & 6 & 7 \\
\hline 12. People say that I am a lazy student. & 1 & 2 & 3 & 4 & 5 & 6 & 7 \\
\hline 13. Nobody at this school cares about me. & 1 & 2 & 3 & 4 & 5 & 6 & 7 \\
\hline 14. There is no way that I could ever be successful in this & 1 & 2 & 3 & 4 & 5 & 6 & 7 \\
\hline
\end{tabular}




\begin{tabular}{|c|c|c|c|c|c|c|c|}
\hline school. & & & & & & & \\
\hline 15. I have trouble keeping track of my school supplies. & 1 & 2 & 3 & 4 & 5 & 6 & 7 \\
\hline $\begin{array}{l}\text { 16. I think that I would be a better student if I could go } \\
\text { to a different school. }\end{array}$ & 1 & 2 & 3 & 4 & 5 & 6 & 7 \\
\hline 17. My teachers don't understand me. & 1 & 2 & 3 & 4 & 5 & 6 & 7 \\
\hline 18. I have trouble concentrating on my schoolwork. & 1 & 2 & 3 & 4 & 5 & 6 & 7 \\
\hline 19. I am unable to do well in school. & 1 & 2 & 3 & 4 & 5 & 6 & 7 \\
\hline 20. No one in this school cares if I am successful. & 1 & 2 & 3 & 4 & 5 & 6 & 7 \\
\hline 21. I have problems with time management. & 1 & 2 & 3 & 4 & 5 & 6 & 7 \\
\hline 22. My teachers' grading practices are not fair. & 1 & 2 & 3 & 4 & 5 & 6 & 7 \\
\hline 23. The teachers at this school do not like me. & 1 & 2 & 3 & 4 & 5 & 6 & 7 \\
\hline \multirow[t]{2}{*}{ 24. I hate the way courses are taught at this school. } & 1 & 2 & 3 & 4 & 5 & 6 & 7 \\
\hline & 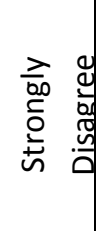 & 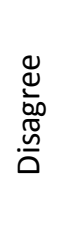 & 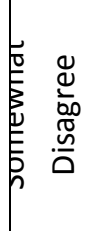 & 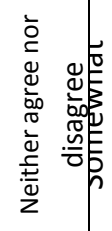 & $\underset{Ð}{\stackrel{Ð}{00}}$ & $\underset{\frac{1}{2}}{\stackrel{0}{\alpha}}$ & 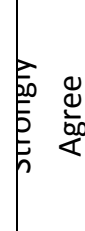 \\
\hline 25. I have problems staying organized. & 1 & 2 & 3 & 4 & 5 & 6 & 7 \\
\hline 26. Grades don't mean anything to me. & 1 & 2 & 3 & 4 & 5 & 6 & 7 \\
\hline 27. No matter what, I will never do well at this school. & 1 & 2 & 3 & 4 & 5 & 6 & 7 \\
\hline 28. I need help to understand many topics in my classes. & 1 & 2 & 3 & 4 & 5 & 6 & 7 \\
\hline $\begin{array}{l}\text { 29. Teachers at this school do not believe that I could be } \\
\text { successful. }\end{array}$ & 1 & 2 & 3 & 4 & 5 & 6 & 7 \\
\hline 30. I have bad relationships with my teachers. & 1 & 2 & 3 & 4 & 5 & 6 & 7 \\
\hline 31. I see no purpose to school. & 1 & 2 & 3 & 4 & 5 & 6 & 7 \\
\hline $\begin{array}{l}\text { 32. I am not as smart as most other students in my } \\
\text { classes. }\end{array}$ & 1 & 2 & 3 & 4 & 5 & 6 & 7 \\
\hline 33. I do not have regular study routines. & 1 & 2 & 3 & 4 & 5 & 6 & 7 \\
\hline
\end{tabular}




\begin{tabular}{|l|c|c|c|c|c|c|c|}
\hline 34. Most teachers here are not very bright. & 1 & 2 & 3 & 4 & 5 & 6 & 7 \\
\hline 35. School does not fit into achieving my goals. & 1 & 2 & 3 & 4 & 5 & 6 & 7 \\
\hline 36. Getting high grades doesn't matter to me. & 1 & 2 & 3 & 4 & 5 & 6 & 7 \\
\hline 37. I dislike my teachers. & 1 & 2 & 3 & 4 & 5 & 6 & 7 \\
\hline 38. I procrastinate when it comes to schoolwork. & 1 & 2 & 3 & 4 & 5 & 6 & 7 \\
\hline 39. School is useless. & 1 & 2 & 3 & 4 & 5 & 6 & 7 \\
\hline $\begin{array}{l}\text { 40. I can't seem to get good grades in school. } \\
\text { 41. The teachers in this school discriminate against me. }\end{array}$ & 1 & 2 & 3 & 4 & 5 & 6 & 7 \\
\hline $\begin{array}{l}\text { 42. Success in life has nothing to do with success in } \\
\text { school. }\end{array}$ & 1 & 2 & 3 & 4 & 5 & 6 & 7 \\
\hline
\end{tabular}

CONTINUE TO NEXT PAGE $\rightarrow$ 
CSAS- REVISED- 2011 Version

FACTOR 1: UNREGULATED STUDY BEHAVIOR (lack of self-regulation)

ITEMS C3 C6 C11 C12 C15 C18 C21 C25 C33 C38

FACTOR 2: NEGATIVE ENVIRONMENTAL PERCEPTIONS

ITEMS C2 C7 C10 C13 C14 C16 C17 C20 C22 C23 C27 C29 C41

FACTOR 3: DISDAINS THE VALUE OF SCHOOL

ITEMS C5 C8 C26 C31 C35 C36 C39 C42

FACTOR 4: NEGATIVE ATTITUDES TOWARD TEACHERS AND CLASSES

ITEMS C9 C24 C30 C34 C37

FACTOR 5: NEGATIVE SELF_CONCEPT

ITEMS C1 C4 C19 C28 C32 C40 


\section{APPENDIX C: ENGAGEMENT VS. DISAFFECTION WITH LEARNING-STUDENT REPORT}

Behavioral Engagement

1. I try hard to do well in school.

2. In class, I work as hard as I can.

3. When I'm in class, I participate in class discussions.

4. I pay attention in class.

5. When I'm in class, I listen very carefully.

Behavioral Disaffection

6. When I'm in class, I just act like I'm working. (-)

7. I don't try very hard at school. (-)

8. In class, I do just enough to get by. (-)

9. When I'm in class, I think about other things. (-)

10. When I'm in class, my mind wanders. (-)

\section{Emotional Engagement}

11. When I'm in class, I feel good.

12. When we work on something in class, I feel interested.

13. Class is fun.

14. I enjoy learning new things in class.

15. When we work on something in class, I get involved.

Emotional Disaffection

16. When we work on something in class, I feel bored. (-)

(When I'm doing work in class, I feel bored. (-))

(When my teacher first explains new material, I feel bored. (-)) 
17. When I'm in class, I feel worried. (-)

(When we start something new in class, I feel nervous. (-))

(When I get stuck on a problem, I feel worried. (-))

18. When we work on something in class, I feel discouraged. (-)

19. Class is not all that fun for me. (-)

20. When I'm in class, I feel bad. (-)

(When I'm working on my classwork, I feel mad. (-))

(When I get stuck on a problem, it really bothers me. (-))

(When I can't answer a question, I feel frustrated. (-))

Note. Items in parentheses can be used to obtain a more differentiated assessment of disaffected emotions (i.e., bored, worried, and frustrated). 
How I Feel About School

1. I try hard to do well in school.
A) Not at all true
B) Not very true
C) Sort of true
D) Very true

2. I enjoy learning new things in class.
A) Not at all true
B) Not very true
C) Sort of true
D) Very true

3. When we work on something in class, I feel discouraged.
A) Not at all true
B) Not very true
C) Sort of true
D) Very true

4. In class, I do just enough to get by.
A) Not at all true
B) Not very true
C) Sort of true
D) Very true

5. Class is fun.
A) Not at all true
B) Not very true
C) Sort of true
D) Very true

6. In class, I work as hard as I can.
A) Not at all true
B) Not very true
C) Sort of true
D) Very true

7. When I'm in class, I feel bad.
A) Not at all true
B) Not very true
C) Sort of true
D) Very true 
8. When I'm in class, I listen very carefully.
A) Not at all true
B) Not very true
C) Sort of true
D) Very true

9. When I'm in class, I feel worried.
A) Not at all true
B) Not very true
C) Sort of true
D) Very true

10. When we work on something in class, I get involved.
A) Not at all true
B) Not very true
C) Sort of true
D) Very true

11. When I'm in class, I think about other things.
A) Not at all true
B) Not very true
C) Sort of true
D) Very true

12. When we work on something in class, I feel interested.
A) Not at all true
B) Not very true
C) Sort of true
D) Very true

13. Class is not all that fun for me.
A) Not at all true
B) Not very true
C) Sort of true
D) Very true

14. When I'm in class, I just act like I'm working.
A) Not at all true
B) Not very true
C) Sort of true
D) Very true 
15. When I'm in class, I feel good.
A) Not at all true
B) Not very true
C) Sort of true
D) Very true

16. When I'm in class, my mind wanders.
A) Not at all true
B) Not very true
C) Sort of true
D) Very true

17. When I'm in class, I participate in class discussions.
A) Not at all true
B) Not very true
C) Sort of true
D) Very true

18. When we work on something in class, I feel bored.
A) Not at all true
B) Not very true
C) Sort of true
D) Very true

19. I don't try very hard at school.
A) Not at all true
B) Not very true
C) Sort of true
D) Very true

20. I pay attention in class.
A) Not at all true
B) Not very true
C) Sort of true
D) Very true 


\section{APPENDIX D: COMBINED INSTRUMENT}

\section{Combined Survey}

Instructions: This survey should take approximately 30 minutes to complete. Please make sure you have answered all questions for Part I, Part II (50 questions total) and Part II I(1 question total).

Part I: Please rate how strongly you agree or disagree with the following statements. In answering each question, use a range from (1) to (7) where (1) stands for strongly disagree and (7) stands for strongly agree. Please circle only one response choice per question.

\begin{tabular}{|c|c|c|c|c|c|c|c|}
\hline Statement & $\begin{array}{l}\text { Strongly } \\
\text { Disagree }\end{array}$ & Disagree & $\begin{array}{l}\text { Slightly } \\
\text { Disagree }\end{array}$ & $\begin{array}{l}\text { Neither } \\
\text { agree nor } \\
\text { disagree }\end{array}$ & $\begin{array}{c}\text { Slightly } \\
\text { Agree }\end{array}$ & Agree & $\begin{array}{r}\text { Strongly } \\
\text { Agree }\end{array}$ \\
\hline 1. I am intelligent. & 1 & 2 & 3 & 4 & 5 & 6 & 7 \\
\hline $\begin{array}{l}\text { 2. I can learn new } \\
\text { ideas quickly in } \\
\text { school. }\end{array}$ & 1 & 2 & 3 & 4 & 5 & 6 & 7 \\
\hline $\begin{array}{l}\text { 3. I am smart in } \\
\text { school. }\end{array}$ & 1 & 2 & 3 & 4 & 5 & 6 & 7 \\
\hline $\begin{array}{l}\text { 4. I am good at } \\
\text { learning new things } \\
\text { in school. }\end{array}$ & 1 & 2 & 3 & 4 & 5 & 6 & 7 \\
\hline $\begin{array}{l}\text { 5. School is easy for } \\
\text { me. }\end{array}$ & 1 & 2 & 3 & 4 & 5 & 6 & 7 \\
\hline $\begin{array}{l}\text { 6. I want to get } \\
\text { good grades in } \\
\text { school. }\end{array}$ & 1 & 2 & 3 & 4 & 5 & 6 & 7 \\
\hline $\begin{array}{l}\text { 7. Doing well in } \\
\text { school is important } \\
\text { for my future career } \\
\text { goals. }\end{array}$ & 1 & 2 & 3 & 4 & 5 & 6 & 7 \\
\hline $\begin{array}{l}\text { 8. I can grasp } \\
\text { complex concepts } \\
\text { in school. }\end{array}$ & 1 & 2 & 3 & 4 & 5 & 6 & 7 \\
\hline $\begin{array}{l}\text { 9. Doing well in } \\
\text { school is one of my }\end{array}$ & 1 & 2 & 3 & 4 & 5 & 6 & 7 \\
\hline
\end{tabular}


goals.

$\begin{array}{lccccccc}\text { Statement } & \begin{array}{c}\text { Strongly } \\ \text { Disagree }\end{array} & \text { Disagree } & \begin{array}{c}\text { Slightly } \\ \text { Disagree }\end{array} & \begin{array}{c}\text { Neither } \\ \text { agree nor } \\ \text { disagree }\end{array} & \begin{array}{c}\text { Slightly } \\ \text { Agree }\end{array} & \text { Agree } & \text { Strongly } \\ \text { Agree } \\ \text { I am capable of } & 1 & 2 & 3 & 4 & 5 & 6 & 7 \\ \text { ting straight A's. } & 1 & 2 & 3 & 4 & 5 & 6 & 7\end{array}$

11. It's important to get good grades in school.

12. I want to do my 1 2 3

4

5

6

best in school.

13. It is important 2 3

4

5

for me to do well in school.

14. No one in this 2 3

4

5

6

school supports me.

15. I am not

1

2

3

4

5

motivated to study

for exams.

16. I have poor

1

2

3

4

study habits.

17. Teachers in this

school do not treat

me fairly.

18. Most teachers

1

2

3

4

5

6

here are bad

teachers.

19. People like me

1

2

3

4

5

can't do well in a

school like this.

20. I have trouble

1

2

3

4

5

6

7

keeping track of my assignments.

21. People say that I 2 3 4 5 6 am a lazy student. 


\begin{tabular}{|c|c|c|c|c|c|c|c|}
\hline Statement & $\begin{array}{l}\text { Strongly } \\
\text { Disagree }\end{array}$ & Disagree & $\begin{array}{l}\text { Slightly } \\
\text { Disagree }\end{array}$ & $\begin{array}{l}\text { Neither } \\
\text { agree nor } \\
\text { disagree }\end{array}$ & $\begin{array}{c}\text { Slightly } \\
\text { Agree }\end{array}$ & Agree & $\begin{array}{r}\text { Strongly } \\
\text { Agree }\end{array}$ \\
\hline $\begin{array}{l}\text { 22. Nobody at this } \\
\text { school cares about } \\
\text { me. }\end{array}$ & 1 & 2 & 3 & 4 & 5 & 6 & 7 \\
\hline $\begin{array}{l}\text { 23. There is no } \\
\text { way that I could } \\
\text { ever be successful } \\
\text { in this school. }\end{array}$ & 1 & 2 & 3 & 4 & 5 & 6 & 7 \\
\hline $\begin{array}{l}\text { 24. I have trouble } \\
\text { keeping track of my } \\
\text { school supplies. }\end{array}$ & 1 & 2 & 3 & 4 & 5 & 6 & 7 \\
\hline $\begin{array}{l}25 . \text { I think that I } \\
\text { would be a better } \\
\text { student if I could go } \\
\text { to a different } \\
\text { school. }\end{array}$ & 1 & 2 & 3 & 4 & 5 & 6 & 7 \\
\hline $\begin{array}{l}\text { 26. My teachers } \\
\text { don't understand } \\
\text { me. }\end{array}$ & 1 & 2 & 3 & 4 & 5 & 6 & 7 \\
\hline $\begin{array}{l}27 . \text { I have trouble } \\
\text { concentrating on } \\
\text { my schoolwork. }\end{array}$ & 1 & 2 & 3 & 4 & 5 & 6 & 7 \\
\hline $\begin{array}{l}\text { 28. No one in this } \\
\text { school cares if I am } \\
\text { successful. }\end{array}$ & 1 & 2 & 3 & 4 & 5 & 6 & 7 \\
\hline $\begin{array}{l}\text { 29. I have problems } \\
\text { with time } \\
\text { management. }\end{array}$ & 1 & 2 & 3 & 4 & 5 & 6 & 7 \\
\hline $\begin{array}{l}\text { 30. My teachers' } \\
\text { grading practices } \\
\text { are not fair. }\end{array}$ & 1 & 2 & 3 & 4 & 5 & 6 & 7 \\
\hline $\begin{array}{l}\text { 31. The teachers at } \\
\text { this school do not }\end{array}$ & 1 & 2 & 3 & 4 & 5 & 6 & 7 \\
\hline
\end{tabular}


like me.

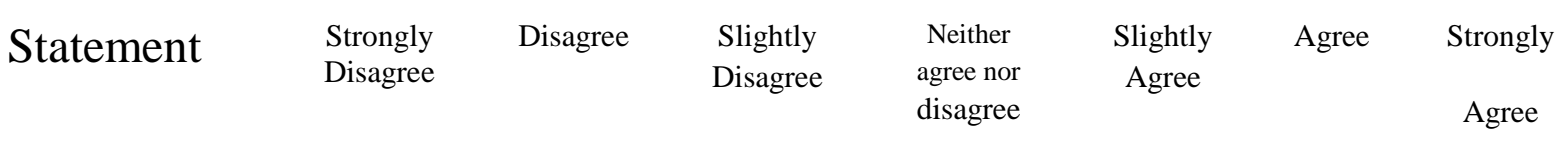

32. I hate the way

1

at this school.

33. I have

problems staying organized.

34. No matter

1

2

4

5

what, I will never

do well at this

school.

35. Teachers at this

1

2

3

4

5

7

school do not

believe that I could

be successful.

36. I have bad

1

2

3

4

5

7

relationships with

my teachers.

37. I do not have

1

2

3

4

5

6

7

regular study

routines.

38. Most teachers

1

2

3

4

5

7

here are not very

bright.

39. I dislike my

1

2

3

4

5

6

teachers.

40. I procrastinate

1

2

3

4

5

6

7

when it comes to

schoolwork.

41. The teachers in

this school

discriminate against

me. 


\section{Part II}

Please rate your agreement with each statement. "A" indicates "not at all true," while "D" indicated "Very True."

1. I try hard to do well in school.
A) Not at all true
B) Not very true
C) Sort of true
D) Very true

2. I enjoy learning new things in class.
A) Not at all true
B) Not very true
C) Sort of true
D) Very true

3. Class is fun.
A) Not at all true
B) Not very true
C) Sort of true
D) Very true

4. In class, I work as hard as I can.
A) Not at all true
B) Not very true
C) Sort of true
D) Very true

5. When I'm in class, I listen very carefully.
A) Not at all true
B) Not very true
C) Sort of true
D) Very true

6. When we work on something in class, I get involved.
A) Not at all true
B) Not very true
C) Sort of true
D) Very true

7. When we work on something in class, I feel interested.
A) Not at all true
B) Not very true
C) Sort of true
D) Very true 
8. When I'm in class, I feel good.
A) Not at all true
B) Not very true
C) Sort of true
D) Very true

9. When I'm in class, I participate in class discussions.
A) Not at all true
B) Not very true
C) Sort of true
D) Very true

10. I pay attention in class.
A) Not at all true
B) Not very true
C) Sort of true
D) Very true

PART II: Please choose only one response choice per question.

1. What is your cumulative GPA? What are your average grades? Circle one choice. 95\% (Mostly A’s) 75\%(More C's than B's)

90\% (More A's than B's) 70\% (More C's than D's)

85\% (More B's than A's) 65\% (More D's than C's)

$80 \%$ (Mostly B's, some A's and C's) $60 \%$ or lower (Mostly D's and F's)

Thank you for your time! 


\section{APPENDIX E: SAMPLE AIG DIRECTOR SCRIPT}

Hello, my name is Jennifer Ritchotte. I am a doctoral student at the University of North Carolina at Charlotte. I recently received Institutional Review Board approval to conduct a research study in your district. For this study, I am testing a model of why bright students underachieve in school. I will administer a brief survey to $6^{\text {th }}$ and $7^{\text {th }}$ grade AIG mathematics students in your district.

I was hoping you could recommend middle schools that might benefit from participating in this study. I am looking for middle schools that are demographically representative of the district and that use homogeneous ability grouping for mathematics.

Thank you for your time and support of this study,

Jennifer Ritchotte 


\section{APPENDIX F: SAMPLE PRINCIPAL EMAIL}

Dear (Insert Principal's name),

I am interested in conducting my dissertation research with (insert district). Based on a recommendation from (insert AIG Director's name), I thought you might be interested in my research topic and would allow me to conduct a brief survey with AIG mathematics students at your school.

Given most students begin to underachieve in middle school, I would like to have teachers at your school administer a survey to all of the $6^{\text {th }}$ and $7^{\text {th }}$ graders in their AIG mathematics classes. Teachers can administer this survey at their convenience so as not to interfere with instructional time. The survey questions have been piloted and are very reliable. The survey will take approximately 30 minutes for students to complete. In addition to the survey, students will be asked to provide basic demographic information, and teachers will be asked to provide students' current mathematics grade point average and the pathway by which students qualified for gifted programming.

The purpose of the survey is to test a theoretical model that predicts why bright students underachieve in school. Testing this model would provide teachers and researchers with valuable information about the source(s) of students' underachievement and what they can potentially do to help students engage and achieve in school.

All student information will be anonymous. The researcher will not be able to tie students' names to any of the information collected. This demographic information form, parental consent, student assent, and the survey instrument are attached to this email.

Appropriate IRB protocol will, of course, be followed. I hope to begin data collection once I receive IRB approval in either September or October 2012. Further, hard copies of parental consent and student assent would be collected by the students' mathematics teacher within one week prior to the start of the study. Parents may opt out of having their child complete the survey.

Results will be shared with the school and the district upon completion of the study. Having presented about gifted underachievement at the local, state, and national level, I know how important this issue is to parents and teachers alike. I hope this research will shed light on why bright students underachieve and what we can do to fix the problem. Please contact me at 704780-7171 or at jritcho@uncc.edu if you have any questions. You may also contact my faculty supervisor, Dr. Claudia Flowers, at 704-687-8862 or cpflower@uncc.edu.

Sincerely,

Jennifer Ritchotte 


\section{APPENDIX G: SAMPLE TEACHER SCRIPT}

- Explain the research study to the class. "A doctoral student at the University of North Carolina at Charlotte is studying why gifted students achieve and underachieve in math. She would like you to complete a brief survey. Your parents must sign this consent form for you to participate. The class that completes the most surveys will receive a prize (pizza party?). Consent forms must be returned by (within 1 week of passing them out)."

- Once informed consent is returned (this may only be a small number of students), schedule part of a class period (about 30 minutes) for these students to complete the survey. Please do this within one week of the informed consent deadline.

- On the day of survey administration please follow these steps:

- Be sure there is adequate space between students to protect student privacy

- Distribute survey forms (Demographic information, survey) to students

- Ensure students have written their student ID\# in the appropriate place on the demographic information form and student survey form. Please have a list of student ID\#s readily available in case students do not know their ID\#.

- Parents may have chosen to have their child not take the survey. They may work on another quiet activity.

- Read all of the script to students as it contains information that must be presented for students. The script should be read before the survey starts students should not be taking the survey while the script is being read. (The survey introduction script contains important information that'll help build 
students' trust in the process and encourage them to answer honestly. If the script is paraphrased, important information could be overlooked. It's better to read the complete script to students rather than try to paraphrase.)

- Pass out and collect assent forms at the appropriate time. Please be sure students have correctly written their student ID \#. If a student does not assent, he/she does not take the survey, even if his/her parent consents.

- Teachers/survey administrators should refrain from wandering around the room during the survey administration to help assure student anonymity.

- Please do not rush students as not to affect the quality of the survey results. Although the survey is estimated to take 30 minutes to complete, please allow up to 10-15 extra minutes if needed.

- Prior to or within a day of survey completion, create a table/spreadsheet of students who have completed the survey. Do not use student names. Only use student ID\#s. Please provide the students current grade in your math class (write this as a percentage), how many grades this is based on, and the pathway by which the student qualified for AIG programming.

- Please email me once you have collected this information and have completed surveys, approximately two weeks after my initial visit to drop off surveys and forms, jritchot@uncc.edu

Thank you for your support of this project!!! 


\section{APPENDIX H: SURVEY SCRIPT}

Please read all of the script to students. The script should be read before the survey starts students shouldn't be taking the survey while the script is being read.

Good morning/afternoon. You're here because a doctoral student at the University of North Carolina at Charlotte is conducting a survey of gifted middle school mathematics students this morning/afternoon. On the survey you'll be asked direct questions about your attitudes toward school and learning in your gifted mathematics class. The results will be used to improve the experience of students who are not achieving to their potential in gifted mathematics classes.

Your participation in this survey is very important, but it's also voluntary. You are not required to take the survey. Your answers will be anonymous - we'll have no way to track your survey, or how you answered the questions, back to you. Your answers are private. So during the survey I'll maintain strict procedures to protect your privacy. Please take a moment to sign a form that verifies your willingness to participate in this survey (pass out assent forms and collect right away).

This survey's not a test of you or this school. Whether you choose to answer the questions or not, your grades will not be affected. It's really important that your answers are based on what you actually think. So please try to answer the questions as honestly as you can, not how you think we'd like you to answer or how you think others would answer. If you have a question about the meaning of a survey question do your best to answer it on your own because I will not be allowed to help you.

You shouldn't talk during the survey, or look at another person's responses. Remember, your answers are private, but so are your neighbors'. For each of the questions on the survey, select the appropriate answer choice that best matches what you think or do. When you have completed the survey, please raise your hand; your survey will be collected at that time. Please refrain from talking once you have completed your survey.

Are there any questions?

To be read once everyone has finished

I want to thank all of you for participating in this survey. The information you provide[d] is very important and will help improve the academic experience of gifted students in the future. Thank you!

Please be sure to follow these steps on the day of survey administration:

- Be sure there is adequate space between students to protect student privacy

- Distribute survey forms (Demographic information, survey) to students 
- Ensure students have written their student ID\# in the appropriate place on the demographic information form and student survey form. Please have a list of student ID\#s readily available in case students do not know their ID\#.

- Parents may have chosen to have their child not take the survey. They may work on another quiet activity.

- Read all of the script to students as it contains information that must be presented for students. The script should be read before the survey starts - students should not be taking the survey while the script is being read. (The survey introduction script contains important information that' 11 help build students' trust in the process and encourage them to answer honestly. If the script is paraphrased, important information could be overlooked. It's better to read the complete script to students rather than try to paraphrase.)

- Pass out and collect assent forms at the appropriate time. Please be sure students have correctly written their student ID \#. If a student does not assent, he/she does not take the survey, even if his/her parent consents.

- Teachers/survey administrators should refrain from wandering around the room during the survey administration to help assure student anonymity.

- Please do not rush students as not to affect the quality of the survey results. Although the survey is estimated to take 30 minutes to complete, please allow up to $10-15$ extra minutes if need 


\title{
APPENDIX I: STUDENT DEMOGRAPHIC FORM
}

\author{
Student Demographic Form
}

Student ID \#

Please circle one response below for each of the five questions

1. Gender M F

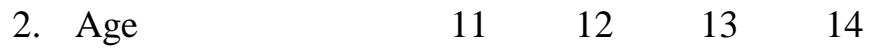

3. Grade $6 \quad 7$

4. Ethnicity Caucasian African American Latino/a Asian Other

5. Gifted Math only Reading only Math and Reading Not Identified 